Florida International University FIU Digital Commons

\title{
The impact of looping of fourth grade students on their reading achievement
}

Mary Jo Almeida-Shore

Florida International University

DOI: $10.25148 /$ etd.FI13101598

Follow this and additional works at: https://digitalcommons.fiu.edu/etd

Part of the Education Commons

\section{Recommended Citation}

Almeida-Shore, Mary Jo, "The impact of looping of fourth grade students on their reading achievement" (2004). FIU Electronic Theses and Dissertations. 1076.

https://digitalcommons.fiu.edu/etd/1076

This work is brought to you for free and open access by the University Graduate School at FIU Digital Commons. It has been accepted for inclusion in FIU Electronic Theses and Dissertations by an authorized administrator of FIU Digital Commons. For more information, please contact dcc@fiu.edu. 
Miami, Florida

THE IMPACT OF LOOPING OF FOURTH GRADE STUDENTS ON THEIR READING ACHIEVEMENT

A dissertation submitted in partial fulfillment of the requirements for the degree of DOCTOR OF EDUCATION in CURRICULUM AND INSTRUCTION

by

Mary Jo Almeida-Shore

2004 
To: Dean Linda Blanton

College of Education

This dissertation, written by Mary Jo Almeida, and entitled The Impact of Looping of Fourth Grade Students on their Reading Achievement, having been approved in respect to style and intellectual content, is referred to you for judgment.

We have read this dissertation and recommend that it be approved.

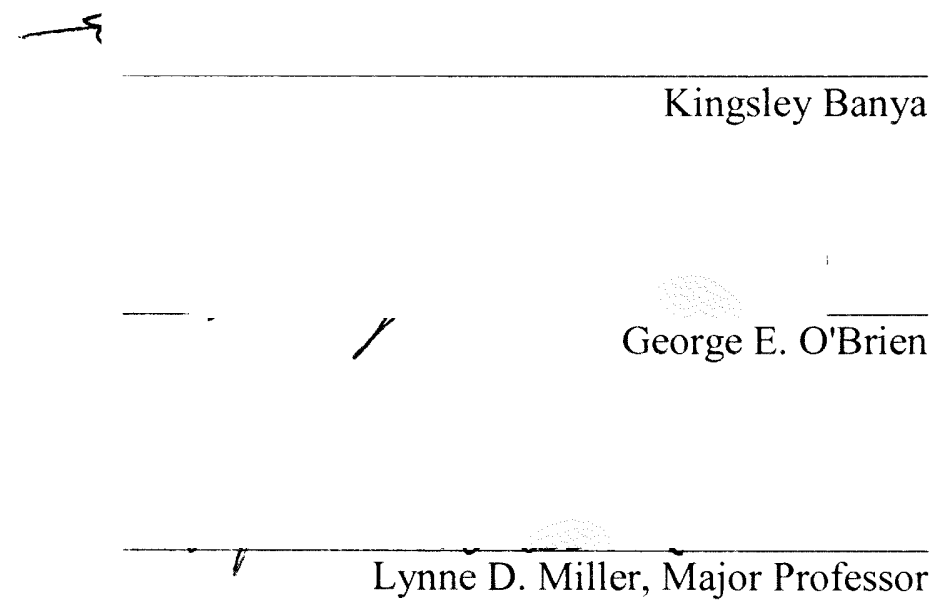

Date of Defense: July 20, 2004

The dissertation of Mary Jo Almeida is approved.

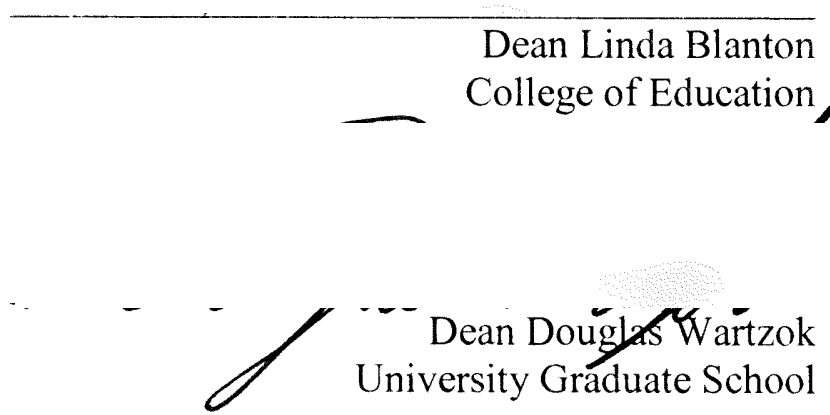

Florida International University, 2004 
(C) by Mary Jo Almeida 2004

All rights reserved. 


\section{DEDICATION}

To Tati and Lero, my very first teachers, for their unwavering faith in me. To my parents, Maria Jose and Santiago Almeida, for their sacrifices, love and support. To my sons, Max and Joseph Alan: the products of all I have ever been, who hold the promise of all I will and will never become. 


\section{ACKNOWLEDGMENTS}

In recognizing that, "It takes a village to write a dissertation," I wish to extend my sincere and deepest gratitude to several people, for without their tireless efforts, this work may not have been completed.

To Drs. Lynne Miller, George E. O’Brien, Kingsley Banya and Frank Di Vesta, thank you for the countless hours you spent reviewing my dissertation and providing much valued feedback and insight. Your experience, knowledge and wisdom helped to shape this work into one of excellence.

To Dr. Miller, my "muse," thank you for your insight and assistance in the writing process- "that of turning blood into ink." Your knowledge and precision helped me to choose the right words again and again. Further, your commitment, kindness and compassion were a source of support and encouragement on many levels.

I also wish to express my appreciation to my friends, colleagues and family. To Lourdes Nodarse, thanks for your friendship, support and vast knowledge. You provided me with critical information and always managed to know exactly where to find the answers to my questions. To Sharon Gonzalez, the principal of PSNE and my dear friend, thank you for your support and understanding.

To my parents, Santiago and Maria Jose Almeida, and to my brothers and sisters, thank you for your love. Knowing that I would make you proud served as a source of strength and encouragement for me throughout this process.

Finally, to my husband Michael Shore, thanks for your technical support and for sharing in my life's greatest joys and accomplishments, especially the miracles of our sons, Max and Joseph Alan. With you I have truly experienced a whole new world! 
ABSTRACT OF THE DISSERTATION

THE IMPACT OF LOOPING OF FOURTH GRADE STUDENTS ON THEIR

READING ACHIEVEMENT

by

Mary Jo Almeida

Florida International University, 2004

Miami, Florida

Professor Lynne D. Miller, Major Professor

This study examines the effects of looping (staying with the same teacher for two grade levels) on the reading achievement of fourth graders within a large, urban, multicultural school. Looping was expected to have a positive effect on reading achievement and reading qualities. Additional benefits, such as its effect on anxiety levels and self-concept were also assumed to accrue from looping.

A causal-comparative design was employed. Four existing classrooms consisting of eighty-one fourth grade students comprised the treatment and comparison groups. The two "looping" treatment groups consisted of students who had the same teacher for their third and fourth grade school years. The remaining two classes comprised the comparison groups. Pre- and post-tests for reading achievement total scores and subscores for main idea and comparisons were obtained using the Florida Comprehensive Assessment Test (FCAT). Assessments were also obtained from the State-Trait Anxiety Inventory for Children, modified to reflect reading, and the SelfPerception Profile for Children. The difference in pre- and post-test FCAT scores were analyzed via a four group simple ANOVA to examine the effects of the looping model on 
reading achievement and reading qualities. Similar simple ANOVAs were performed to investigate the relationship of looping to anxiety and self-concept.

The findings led to the conclusion that looping was significantly related to improvement in reading achievement and reading qualities. In addition, the hypothesized relationship of lower anxiety in the looping group compared to the comparison group was supported. There were no significant effects on self-concept for any of the comparisons. The study clearly demonstrated the positive effects of looping, on total reading achievement scores, on reading qualities of fourth grade students who participated in looping classes and on differences in students' anxiety. Looping did not have an effect on general self-concept.

The results demonstrate the effects of looping on teaching methods. In looping practice teachers have the advantage of knowing their students and the students' readiness and can make adaptations of teaching methods accordingly. From the students' perspective, the looped students do not have to adapt to a new teacher and thus, experience lower anxiety. 


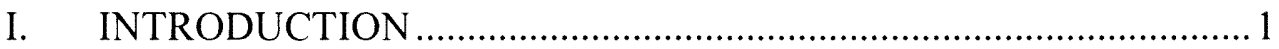

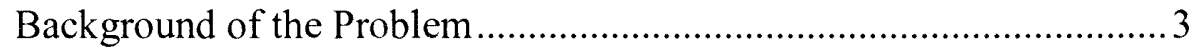

Context for the Current Study .......................................................... 3

Rationale for the Implementation of Looping ...................................... 8

Lack of Empirical Studies Related to Looping .................................. 12

Rationale for the Focus on Reading Achievement, Reading

Qualities and Related Affective Variables ......................................... 14

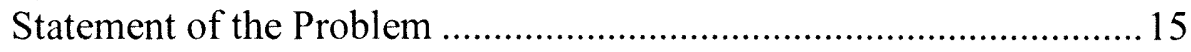

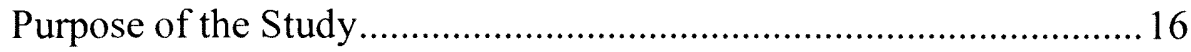

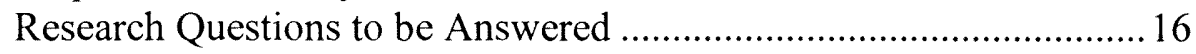

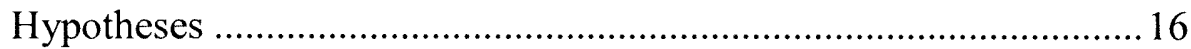

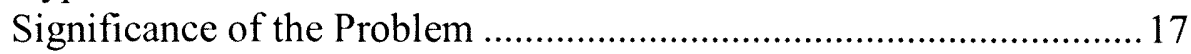

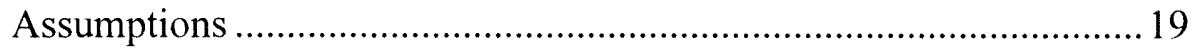

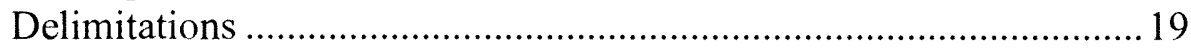

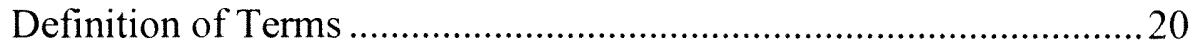

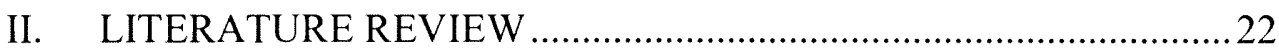

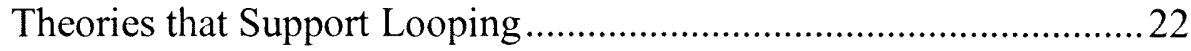

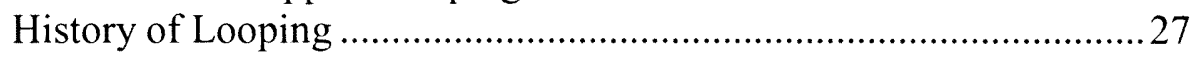

Looping Benefits to Teachers, Parents and Students ..........................31

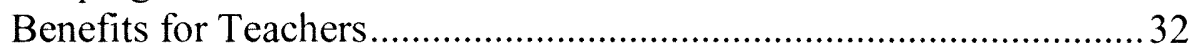

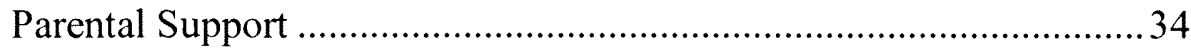

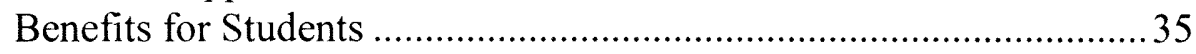

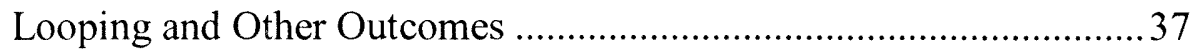

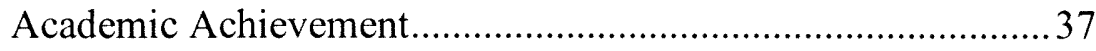

Affective Benefits of Looping ....................................................40

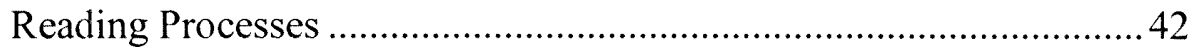

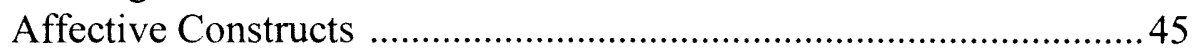

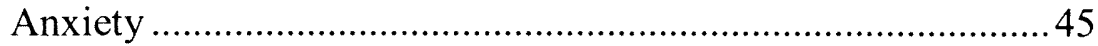

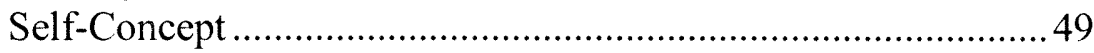

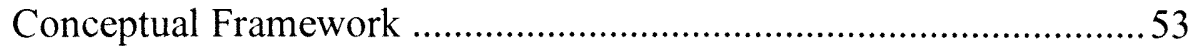

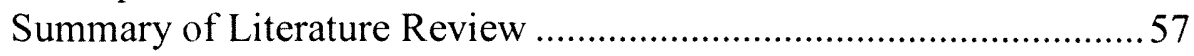

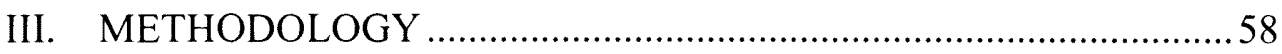

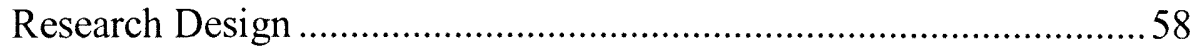

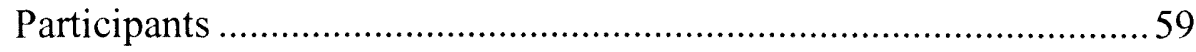

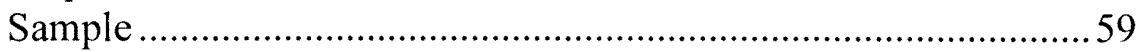

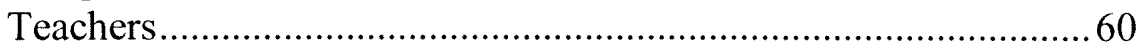

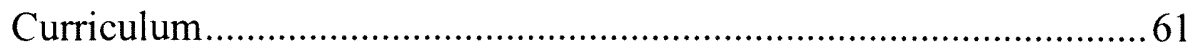

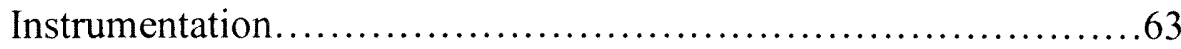

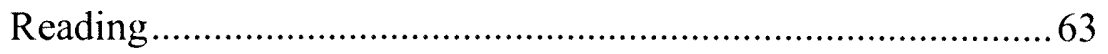




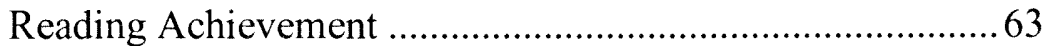

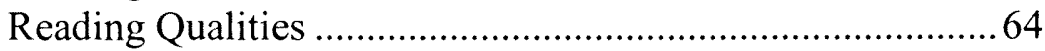

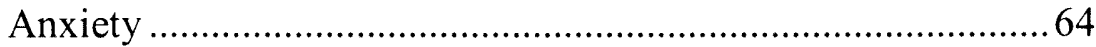

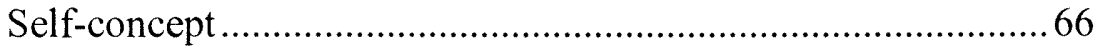

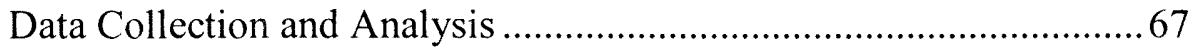

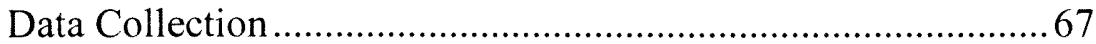

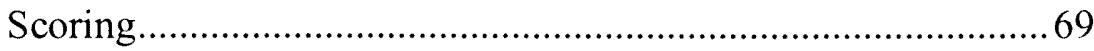

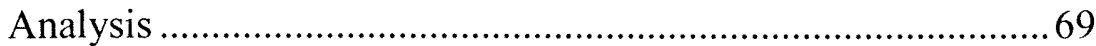

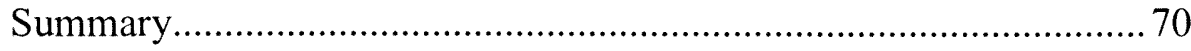

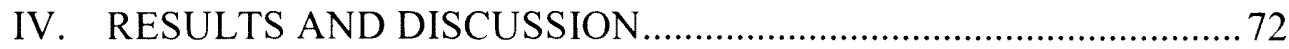

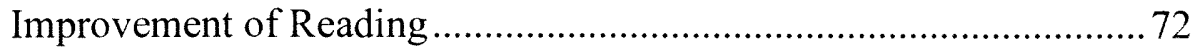

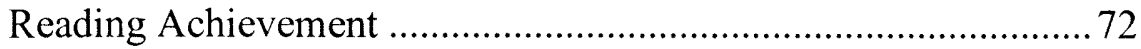

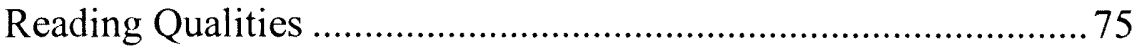

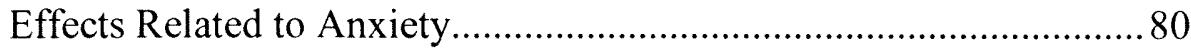

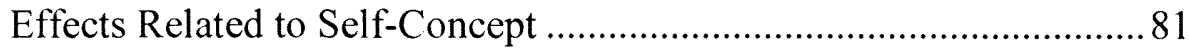

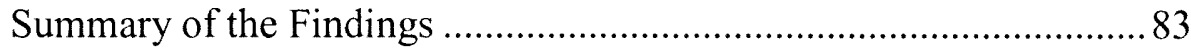

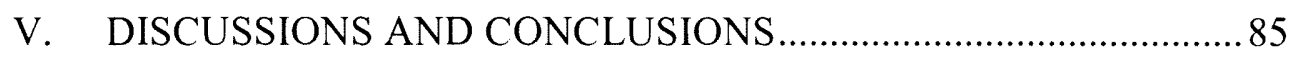

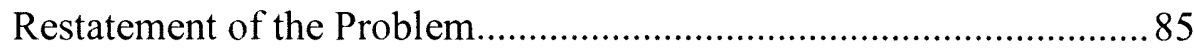

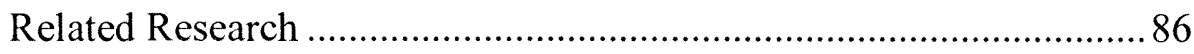

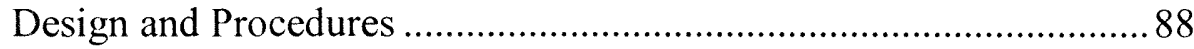

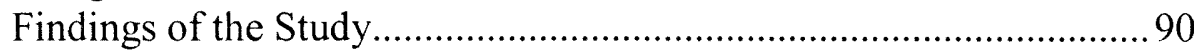

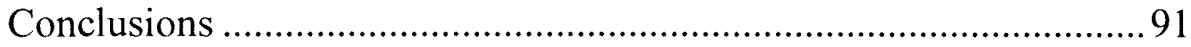

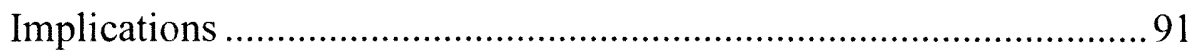

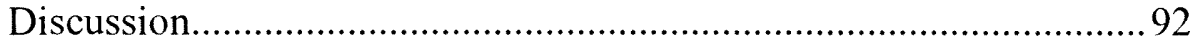

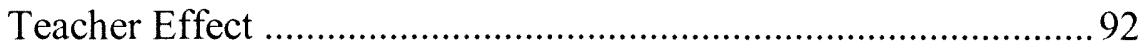

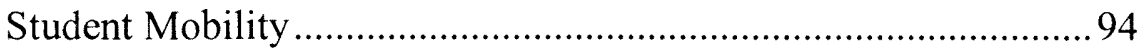

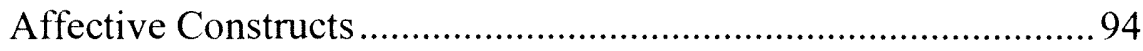

Comparison Groups' Reading Achievement .................................96

Cautions for the Implementation of Looping ................................98

Recommendations for Future Research........................................... 100

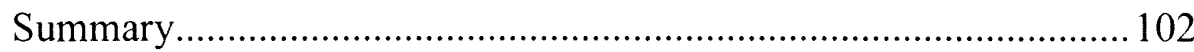

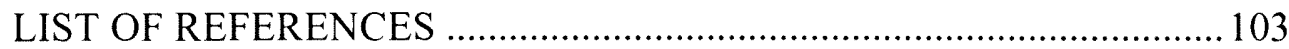

APPENDICES .......................................................... 113

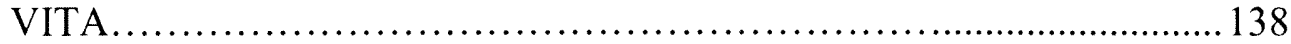


TABLE

PAGE

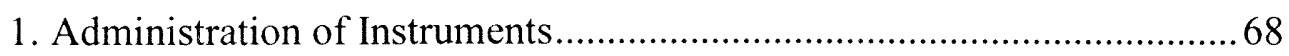

2. Posttest Reading Achievement ANOVA: Reading FCAT 2002 ….......... 73

3. Difference in Reading Achievement Pretest to Posttest ANOVA:

Difference FCAT 2001-2002 .74

4. Difference in Reading Quality (Main Idea) Pretest to Posttest ANOVA: Difference FCAT 2001-2002...

5. Difference in Reading Quality (Comparisons) Pretest to Posttest ANOVA: Difference FCAT 2001-2002. .78

6. Anxiety Measure by Treatment Group: STAIC .80

7. Self-Concept Measure by Treatment Group:

The Self-Perception Profile for Children 82

8. Pretest Means Pooled Experimental and Comparison Groups:

Reading FCAT 2001 136

9. Pretest Reading Achievement ANOVA: Reading FCAT 2001 137

10. Vocabulary/Aptitude Measure ANOVA: MAT-7. 137 


\section{CHAPTER I}

\section{INTRODUCTION}

Students in any given classroom possess a variety of ability levels and psychological and emotional needs (Vann, 1997). In schools with larger class sizes, it becomes increasingly difficult to address the varied and multiple needs of students, and schools are being asked to do more than ever to meet the needs of these children (National Education Commission on Time and Learning, 1994). In addition to providing for their academic needs, schools are being called upon to provide for the psychological and emotional stability that is often missing in the home (Forsten, Grant, \& Richardson, 1999).

The traditional model of schooling, divides students into defined grade levels by age, regardless of the students' previous experiences, home environments or social and emotional needs. In the traditional model, students change teachers at the end of every school year. While teachers are able to address some of the academic, psychological and emotional needs of students in one academic cycle or year, the effectiveness of this model of schooling, which brings teachers and students together in one year cycles is being questioned by educators who are aware of alternative models of schooling. For example, Rappa (1993), Superintendent of Schools in Attleboro, Massachusetts, in his presentation to the National Education Commission on Time and Learning stated:

I ask you to think of any relationship, yes, any relationship as important as that between a teacher and a learner which we routinely, perhaps even thoughtlessly terminated on an annual basis. Can you think of one? I can't! If we find a physician, do we leave her just as soon as she begins to understand us and our medical history?" "In all honesty, can you think of a relationship with any person, especially one who purports to be interested in your growth, development and welfare, which is ended simply because it's June $17^{\text {th }}$, or Memorial Day, or 
summer? We have stripped schools of the very foundation for building trusting, stretching, learning relationships- time. (p. 3)

Particularly in large, urban multicultural school settings, it becomes increasingly challenging for a teacher to become familiar with and support the academic and emotional needs of students in the time span of one academic school year. In such settings, characterized by high mobility, time constraints, large class sizes and shrinking budgets, this challenge is even greater. In such settings it is difficult for a teacher to develop the knowledge of and build a relationship that supports the academic, social and emotional development of each individual child (Samway, Whang \& Pippit, 1995).

In some areas, as an alternative to the traditional model of schooling, some school districts have implemented looping as a model for addressing the perceived shortcomings of the traditional model of schooling (Rappa, 1993; Grant \& Johnson, 1995). To date, this practice has neither been implemented nor studied widely in a large urban multicultural school.

The typical model for looping involves a teacher working with a cohort of students for one academic year and then moving with them to the next higher grade level. At the end of a two-year cycle, the cohort of students moves on to the following grade level and a new teacher. The original teacher returns to the previous grade to begin to teach a new cohort of students, beginning the two-year cycle again (Krogmann \& Van Sant, 2000).

Theories that support looping stem from the work of motivational theorists and serve as the basis of the conceptual framework for the current study by emphasizing that motivation highly influences learning, that it is critical to literacy learning and that by 
reducing anxiety and by providing a stable and secure environment for students, looping provides a context that is conducive to literacy learning (Little \& Little, 2001;

O'Flahavan, Gambrell, Guthrie, Stahl, \& Alvermann, 1992; Gambrell, 1996). Additional theories that support looping for literacy learning suggest that self-concept is associated with literacy learning and that increased time on task increases opportunities for reading achievement (Ford, 1992; Henk \& Melnick, 1995; Wigfield, 1994).

The limited research available on looping points to its many positive effects on instruction, particularly in the area of reading (Hill, Lofton, \& Purvis 1999; Hampton, Mumford, \& Bond, 1997; Yang, 1997; Schneyderman, 2000). Additionally, this research has alluded to looping as a model that may have positive effects on the academic, emotional and interpersonal progress of students. However, with the exception of one, looping studies have not included large, urban, multicultural schools.

\section{Background of the Problem}

In examining the background of the problem, it is necessary to consider the context for the current study, rationale for the implementation of looping, lack of empirical studies related to looping, and rationale for the focus on reading achievement, reading qualities and related affective variables.

\section{Context for the Current Study}

The context of the current study is Palm Springs North Elementary School (PSNE), one of the largest elementary schools within the Miami-Dade County Public School System (MDCPS). The study took place during the 2001-2002 school year. Miami-Dade County Public Schools is a multibillion-dollar-a-year, publicly funded school system that was established in 1886 . It is the fourth largest school system in the 
nation and employs more than 27,000 full-time staff, over 7,800 part-time staff, and serves over 372,000 students. The student ethnic breakdown consists of approximately $12 \%$ White non-Hispanic, 32\% Black non-Hispanic, $54 \%$ Hispanic, and $2 \%$ Asian/Indian/Multiracial (Miami-Dade County Public Schools, Office of Educational Planning and Quality Enhancement, 2001).

PSNE is part of a region that encompassed 45 schools in the northwest area of the county. It is a large, urban, multicultural pre-kindergarten through fifth grade school that houses students whose families are mainly middle class to lower class. At the time of the current study (2001-2002), this school was one of the largest elementary schools in the United States, housing approximately 2,190 students, and continued to increase in population. The average school in the United States houses 741 students (Kieff, 2001). At PSNE, forty-six percent of the students were on free or reduced lunch. The racial/ethnic composition of the student body was as follows: $72 \%$ Hispanic, $14 \%$ White, $11 \%$ Black and 3\% Asian/Indian/Multiracial. This is reflective of a large, urban school comprised of students from diverse cultural backgrounds and is also representative of the Miami-Dade County Public School System (Miami-Dade County Public Schools, Office of Educational Planning and Quality Enhancement, 2001).

As a large, urban, multicultural school, PSNE is fraught with many of the problems faced by large urban schools with culturally and socio-economically diversified student populations. These include, but are not limited to, large, overcrowded classrooms, time and budget constraints, depersonalization of the educational experience, transient student populations, inconsistent schooling experiences, achievement gaps and limited parental involvement. 
Within any classroom, teachers at PSNE must deal with students who come from various races and ethnicities and build upon the similarities and differences among these students' backgrounds. These teachers must strive to get to know each student and their families in order to provide a meaningful foundation for their learning and create the mutual respect and cohesion within the classroom conducive to optimal learning experiences (Nichols \& Nichols, 2002). Many of these students lack mastery of the English language, so critical to reading comprehension in English (Samway, Whang \& Pippit, 1995). Teachers must then strive to educate these students within grade level expectations while facilitating their acquisition of the English language. This challenging task becomes increasingly difficult as classes become larger and curricular expectations make increasing demands on the already limited instructional time. Because of the large numbers of students in each class, teachers are also often limited in instructional materials.

Another problem faced by teachers at PSNE stems from the diversity in students' socio-economic backgrounds. Many of these students come from homes where parents are financially unable to support their children's educational needs. In some cases, parents must work two jobs to make ends meet and, with the heavy demands upon their time, they are often unable to participate in their child's schooling. The lack of financial resources particularly impacts the struggling learner who is in need of tutoring services or outside counseling because their parents cannot afford nor have the time to provide for these (Obiakor, Obi, \& Algozzine, 2001). Another issue faced by these struggling families is that parents do not have the time or money for students to participate in extracurricular activities so necessary to the social development of the child (Obiakor, 
Obi, \& Algozzine, 2001). Therefore, the school is being called upon to provide for these additional instructional programs and positive social experiences needed by struggling, impoverished learners. At PSNE, time and budget constraints make addressing the needs of these students extremely difficult.

Classes at PSNE are often overcrowded, as in many large, urban, multicultural schools. This makes increasing time demands on the teachers, who must get to know and teach students with varied instructional, social and emotional needs within a limited time period. As more and more students enroll in the classroom, teachers must take time away from instruction to diagnose students' learning abilities, become familiar with their backgrounds, acclimate them into the classroom expectations and routines and make them feel part of the group. Teachers must accomplish these tasks while continually addressing the needs of the students they already have. This makes it extremely difficult to develop the meaningful teacher-student relationship with each child during one academic school year (Nichols \& Nichols, 2002).

Like most large, urban multicultural schools, a large student population, composed of many transient students, characterizes PSNE. This instability leads to depersonalization among students and teachers (Kieff, 2001). Due to student mobility, students often find it difficult to develop meaningful, long-term relationships with their teachers and with each other. Some of these transient students have been in two or three schools by the time they begin third grade. This inconsistency of schooling results in gaps in instruction and academic achievement. Teachers at PSNE are faced with the challenge of filling in these instructional gaps, diagnosing and remediating learning needs and providing social and emotional stability for students in a limited time period. The 
diversity among students' prior learning experiences within any given classroom requires teachers to build schema and prior knowledge necessary for grade-level instruction.

Another critical challenge at PSNE, as in most large, urban, multicultural schools is that of inconsistent parental involvement that may be due to differences in cultural and ethnic backgrounds, varied socioeconomic pressures and time constraints. Many parents at this school complain that they have difficulty communicating with their child's teacher due to language barriers resulting from varied ethnic backgrounds (Samway, Whang \& Pippit, 1995). These communication gaps also make it difficult for parents to trust their child's teacher. Teachers at this school must strive to open the lines of communication for these parents, earn their trust and build meaningful relationships (Nichols \& Nichols, 2002). Because many of the parents are struggling financially to support their families, they simply do not have the time to come to parent conferences or participate in schoolwide workshops or activities. Those with limited financial resources are unable to carry out the necessary tutoring or counseling recommended by the school. Many of these parents are also faced with job demands that preclude them from even helping their children with their homework after school. The large size of PSNE also makes increased time demands on teachers to hold regular parent conferences with each student's parents throughout the one-year academic cycle.

Prior to the current study, as the school continued to grow, several procedures that served to personalize and support the educational needs of students were put into place. The three counselors and the three assistant principals on the main campus were assigned to the same children each year; that is, they followed the students to the subsequent grade levels. For example, if in one year a counselor and assistant principal were assigned to 
kindergarten, second and fourth grade, the following year they would be assigned to first, third and fifth grade. Additional strategies employed included the grouping of grade level classrooms by location at the school site and the provision of common teacher planning time. Even with these initial school-wide interventions in place, the above strategies were not enough to specifically address students' learning needs within the instructional setting.

\section{Rationale for the Implementation of Looping}

Obiakor, Obi and Algozzine, (2001) explain that multidimensional issues confront students who live in urban communities. These researchers posit that educators must explore innovative ways to maximize the potential of urban learners. As one possible intervention, looping is being looked at in various school districts across the United States as a low-cost, easily implemented model to address the academic and emotional needs of children that may not be addressed in a traditional one-year setting. According to the National Education Commission on Time and Learning (1994) the time available in a traditional six-hour day and 180-day year is an acknowledged design constraint in American education. This issue of limited time must be addressed, particularly as public school systems attempt to respond to an increased call from the public and politicians for accountability. Since time has become a large factor in current discussions about improving America's schools, it has become the responsibility of school-site personnel to assure that time is used efficiently. Rappa (1993) concurred, by stating, “...before you ask for more time, what can you do better with the time you already have?" (p. 3).

In an attempt to counter this problem, some schools have implemented looping in order to use instructional time more efficiently. As teachers and students settle into the 
first month of school of the second school year with each teacher who loops, most instructional time can be spent on teaching, rather than on assessment and the establishment of routines, a savings of approximately six weeks of instructional time (Rappa, 1993). The cumulative amount of time saved could amount to 5 months over the course of a student's schooling (National Education Commission on Time and Learning, 1994). Recently, the press and legislators have discussed extending the school day and the school year. In response to Florida Governor Bush's A+ Plan, many districts in Florida have instituted an extended school year (Brown \& Vaughan, 2002). Proponents of looping often report that the more efficient use of instructional time afforded by looping provides similar benefits for students as those cited by proponents of the extended school year (Burke, 1996; Forsten, Grant, \& Richardson, 1999).

Looping establishes a two-year partnership between the teacher and students. This partnership has specific implications for the learning process, classroom setting, home environment and social development (Vann, 1997). The partnership of the teacher and students in the learning process and classroom setting manifests itself in various ways. In addition to meeting grade-level expectations and curricular demands, during the first year of the looping model, the teacher becomes familiar with the students' abilities, learning needs and interests; the student learns the teacher's teaching style and expectations for academic performance and conduct. The partnership continues throughout the second year of the looping model, eliminating the need for the creation of rules, routines and duplicate diagnoses of academic abilities that have been established during the first year. The learning experiences and key concepts developed during the first year of the model become stepping stones for learning during the second year. 
The partnership between teacher and student and the home environment develops as a result of the extended time together afforded by the looping model. During the twoyear model, the teacher has the opportunity to become familiar with student's home and family situations. Further, research has shown that parents are more supportive of teachers with whom they have previously- established relationships. Hill et al. (1999) found that parental involvement in school activities increased significantly in looped classrooms.

The teacher and student are also allied in the student's social development because throughout the two-year model the teacher is able to monitor and assess the student's interaction with his peers. The teacher is able to facilitate the student's social development through activities that promote cooperative learning. In a looping model, the partnership between the teacher and student in the learning environment, classroom setting, home-school connection and social development plays a key role in the student's school performance. This is particularly important in a large, urban, multicultural school, like the one in the current study, where the development of these critical factors becomes increasingly challenging. A looping classroom can provide the social context where a struggling, economically disadvantaged student can develop the positive social interactions and build relationships otherwise found in team sports and other extracurricular activities, that financially struggling parents are not able to provide.

The partnership created in the looping model is particularly beneficial to struggling learners, who typically need more time to acquire concepts, greater amounts of individual attention, increased parental support and an environment that fosters social and emotional growth. The traditional model of instruction provides the following options 
for struggling learners. At the end of the school year, students who are found to be below grade level are often retained in the same grade, socially promoted or referred to special education programs. Numerous studies on the effects of retention point to its detrimental effects on the emotional welfare and academic success of the child (Rasmussen, 1998). Many retained students end up dropping out of school during the high school years (Darling-Hammond, August, 1998). Perhaps, in a looping model, these students would benefit as well.

The research articles and books that have been written about looping suggest that this practice provides an alternative for struggling learners. Bracey writes, "The researchers suggest that looping might be especially useful for those struggling academically. The teacher has more time to analyze and observe the children and more time to try different strategies" (1999, p. 169). Students who participate in a looped classroom are given the "gift of time" by being provided with an additional year with the same teacher, who knows them and is keenly aware of their strengths and weaknesses (Rasmussen, 1998, p. 3). The teacher and students can hit the ground running at the beginning of the second school year, initially targeting instruction based on the previously established needs of the student.

For the current study, looping was proposed at PSNE as an added intervention to make schooling more personalized for students and provide continuity in academic, social and emotional development, with a focus on reading achievement. With the variety of problems characteristic of a large, urban, multicultural school, reading became the focus of the current study on looping, primarily, because of the district's and state's emphasis in this area. At PSNE teachers in the looping classes would be given an 
additional year with students to become familiar with their backgrounds and build upon their prior experiences, provide more individualized instruction, address their instructional, emotional and social needs, develop long-term trusting relationships with their parents and fill in the learning gaps experienced by transient students (Nichols \& Nichols, 2002). It was hoped that implementing looping as an intervention in this large, urban, multicultural school would result in positive outcomes on student reading achievement, reading qualities, reduced anxiety and increased self-concept.

\section{Lack of Empirical Studies Related to Looping}

While numerous articles have been written extolling the benefits of looping, little empirical research exists related to this topic. Two of the existing empirical studies are particularly important for the current research. Hill, Lofton and Purvis (1999) studied students in a rural elementary school in the Livingston Parish System in Louisiana. These researchers examined three third grade classes which were involved in looping over a two-year span, from third to fourth grade. Hill, et. al. report qualitative data showing overwhelmingly positive outcomes for parents, students, and teachers. Quantitative data, gathered from achievement test results revealed student gains in the total reading portion of the California Achievement Test. While the current study resembles this study in that it looked at the reading achievement of students being looped from third to fourth grade, it differs from the above study in that the current study examined looping within the context of a large, urban, multicultural school, rather than a small, rural school. Also, the Hill, Lofton and Purvis study was a case study, which employed qualitative methods to examine affective benefits. Conversely, the current 
study employed quantitative methods to examine the affective factors of anxiety and selfconcept in addition to measuring gains in reading achievement.

Another study related to the current research was conducted by Schneyderman (2000) in the Miami-Dade County Public School System during the 1999-2000 school year. Schneyderman conducted a broad study, employing some empirical methods, looking at 1,224 students from second through fifth grade across the school district. The looping sample consisted of 612 students and the matching sample also consisted of 612 students. He analyzed reading and math test scores from state-mandated norm-referenced standardized tests, as well as attendance and retention figures. From a district-wide sample of students, at varying grade levels from a variety of schools he found that students who participated in looping classes demonstrated positive results based on the data he gathered. The above study provided a first step in researching looping in the Miami-Dade Public School System. The Schneyderman study demonstrated that leaders within this school district felt that the practice of looping may provide benefits worthy of study. The current study sought to more closely examine the benefits of looping at the point of instruction, employing well-developed empirical methods. Therefore, it sought to control the matching of students, teachers, curriculum and instructional materials. In addition to evaluating the effects of looping on reading achievement, the current research examined reading qualities (main idea and comparisons) and analyzed the effects of looping on both anxiety, as related to reading, and on self-concept. 
Rationale for the Focus on Reading Achievement, Reading Qualities and Related Affective Variables

The current study focused on the effects of looping on reading achievement, reading qualities, anxiety as related to reading and overall self-concept within the instructional setting. Reading achievement was the major focus of this study for the following reasons, as outlined by Jim Warford, the Florida Chancellor for K-12 Education. In his report on K-12 activities presented a the State Board of Education Meeting on September 16, 2003, Warford explained,

Reading and comprehension are the foundations for all academic learning; students need strong reading skills in order to learn in all other subjects; by the end of third grade, students are expected to read independently; and seventy-five percent of students who cannot read by age nine will struggle with reading throughout adulthood. (Warford, 2003, p.6)

These tenets are fundamental to the Florida state statute which requires that beginning with the 2002-2003 school year, any student who demonstrates reading deficiency by the end of grade 3, by scoring at a Level 1 on the Florida Comprehensive Assessment Test (FCAT) must be retained [s. 1008.25(5)(b), F.S. In Warford, 2003]. Looping may provide one means toward promoting reading achievement for students who are deficient in reading. By providing added instructional time, the implementation of looping may result in narrowing the reading achievement gap of struggling learners. Because reading is comprised of physical, social, emotional and psychological and linguistic processes, there seems to be a logical fit between the study of looping and reading achievement.

In the current study, the effect of looping on reducing anxiety as related to reading will be measured quantitatively. The reduced anxiety associated with looping is expected 
to have a positive effect on reducing cognitive load in the reading process. Thus, students who participate in a looped classroom should also experience increased performance in reading achievement. While reduced anxiety has been reported by proponents of looping as one of its benefits based upon classroom observations, no quantitative empirical studies have been conducted in this area (Burke, 1996; Forsten, Grant, \& Richardson, 1999; Gaustad, 1998 ).

Because the physiological processes involved in reading must be considered along with the social, emotional and psychological aspects, the current study will quantitatively examine the effects of looping on students' overall self-concept (Rosenblatt, 1978; Bleich, 1975, and Fish, 1980 in Weaver, 1988). Some proponents of looping also point to its positive effects on students' self-concepts (Gaustad, 1998). Most educators, counselors, parents and community leaders agree that developing healthy, authentic selfconcept in children is among the most effective and promising ways of preventing destructive behavior (Quandt 1973; Vasconcellos, Reasoner, Borba, Duhl \& Canfield 2000).

\section{Statement of the Problem}

Palm Springs North Elementary School (PSNE) is a large, urban multicultural school with an array of problems typical of schools with large, diverse, transient student populations. Of particular concern at PSNE is bolstering students' reading achievement, which is at the forefront of school accountability by district and state mandates. PSNE continuously seeks workable, cost-effective interventions to meet the academic, social and emotional needs of students. Across the United States, several schools have implemented looping as an alternative instructional model. Proponents advocate that the 
looping model provides more efficient use of instructional time and continuity for teachers to deliver instruction to students at their individual levels, regardless of students' current grade level expectations. Looping could be an intervention beneficial to students at PSNE, however, little empirical research exists related to looping in general, and virtually no research exists related to looping in a large, urban, multicultural school.

\section{Purpose of the Study}

The purpose of this study was to evaluate the impact of looping on reading achievement, reading qualities, anxiety and self-concept within the context of a large, urban, multicultural school.

\section{Research Questions}

Specifically, this study addressed four research questions:

1. Does looping contribute to improving students' reading achievement?

2. Is there an improvement in reading qualities (main idea and comparisons) in the looping group as compared to the comparison groups?

3. Does looping affect students' anxiety levels related to reading?

4. Does looping affect students' self-concept?

\section{Hypotheses}

\section{Reading:}

1. Null: The population-mean posttest reading achievement scores adjusted for the pretest are equal for the experimental groups and the comparison groups.

Alternate: The population-mean posttest reading achievement scores are higher for the experimental groups than those for the comparison groups. 


\section{Reading Qualities:}

2. Null: The population-mean posttest raw scores for reading qualities (main idea and comparisons) are equal for the experimental groups and the comparison groups.

Alternate: The population-mean posttest raw scores for reading qualities are higher for the experimental groups than those for the comparison groups. Anxiety:

3. Null: The population-mean anxiety measure scores are equal for the experimental groups and the comparison groups.

Alternate: The population mean anxiety scores are lower for the experimental groups than those for the comparison groups.

Self-Concept

4. Null: The population-mean self-concept measure scores are equal for the experimental groups and the comparison groups.

Alternate: The population-mean self- concept scores are higher for the experimental groups than those for the comparison groups.

\section{Significance of the Problem}

This study sought to examine the effect of looping on reading achievement, reading qualities (main idea and comparisons), anxiety and selfconcept, within the context of a large, urban multicultural school setting. This study employed quantitative measures to examine the effects of looping in these areas. Other researchers investigating the effects of looping on achievement have 
neglected to cite quantitative research findings on the effects of looping on anxiety as related to reading and on overall self-concept. Grant, Johnson and Richardson (1996), authors of The Looping Handbook, used in this study, report qualitative reports from teachers that looping decreases anxiety and increases selfconcept in students. The current study will add quantitative data on these affective constructs to the current body of research in the area of looping.

The research findings from the current study will have potential implications for guiding instructional decisions as represented in the practice of looping, particularly in the wake of increased school accountability. Such decisions may have implications for the learner within the classroom, as well as for policy decisions at local, state and national levels. For the learner, the looping model may create a stable, nurturing learning environment that may lead to improvement in reading achievement, reduced anxiety and increased self-concept. For the Miami-Dade Public School System, the implications of this study demonstrate that implementing looping could be a viable intervention to make schooling more personalized for students in the large, urban, multicultural schools prevalent throughout this district. Looping may help to accomplish this by providing for the creation of meaningful relationships between students and their teachers and among the students themselves due to the extended time provided by the two-year looping cycle, providing continuity in the academic, social and emotional development of these students. 
Assumptions

The study had the following assumptions:

1. Positive self-concept and decreased anxiety are related to reading achievement.

2. Vocabulary is closely related to intelligence quotient.

3. The Florida Comprehensive Assessment Test (FCAT) accurately reflects students' reading abilities and differences in reading qualities.

4. The State-Trait Anxiety Inventory for Children (STAIC), developed by C.D. Spielberger is an accurate measure of anxiety.

5. The Self-Perception Profile for Children, developed by Susan Harter is an accurate measure of self-concept.

\section{Delimitations}

The limitations of the study are outlined below.

1. Students in the experimental and comparison classrooms had been preassigned to their classrooms using standard school procedures. (Appendix G) The use of intact classrooms may impact the broader generalizability of the study.

2. Due to the school district policy limitations of administering individual Intelligence Quotient or aptitude tests, the score on the MAT-7 vocabulary test was used to establish a match of control and experimental groups.

3. It is recognized that in an urban setting there tends to be student mobility. The mobility of students in looped and comparison classes could impact the study. 
For the purpose of this study, these terms were defined as follows:

Anxiety: state of being troubled, worried or uneasy

Aptitude: ability, skill or capacity in a given subject area or activity

Looping: instructional practice of keeping students with the same teacher for two to three successive years, as they advance to the next higher grade level.

Looping model: For the current study, the looping model involved a two-year placement for the teacher as well as for the students, specifically, two third grade teachers moved to the fourth grade with their students. The term looping classroom may be used interchangeably with looping model.

Multiyear education: resembles looping in that it allows students to remain with the same teacher for two or three years (Yang, 1997, p.3)

Physio-socio-emotio-psycho Linguistic Process: a term used to describe the key processes that are simultaneously involved in the act of reading

Reading Achievement: a student's ability to gain meaning from text that is written at his grade level equivalent, as measured by a standardized instrument

Reading qualities: student achievement in critical areas of reading comprehension: main idea and comparisons

Self-concept: a term used interchangeably with self-perception; the image one has of himself; positive or negative feelings a person possesses about himself

Teacher: individual responsible for instruction in the experimental and control groups involved in the study 
Traditional model: grouping of students by age or subject among different grade levels; the single grade -single teacher educational model that emphasizes separation between grade-levels and subject areas. 


\section{CHAPTER II}

\section{LITERATURE REVIEW}

This literature review will focus on information relevant to looping, as it impacts students' reading achievement, reading qualities, anxiety levels and self-concepts. This chapter will provide a review and discussion related to the following topics, (a) theories that support looping, (b) history of looping, (c) research on looping, (d) looping benefits to teachers, parents and students, (e) looping and other outcomes, (f) reading processes, (g) affective constructs with review of instruments, (h) conceptual framework and (i) summary of literature review.

\section{Theories That Support Looping}

Theories that support looping stem from the work of motivational theorists such as Abraham Maslow. These theories form the foundation of the conceptual framework for the current study by emphasizing that motivation highly influences learning, that it is critical to literacy learning and that by reducing anxiety and by providing a stable and secure environment for students, looping provides a context that is conducive to literacy learning (Little \& Little, 2001). Additional theories that support looping for literacy learning suggest that self-concept is associated with literacy learning and that increased time on task increases opportunities for reading achievement (Deci \& Ryan, 1985; Ford, 1992; Kuhl, 1986; Lepper, 1988; Maehr, 1976; McCombs, 1991; Wigfield, 1994).

Because looping provides a forum for fostering positive self-concepts in students and allows for maximized use of instructional time, it is expected that looping will positively impact reading achievement (Payne, 1998; Forsten, Grant, \& Richardson, 1999; Hampton, Mumford, and Bond, 1997; Krogman and Van Sant, 2000; Reynolds, Barnhart 
\& Martin, 1999). The theoretical framework outlined below serves as a foundation for the variables to be examined in the current study. Specifically, looping as it relates to increasing reading achievement and to the attainment of reading qualities, reducing anxiety and increasing self-concept within a large, urban, multicultural school setting.

One theory that supports the benefits of looping towards increasing students' reading achievement is derived from the work of Abraham Maslow. Maslow's Hierarchy of Needs reveals an individual's behavior at any given moment is motivated by achieving his strongest need at that moment (Little \& Little, 2001). When an individual's lower-level needs are met he will focus on the attainment of the higher needs. For example, if an individual's basic needs of food, shelter, clothing and safety are met, the person will focus on the satisfaction of higher-level needs such as social needs, esteem and self-actualization (Little \& Little, 2001). This is relevant to the study of looping because many students' basic needs are not met or only marginally satisfied in the home. These students may look to the school to fulfill the needs that are not being met at home. For example, students' whose safety and security needs are not met at home may experience the satisfaction of these needs at school. These students may feel even more safe and secure in a looping classroom due to the continuity, familiarity and stability of their surroundings. In the secure looping classroom, they will be motivated toward the attainment of the next hierarchical needs-the social needs (Little \& Little, 2001).

The establishment of meaningful relationships with others is crucial to an individual's development. A looping classroom fosters the opportunity for students to build meaningful social relationships with their teacher and with each other, due to the extended time period that these students spend together. In Maslow's theory, once an 
individual has developed interaction with a group, the higher need for becoming more than just a member of the group begins to arise. Because of his comfort level within the group, the individual will then seek to be accepted, recognized, appreciated and esteemed by the group. "Self confidence begins to develop as the individual emerges as a leader or a 'resident expert' in a certain area (Little \& Little, 2001, p. 8)."

Since teachers of looping classes have developed relationships with students and have come to know their students' strengths and weaknesses over an extended time period, they are more readily able to recognize when a student has reached a level of proficiency and confidence to perform in a leadership role within the group. Within a looping classroom, this proficiency and esteem may stem from student success in academics, athletics, social skills, artistic abilities, management or organizational capabilities. The teacher's role is to recognize the student's proficiency and foster its value among the group. Additionally, the teacher must guide the interpersonal dynamics of the group in ways that promote acceptance and appreciation for many levels of proficiency. This can be achieved by building upon the strength of a group as a whole as well as nurturing the maturation and development of each individual (Little \& Little, 2001).

The results of a national survey conducted by the National Reading Research Center reported that creating classroom cultures that support children in becoming highly motivated readers is of critical concern to educators (O'Flahavan, Gambrell, Guthrie, Stahl, \& Alvermann, 1992). While most educators would agree that motivation plays a crucial role in learning, its influence is particularly powerful in literacy learning because willingness to read results in improved reading ability and vice versa (Anderson, Hiebert, 
Scott, \& Wilkinson, 1985; Borkowski, Carr, Rellinger, \& Pressley, 1990; Paris \& Oka, 1986; Winograd \& Greelee, 1986). In other words, the more motivated a student is to learn to read, the better he will become at reading. Similarly, the more successful a student feels as a reader, the more motivated he will be to read. One way to foster motivation for learning, especially literacy learning, in students is to provide a classroom culture that fosters feelings of safety and security in students (Gambrell, 1996; Little \& Little, 2001). According to Gambrell, "The current interest in reading motivation is an outgrowth of the research of the 1980s that emphasized cognitive aspects of reading such as prior knowledge and strategic behaviors. A number of these scholars have cautioned, however, that in order for students to develop into mature, effective readers they must possess both the skill and the will to read" (Anderson, Hiebert, Scott, \& Wilkinson, 1985; Borkowski, Carr, Rellinger, \& Pressley, 1990; Paris \& Oka, 1986; Winograd \& Greelee, 1986). Building upon the research foundation of the 1980s, the research of the 1990s emphasized a more comprehensive and balanced view of reading which encompasses motivation and social interaction as well as cognition and knowledge acquisition (Brandt, 1990; Csikszentmihaly, 1991; McCombs, 1989; Turner \& Paris, 1995).

These researchers and theorists have stressed that teachers must balance both affective and cognitive aspects of reading development. In a looping classroom, this balance may be achieved through the motivation students experience as an outgrowth of the relationships, social interactions, reduction in anxiety and development of positive self-concept that develop over the extended time period (Payne, 1998; Forsten, Grant, \& Richardson, 1999; Hampton, Mumford, and Bond, 1997; Krogman and Van Sant, 2000; Reynolds, Barnhart \& Martin, 1999). 
The work of other motivational theorists points to the importance of motivational factors that influence literacy learning (Deci \& Ryan, 1985; Ford, 1992; Kuhl, 1986; Lepper, 1988; Maehr, 1976; McCombs, 1991; Wigfield, 1994). These researchers propose that self-perceived competence and task value are major determinants of motivation for reading. Winne (1985) maintains that the "idealized reader" is one who feels competent and perceives reading as being of personal value and practical importance. Within this theoretical framework, lies the definition of reading motivation as "an individual's self-concept and the value the individual places on reading." (Gambrell, Palmer, Codling, \& Mazzoni, 1996, p. 519). Evidence from theory and research suggest that high motivation to read is closely related to positive self-concept, while low motivation to read is related to poor self-concept (Ford, 1992; Henk \& Melnick, 1995; Wigfield, 1994). Therefore, the more positive the view a student holds of himself and of his ability to read, the greater the achievement he should experience in reading. Books and research articles written about looping report the development of positive self-concept in students as a potential result of participation in a looping classroom (Payne, 1998; Forsten, Grant, \& Richardson, 1999). The theories described above, related to self-perceived competence and task value are important to the current study because they provide a theoretical foundation for analyzing self-concept as a potential outgrowth of looping due to its value in motivation for reading.

Additional support for studying motivation for reading fostered by looping stems from the theory of time on task (Rappa, 1993). Research has shown that children who spend more time reading become better readers (Anderson, Wilson, \& Fielding, 1988; Morrow, 1992; Taylor, Frye, \& Maruyama, 1990). Because of the extended time period 
afforded in a looping classroom, more instructional time can be spent on reading rather than on the establishment of rules and routines and on diagnosis during the second year of the looping model (Rappa, 1993; Payne, 1998; Forsten, Grant, \& Richardson, 1999; Jensen 1998). Additionally, teachers in a looping classroom can take advantage of the summer break by assigning reading projects to be completed during the summer and to be shared and discussed by the group as early as the first day of the subsequent school year (Rappa, 1993; Forsten, Grant, \& Richardson, 1999). The looping advocates claim that this can result in an additional two-months of reading time for students. If accurate, this additional reading time, afforded by the looping model may result increased reading achievement for students who participate in this model.

These theories provide a theoretical framework for the study of looping as it affects reading achievement, reduced anxiety and improved self-concept. Additional research in the field of reading processes, as related to looping will be discussed further in this chapter.

\section{History of Looping}

Prior to the industrial revolution, both in the United States and internationally, it was not uncommon for a classroom to consist of students of multiple ages being taught by one teacher. Typically, the teacher and students would remain with one another over numerous school years. This multi-year educational model of schooling provided several benefits for students. Some of these included the establishment of long-term relationships between the teacher and students, the familiarity among students, closer home-school connections and the increased attention to the emotional and social development of students. While this model had various benefits, it also had several 
drawbacks. One of the major drawbacks dealt with the necessary expertise of the teacher who was called upon to teach children in multiple grade levels and to teach many different subjects (Grant, Johnson \& Richardson, 1996; Blanton-Smith, 2002).

With the onset of the industrial revolution, more families moved to urban areas. Schools in these areas became more populated and the grouping of students by age or subject among different teachers began to emerge. As urban populations continued to grow, the shift towards what is now considered the traditional model of schooling developed. This resulted in the single grade - single teacher educational model (Forsten, Grant \& Richardson, 1999). Eventually, this traditional model evolved not only to emphasize separation between grade-levels, but between subject areas as well (BlantonSmith, 2002). With this separation of grade levels and subject matter, teachers were better able to focus on the curriculum and developmental needs of children. Further, teachers had an opportunity to develop expertise in specific subject matter, because they were no longer teaching as many subjects or teaching one subject across as many grade levels.

Although this traditional model seemed to advance schooling in a variety of ways, it brought with it several drawbacks. In a multi-year classroom, students advanced in curriculum based upon their individual development of knowledge and skills, whether or not this took longer than an academic year to accomplish. With the new single gradesingle teacher educational model, it became expected that students would acquire specific grade-level skills within a set time frame, one academic year. Often, students were not necessarily ready academically, socially or emotionally to enter a particular grade level. Likewise, certain students were not able to acquire the identified knowledge and skills for 
a particular grade level during a single academic year (Forsten, Grant \& Richardson, 1999). This became a dilemma for educators who then had to deal with issues of retention or social promotion for these struggling students (Reynolds, Barnhart \& Martin, 1999).

The traditional model continued to gain wide-acceptance across the United States and internationally, but the benefits of a multi-year educational model were not ignored by a variety of educators (Krogmann \& Van Sant, 2000). For example, in 1913, the Officer of Education from the United States Department of Education proposed a multiyear educational model as an alternative to the traditional model of schooling. He stated, "What the child needs is not an ever changing personality, but a guide along the pathway of knowledge to the high road of life" (Grant, Johnson \& Richardson, 1996, p.30). The benefits of the multi-year educational model were also recognized by Rudolf Steiner, an Austrian educator and philosopher, who established the Waldorf Schools in Germany during the early 1900s. The Waldorf schools were developed to educate the children of the employees of the Waldorf Astoria cigarette factory in Stuttgart, Germany. In these schools, students stayed with the same teachers from first through eighth grade (Grant, Johnson, \& Richardson, 1996).

From the early 1900 s to date, the multi-year model has been more widespread internationally than in the United States. Currently, this practice of looping exists in certain schools in Germany as well as in Israel and Japan, where students participate in multi-year family groupings in the primary grades and in multi-year relationships by content area in the secondary schools. Bracey, (1999) states, "The idea that students fare 
better when they have teachers who stay with them more than one year is well established in Europe and Asia." (p. 169)

A multi-year educational model, or looping model as it is known today, was reintroduced in the United States in 1974, primarily through the work of Deborah Meier, an award-winning educator. This educator considered the multi-year assignment to be an essential component of her ideal school because it allowed the teacher and students to come to know each other well (Goldberg, 1991 in Hanson, 1995). One example of a school district in the United States that has maintained a long-term implementation of the looping model is the Attleboro School District in Massachusetts. This district has been looping students in all of its first through eighth grade classrooms since the late 1980s. In Attleboro, teachers typically remain with their students for two to three year cycles. Since its establishment in this school district, the looping model has proven to be beneficial for teachers, students and parents (Rappa, 1993). In addition to Attleboro, other school districts in the United States have implemented a looping model on occasion. While strongly advocated as beneficial to students, teachers and parents by those educators who implement a looping model, its use has not become widespread in the United States.

Perhaps looping has not become established in American schools to date due to the factor of teacher and student mobility. One critical dimension to the success of the looping model is that of the stable school and staff population. In order for the looping model to be implemented the teachers who participate must be available to teach for a minimum of a two-year cycle. Also critical for the implementation of looping is the stability of the school administration, which must provide support in the forms of staff 
training and scheduling essential for the success of the looping model. A stable student population is also key to the success of looping because the "sense of family" prevalent in looped classes can be hindered when numerous students leave the looped classroom and are replaced by new students (Simel, 1998 in Gaustad, 1998). Thus, the looping model may be difficult to implement in the United States, particularly in large, urban school districts characterized by the mobility of children and families.

Looping Benefits to Teachers, Parents and Students

The literature on looping that will be discussed throughout this section provides insights into the benefits of looping for teachers, parents and students. Much of this discussion is based on articles and reports on looping, in that to date, little empirical research exists related to this topic. Further, the effects of looping have not been examined within the context of a large, urban, multicultural school setting, nor have looping studies been found that quantitatively examined the affective benefits of looping for students. Therefore, the literature and research on looping that will be reviewed in this section serves as a foundation for conducting the current study. Due to the purported success of looping in various settings, it seems to be a promising practice to implement within a large, urban, multicultural school setting, like the one in the current study. Specifically, the following areas related to looping research will be discussed in this section: benefits for teachers, parental support, benefits for students, academic achievement and affective benefits of looping. The current study will build on and add to the empirical data on three of these variables: academic achievement, specifically, reading achievement, and affective variables, which include reduced anxiety and increased self-concept. 
Numerous benefits of looping affecting teachers are outlined in the literature. While the current study did not examine benefits for teachers, the following discussion provides contextual implications for the current study. The literature on looping (Burke, 1996; Grant \& Johnson, 1995) as cited in the Miami-Dade County Public Schools Evaluation on Looping in September 2000, reports the following benefits to the practice: teachers gain valuable learning time in the second year of the loop not having to begin a new school year with a brand new class; teachers accrue more detailed knowledge of the students after spending multiple years with them and students gain stability by having the same teacher for more than one year (Schneyderman, 2000). Similar teacher benefits were reported by Grant, who explains, "While looping itself may not cause students' achievement scores to skyrocket, it is a very powerful means of improving attendance as well as teacher satisfaction" (In Reynolds, Barnhart \& Martin, 1999, p.18). Additional advantages for teachers include greater efficacy, more efficient use of time, a more positive approach to classroom management, greater student participation in class discussions and deeper relationships with colleagues and parents (Grant et al., 1996). In one pilot study between East Cleveland, Ohio Schools and Cleveland State University, project F.A.S.T., gains in students' reading achievement and math achievement as a result of looping were coupled by advantages for teachers. Teachers who participated in this study revealed that they felt they possessed an increased sense of ownership for student outcomes and a greater sense of efficacy. This was a result of the teachers' increased decision-making autonomy for students (Hampton, Mumford, and Bond, 1997). Benefits of looping for teachers were also reported in the work of Forsten, 
Grant, and Richardson (1999). These researchers suggested that teachers who remain with students for a second year get to know students better, conduct more thorough evaluation during a longer evaluation period, better address student needs, evaluate teaching methods and practices and form a stronger bond with students. Likewise, Bellis (1999) asserts "looping also gives teachers the ability to monitor a child's progress over a two-year period before recommending a child study team evaluation" (p. 71). Because a teacher knows a child's strengths and weaknesses, students receive customized instruction. Students in the Hill, et al. (1999) bore witness to this. The researchers write, "They felt their learning needs were being met because their teacher knew what they needed." Musick (1998) agrees, reporting fewer referrals for special education classes and retentions (In Reynolds, Barnhart \& Martin, 1999).

As part of the data collection on looping, researchers took testimonials of teachers who laud the benefits of looping. Crosby (1998) a teacher who participated in looping in the Attleboro School District states: "Since we see so much of our students, we get to know their strengths and weaknesses, and can target acceleration or remediation based on individual needs. We begin the year teaching, not just reviewing... actually; we gain about four months over the two-year span." Two other teachers, Lisa Andrews and Sheila Hattey express that looping supports what is best for the children. They explain, "That the long-term relationship of looping offers consistency, stability and nurturing, thus creating the feeling of 'family' within the classroom" (Reynolds, Barnhart \& Martin, 1999, p.19). Such an environment creates a climate that fosters learning and cooperation. Teacher satisfaction with looping is often tied to the increased teaching time afforded by the looping model. Jordan's research suggests that careful planning among 
participating teachers in looping eliminates much of the regression that occurs during the summer months. Because looping teachers view their term with students as a two-year cycle, they often assign reading, writing and organizational projects to their students over the summer. Since students know they will be responsible for the completion of assignments by the first day of school, they are likely to complete them. This continuity also promotes a greater home-school connection and adds more learning time during the academic year by including the summer as part of the academic program (2000). Payne (1998) concurs, advocating "looping decreases back-sliding after summer break." (Forsten, Grant, \& Richardson, 1999)

Although benefits of looping for teachers were not examined in the current study, teacher benefits are relevant to the context of the current study because of the increased challenges faced by teachers within a large, urban, multicultural school. A review of the professional literature related to the benefits of looping for teachers lends support for the selection of looping as an instructional intervention for the current study.

\section{Parental Support}

Various articles found within the professional literature report support for looping from parents. The parents at John Nowlin Elementary stated, almost unanimously, "that they believed their children benefited academically because of the looping program" and "that they would place their child in another looping class if available" (Reynolds, Barnhart \& Martin, 1999, p. 19). Looping also increases parental involvement because parents are more inclined to participate in classrooms of teachers with whom they have established relationships (Hill et al., 1999). Jubert (1996) found that familiarity between the teacher and the parents during the second year promoted stronger home-school 
relationships. This research indicates that looping provides for greater communication between the home and the school. One common practice was for parents to call the teacher and discuss openly events that may impact their child's overall development and/or immediate behaviors at home and school. Grant et al. outlined various benefits to parent involvement. For instance, children of involved parents demonstrate higher academic achievement, better relationships with their parents, participate in more activities with their parents, and have a more positive attitude about school.

The F.A.S.T. study found that parents were positively impacted by the looping model in that they felt more respected by teachers and reported that they had more confidence in their child's teachers and administrators (Hampton, Mumford, and Bond, 1997). The Blue Springs School District, in suburban Kansas City, has been practicing looping in their first and second grade classes at John Nowlin Elementary for the past four years. Ninety-seven percent of the parents at the school responded favorably to a survey about looping.

Although benefits of looping on increasing parental support were not examined in the current study, those outlined above are relevant to the context of the current study. A review of the professional literature revealed that parents claim that looping provided benefits for their children and families, thus adding to the rationale for the implementation of looping as an intervention within a large, urban, multicultural school. Benefits for Students

Whether as research reports or research findings, the examination of looping is most often reported with a focus on benefits for students. Educators and researchers claim that looping has resulted in increased academic achievement (Hampton, Mumford, 
and Bond, 1997; Krogman and Van Sant, 2000; Yang, 1997; Schneyderman, 2000) provides an alternative to retention, (Grant, Johnson \& Richardson, 1996; Rappa, 1993; Reynolds, Barnhart \& Martin, 1999) leads to a decrease in exceptional education and discipline referrals (Reynolds, Barnhart \& Martin, 1999; Rappa, 1993), improves attendance (Rappa, 1993; Schneyderman, 2000), and develops a sense of belonging, comfort and security (Rasmussen, 1998; Grant, 1999; Hill, Lofton, and Purvis, 1999; Nichols \& Nichols, 2002).

The most widespread use of looping occurs in the Attleboro, Massachusetts School District, which loops students in all of its' first through eighth grade classrooms. Joseph Rappa, the superintendent of Attleboro used school district data to develop a report that highlighted the benefits of looping for his school district. Rappa reported that since the inception of looping in 1991, student attendance in grades two through eight increased by five percent, from 92 percent to 97 percent. Retention rates decreased by over 43 percent and exceptional education referrals decreased by over 55 percent. Additionally, discipline referrals and suspensions decreased and staff attendance improved by over four days per year per staff member (1993). While helpful in understanding some of the possible benefits of looping Rappa's report does not include empirical research. Further, the Attleboro School District is comprised of a total of 11 schools. While these schools are in an urban setting, they differ greatly from the school in the current study in the areas of student diversity, student mobility and size of student population at each school.

Another study, conducted by Hill, Lofton, and Purvis (1999) reported gains on standardized tests for students who were looped from third to fourth grade, as well as 
qualitative reports of improvement in social and emotional bonds between students and teachers. While the above study evaluated looping from third to fourth grade, it was a case study which took place in a rural setting. The current study expands on this study by quantitatively examining the affective benefits of looping, including reduced anxiety and increased self-concept within a large, urban, multicultural school.

\section{Looping and Other Outcomes}

While Jim Grant, founder of the Society of Developmental Education, did not conduct an empirical study, he co-authored The Looping Handbook, and is one of the greatest proponents of looping. He describes looping as "the opportunity for students and a teacher to stay together for two or more years and share in individual growth and development in all areas; such as cognitive, academic, emotional, psychological, social, etc." Grant's description compares looping to developing a "close-knit" family of "successful individual and group learning, cooperation and collaboration, positive social skill development and interactivity, and individual and group responsibility and independence in learning, growing and developing into life-long learners." (1996, p. 1) Grant's work is relevant to the current study by providing an impetus for looking at looping and its relationship to reducing anxiety and improving self-concept from an empirical perspective.

Academic Achievement

Various research reports have shown the positive effect of the looping model on students' academic achievement. Krogman and Van Sant (2000) conducted an action research project in a blue-collar, middle-class community in Iowa. They reported positive findings in a first to second grade looping class in reading achievement on norm- 
referenced results of the Gates-MacGintie Reading Test. The results demonstrated a median reading improvement gain of 17 points for looped students, a 7.5-point difference over the non-looped group. Parent interviews also revealed that students experienced less anxiety at the beginning of the second year of looping. This study is relevant to the current study in that it examined the effects of looping on reading achievement. However, the context within which this study was conducted is markedly different from that of the current study. The school in the Krogmann and Van Sant study, was extremely small, housing only 314 students, $95 \%$ of whom were Caucasian. The entire school district consisted of only two high schools, two middle schools and seven elementary schools. By contrast, the school in the current study housed approximately seven times the number of students in this study, from extremely diverse cultural and socioeconomic backgrounds. The current study extends the findings of the Krogmann and Van Sant study by examining reading achievement of students in a large, urban, multicultural school, within a large, urban, school district comprised of students from numerous ethnic and socio-economic backgrounds.

The East Cleveland Ohio Schools and Cleveland State University collaborated to create Project F.A.S.T. (Families are Students and Teachers), which included looping assignments at its core. This project resulted in increased student achievement in reading and math as evidenced by standardized test scores. Parents were also positively impacted in that they felt more respected by teachers and reported that they had more confidence in their child's teachers and administrators (Hampton, Mumford, and Bond, 1997). The socio-economic background of the student population in this project resembled that of the one in the current study, since approximately $50 \%$ of the students in 
both studies were from low socio-economic backgrounds. However, a key difference between this project and the current study is that the ethnic background of the population in Project F.A.S.T. was homogenous, consisting of 99.4 African Americans. The current study built upon this project by evaluating looping and reading achievement within a school population comprised of students from diverse ethnic backgrounds.

During the 1994-1996 school years the Berino Elementary School in New Mexico, where eighty-six percent $(86 \%)$ of the students qualify as low socio-economic status based upon an annual low-income survey and approximately 70 percent of the students start school speaking only Spanish, implemented a looping program with great success. The findings of this study included student gains on the reading subtests on the ITBS and on the SABE (Yang, 1997). This study resembled the current study, since at PSNE many students also begin school with limited proficiency in English due to their diverse ethnic backgrounds. Both studies have approximately $70 \%$ Hispanic students. However, in the above study, almost twice as many students were from low socioeconomic backgrounds. Because the Berino Elementary School found looping to enhance student reading achievement with a large Hispanic student population, it is possible that looping could provide similar results at PSNE.

One other study of note related to looping and academic achievement was conducted in the Miami-Dade County Public School System during the 2000-2001 school year. This was a district-wide study which assessed the impact of looping by comparing two groups of 612 students each in grades two through five. Six hundred twelve students participated in the looping sample and six hundred twelve students participated in the matching sample. For this study, testing data from the 1999-2000 school year and 
surveys of teachers and principals were analyzed. The students in the looped groups demonstrated positive results on both, the reading comprehension and math application subtests of the Florida Comprehensive Assessment Test (FCAT) Norm-Referenced Test. Additionally, students in the looping sample had increased attendance and lower retention rates (Schneyderman, 2000). The relationship between this study and the current study will be discussed later in this chapter.

\section{Affective Benefits of Looping}

Looping seems to reduce anxiety and fosters a positive self-concept in students. These two affective factors can potentially impact learning. Payne (1998) explains that a long-term, caring environment with a teacher has a definite, positive effect on a child's well - being. Jensen (1998) suggests, "The affective side of learning, the link between mind and emotions influences the way we feel, act and think. Emotions drive attention, create meaning, and have their own memory pathways in the brain." (In Hill, Lofton \& Purvis, 1999, p. 8)

A case study into the positive effects of looping on affective factors was conducted by Hill, Lofton and Purvis (1999). In this study, four classrooms in a rural elementary school in the Livingston Paris System in Louisiana were studied. One group of students was involved in looping over a three-year span, pre-k through third grade. Three classes at the same school were looped over a two-year span from third to fourth grade. Qualitative results revealed significant positive results for parents, students, and teachers. These included a sense of support and stability for students, familiarity and comfort for teacher's instructional styles, and assistance from peers within the family style classroom setting. 
Various research reports point to the affective benefits of looping for students. These reports depict students' connectedness to school, satisfaction with looping and emotional ties between the home and school as affective advantages of looping for students. One of the aforementioned research reports provides a set of promising reforms that connect families and communities to schools. Jim Comer's work in New Haven found that looping made it possible for students to feel connected in their schools as well as in their homes" (In Darling-Hammond, November, 1998).

Qualitative data were gathered in the form of testimonials. Reynolds, Barnhart \& Martin (1999) highlight student satisfaction with looping. Second grader Lindsey states that "You really get to know your teacher and classmates...Looping is also good for your parents to get to know your teachers." Classmate Jessica exclaims "I am smart and so is looping," Brittney shares, "If you loop, you probably won't be scared at the beginning of school...School feels like home." (Bracey, 1999, p. 169) Jensen describes that looping creates "emotional bridges from the students' world outside the classroom to learning. Students come to realize "that they do matter to others and that they can choose good decisions and get support from their team." This creates a learning community that motivates learning (In Hill, Lofton \& Purvis, 1999, p. 8).

In summary, research reports and testimonials show strong support of looping from students in the areas of students' sense of connectedness to school, satisfaction with looping and emotional ties between the home and school as affective advantages of looping for students. These advantages of looping could be especially beneficial within the context of Palm Springs North Elementary, where students may feel overwhelmed due to the large size of the school and instability often present in their homes. The 
current study expanded on the work of the above researchers by quantitatively examining the effect of looping on the affective constructs of reduced anxiety and increased selfconcept of students within the context of a large, urban, multicultural school.

\section{Reading Processes}

Other research pertinent to the current study relates to reading. The complex tasks involved in reading include the simultaneous functioning of physiological, sociological, emotional and psychological and linguistic processes (Weaver, 1998). The reading process involves the interaction or "transaction" between the reader and the written text within a specific social context (Rosenblatt, 1978). This philosophy of the reading process arose during the 1960 s and reflects a paradigm shift demonstrated through the seminal research of various experts in the field of reading. This paradigm shift also redefined the role of the student and that of the teacher in the reading process (Dechant, 1970; Goodman, 1967; Rosenblatt, 1978; Weaver, 1988).

During the 1960s and 1970s reading researchers began to realize the importance of understanding the individual reader in order to help him develop and comprehend the text being read. This research also determined the value of capitalizing on the reader's strengths and addressing their weaknesses, realizing that the understanding of these develops over time. During this era, the role of the teacher in the teaching of reading was also changed. Prior to the 1960s and 1970s, the primary role of the teacher was to present information. The critical research from this time period shifted that role to including the understanding of students' background knowledge, experiences, abilities and learning needs. Since then, reading teachers have been called upon to adjust their teaching styles to focus on each individual student's modes of learning. Through the 
two-year time period provided in the looping model, teachers can provide an environment conducive to the development of the aforementioned complex processes involved in reading (Dechant, 1970; Goodman, 1967; Rosenblatt, 1978; Weaver, 1988). The familiarity among the student and his classroom setting, teacher and classmates fosters a positive social context conducive to reading achievement.

Some of the seminal research demonstrative of the paradigm shift in the teaching of reading are outlined below. This research demonstrates that the act of reading goes far beyond the mere physical act of viewing words on a page. Dechant states "When the light rays from the printed page hit the retinal cells of the eyes, signals are sent along the optic nerve to the visual centers of the brain. This is not yet reading. The mind must function in the process, the signals must be interpreted, and the reader must give significance to what he reads. He must bring meaning to the graphic symbol." (1970, p.

Further, according to Louise Rosenblatt, "The reader brings to the text his past experiences and present personality. Under the magnetism of the ordered symbols of the text, he marshals his resources and crystallizes out from the stuff of memory, thought, and feeling a new order, a new experience. This becomes part of the ongoing stream of his life experience, to be reflected on from any angle important to him as a human being." (1978, p. 12) Rosenblatt emphasizes that the critical point is that meaning does not reside in the text itself, rather arises during the transaction between the reader and the text. It is in this transaction that meaning evolves. Rosenblatt's research is relevant to the current study because it implies that the more time a teacher spends with a student, the deeper the 
understanding he will develop of the student's past experiences, present personality, and overall meaning he brings to the text.

Psycholinguists and socio-linguists point out that if a student is to get meaning from a text he must actively and deliberately search for and create meaning. The significance a student gains from a text results from the interaction of the meaning which he brings to what he reads to the new text being read. The construction of meaning is more important that identifying words. Recognition of all words in a text is not a requirement of gaining meaning from the text (Weaver, 1988).

These examples illustrate that the reading process involves a transaction between the student and the text. Constance Weaver emphasizes that this transaction occurs within a particular social context (1988). This context includes the expectations that students bring with them to the classroom, the classroom itself and the teacher's expectations of the students. These and other social factors contribute to making reading a complex process involving psycholinguistic and socio-psycholinguistic processes. According to Weaver, the reading process is "psycholinguistic" in nature because it involves a "transaction" between the mind of the reader and the text being read. Weaver explains that, equally important, this transaction occurs within a particular social and sociolinguistic context (1988). Various researchers concur with this view that literary meaning is developed through social interaction (Rosenblatt, 1978; Bleich, 1975, and Fish, 1980 in Weaver, 1988).

A logical extension of these ideas is that the more familiar the school context and the knowledge that the teacher and students have of one another, the more conducive to the evolution of the transactions involved in the reading process. Looping provides for 
such a context because during the first academic year the teacher gains valuable knowledge and information about students, provides for learning experiences that build schema and diagnoses students' strengths and weaknesses so that he/she can build on this knowledge and experiences during the second year of the looping model. During the second year of looping, students are familiar with the social setting, are comfortable with their teacher and classmates and know the expectations that their teacher has of them. It is hypothesized that this may positively impact reading achievement. The current study seeks to empirically examine this relationship between selected affective variables and reading within the looping context.

\section{Affective Constructs}

The affective variables examined in the current study are anxiety and selfconcept. Because cognitive factors involved in learning, specifically in reading, cannot be separated from the affective factors, anxiety and self-concept are two critical, affective factors that warrant examination. The literature related to affective constructs will be reviewed below.

Anxiety

This review of the research related to anxiety will focus on providing its definition and on explaining why it is important to consider anxiety within the learning context. According to Spielberger and Rickman (1991), "Anxiety has been defined as an unpleasant emotional state or reaction that can be distinguished from others, such as anger or grief, by a unique combination of experiential qualities and physiological changes. An anxiety state consists of feelings of tension, apprehension, nervousness, and worry, and activation of the autonomic nervous system. The physiological 
manifestations generally include increased blood pressure, rapid heart rate, sweating, dryness of the mouth, nausea, vertigo, irregularities in breathing, and muscular skeletal disturbances." (in Sartorius, 1991, p. 69) These researchers also explain that although the meaning of anxiety differs among cultures, it is generally believed that increased anxiety arises from situations that pose an immediate danger that may result in physical harm. Anxiety is also an atypical reaction in social-evaluative situations that pose threats to self-esteem or psychological well-being.

Spielberger, Gonzalez and Fletcher conducted primary research in the study of anxiety. These researchers state, "In research on learning strategies, it is essential to consider both cognitive and affective factors that influence the learning process" (In O’Neil and Spielberger, 1979, p. 111). Some cognitive factors include intelligence, ability and previous knowledge; affective factors include emotions, anxiety, self-concept, self-esteem and self-efficacy. This information is pertinent to the current study because it shows that the affective factors of learning should be considered along with the cognitive. For example, all things being equal, (e.g., cognitive factors) a person with high anxiety will not perform as well as one with low anxiety.

In another key study, Schachter (1964) categorizes emotional states into two major components: physiological arousal and socially determined cognitions. He explains that cognitive or situational factors trigger physiological responses. One example related to this study is the state of anxiety in students at the beginning of the school year (physiological arousal) that is triggered by the uncertainty of knowing who their teacher and classmates will be (situational factor). Year two of looping alleviates the transitional anxieties often experienced by students at the beginning of the school 
year. It ensures that by the second year students are acquainted with the teacher and the classroom environment. This relieves stress on both the part of the students and the teacher. Because the teacher already knows students' abilities, needs, interests, behaviors, work habits, background and home situations, a closer, more knowledgeable and trusting working relationship between teachers, students, parents, administrators and support personnel may be facilitated. Students who have been looped for two or three years describe the beginning of the school year as being a "family reunion." Krogmann and Van Sant state, "When students come to school each day, they know what to expect. The routines and the people stay the same, allowing the students more freedom in their learning, because they are not worried about unexpected events." (2000, p. 11) Looping may be one way of alleviating the physiological and situational arousal of anxiety.

Another example, related to reading achievement, is the feeling of anxiety experienced by low-achieving students who are called upon to answer questions aloud or work on group projects in an unfamiliar class setting. Spielberger and Rickman explain that to cope with these feelings of anxiety, which are unpleasant and painful, students may avoid the situation (In Sartorias, 1991, p. 73). According to Bandura, (1997) "By conjuring up aversive thoughts about their ineptitude and stress reactions, people can rouse themselves to elevated levels of distress that produce the very dysfunction they fear (p. 107).

While not empirically researched, it has been proposed that students in looped classes may be less likely to experience anxiety during the school year because of the tight-knit bonds they have formed with their teacher and peers (Grant \& Johnson, 1995). This may result in students' willingness to take risks in class, be more open to group 
work and presentations and experience more positive feelings during testing sessions. Krogmann and Van Sant explain, "The extended period of time spent together in the looping classroom encourages higher academic achievement because students are more comfortable with the teacher and the classroom expectations and can therefore concentrate on learning." $(2000$, p. 11) Teachers in looping situations are also more able to plan and provide for more pleasant learning experiences, due to the addition of time. Bower, (1991) encourages this by stating, "When positive environmental factors exist during stress-free instructional sessions, the learner will implement the strategy taught with little stress. If a student acquires a skill despite stress caused by an unpleasant, disruptive learning environment, the anticipation of implementing that skill will be accompanied by the memory of stress (In McCabe, 2003, p. 18). Therefore, the reduced anxiety associated with the looping model may improve reading ability.

McCabe (2003) suggests that reading scores on high-stakes testing, such as the FCAT, "often reflect test anxiety to a large degree, rather than true reading ability."(p. 12) Pintrich and Schunk (1996) report that as many as $25 \%$ of all elementary and secondary level children in the United States have some degree of test anxiety, and that approximately $10 \%$ of American students have a level of test anxiety that is considered high (In McCabe, 2003, p. 12). It is important to address this anxiety because critical decisions regarding promotion to the next grade often depend on these test outcomes.

In addition to measuring the effects of looping on reading achievement and reading qualities, the current study quantitatively evaluates the affective construct of anxiety as related to reading using the State-Trait Anxiety Inventory for Children developed by Charles D. Spielberger and overall self concept using Susan Harter's Self- 
Perception Profile for Children. A discussion for the selection of the above-named instruments is to follow. The State-Trait Anxiety Inventory for Children (STAIC) was chosen for this study for various reasons. First, it provides a simple assessment of a child's anxiety level in the school setting. Second, the scale was developed for use with nine to twelve year old children. All of the children in the current study were between the ages of nine and eleven when the instrument was administered. A third reason for the use of the STAIC was the flexibility afforded by the scale to modify its instructions to measure state anxiety in a variety of settings (Spielberger, 1985). For the purpose of this study, the instructions in the State-Trait Anxiety Inventory for Children (STAIC) were modified to include the words, "while reading," to assess each student's state anxiety during the task of reading. Spielberger states, "For the A-State scale, the instructions may be modified to permit the evaluation of level of A-State intensity for any situation or time interval that is of special interest to the clinician or experimenter $(1985$, p. 4). Finally, yet most importantly, the STAIC was used in this study because of its high validity and reliability ratings, as reported by Spielberger (1985).

Self-concept

The physiological processes involved in reading cannot be separated from the social, emotional and psychological aspects (Weaver, 1988). This review of the research related to self-concept will focus on providing its definition and on explaining why it is important to consider self-concept within the learning context. Much of the research on looping proposes increased positive self-concept or self-perception as one of its benefits. Most educators, counselors, parents and community leaders agree that developing 
healthy, authentic self-concept in children is among the most effective and promising ways of preventing destructive behavior.

Purkey (1988) defines self-concept as, "The totality of a complex, organized and dynamic system of learned beliefs, attitudes and opinions that each person holds to be true about his or her personal existence" (In Walz, 1991, p. 1). Self-esteem focuses upon feelings of personal worth and the level of satisfaction regarding one's self (Mecca, Smelser and Vasconcellos, 1989, in Walz, 1991, p. 1). Nathaniel Branden, defines selfesteem as "the disposition to experience oneself as being competent to cope with the basic challenges of life and being worthy of happiness (In Vasconcellos, Reasoner, Borba, Duhl \& Canfield 2000, p. 2). It can be assumed that students who possess high levels of satisfaction within themselves will potentially experience greater academic success.

Quandt advocates the importance of students' feelings of acceptability to their teacher, which can be accomplished through a sharing of interests and a classroom atmosphere conducive to favorable self-concepts (1973). He states, "Above all, teachers should recognize that success or acceptance or products of the teacher.'(p. 39) Quandt suggests that positive self-concepts in students can be nurtured through home-school connections. The research findings on self-concept demonstrate that a positive learning environment may heavily impact a student's self-concept or self-perception. Students who perceive a learning environment that nurtures success will be more likely to take risks that may improve their academic achievement.

Although the constructs, self-concept and self-esteem are used interchangeably, it appears that one's self-esteem, high or low, is a significant outgrowth of his self-concept. 
Few would argue that a person's self-esteem is a major determinant of what a person accomplishes and how fulfilled and rewarding a life he lives. Most educators, counselors, parents and community leaders agree that developing healthy, authentic selfesteem in children is among the most effective and promising ways of preventing destructive behavior (Vasconcellos, Reasoner, Borba, Duhl \& Canfield, 2000). Walz states, "The importance of self-esteem can be considered from several perspectives. First, it is important to normal, psychological development. To adequately cope with the challenges of growing and developing, persons need to believe that they have the capacity to achieve what they need and want to and that they are deserving of happiness and joy in life." (1991, p. 2)

The California Task Force to Promote Self-Esteem points out, "School climate plays an important role in the development of the self-esteem of students. Schools that target self-esteem as a major school goal appear to be more successful academically as well as in developing healthy self-esteem among their students." $(1990$, p.5) Walz (1991) adds that self-esteem and achievement may be either the cause or the effect of each other, depending upon the person and the particular situation. This lends credence to the theory that exclusive attention to either self-esteem or achievement may not yield such positive outcomes as an approach which focuses on both. Walz and Bleuer postulate, "The presence of an 'esteem-achievement connection' can be created in schools by presenting students with challenging experiences that enable the student to 'earn' high esteem by successfully coping with difficult tasks."(1991, p. 3) Vasconcellos, Reasoner, Borba, Duhl \& Canfield (2000) explain that a person's sense of competence is grounded in the belief that he is capable of producing desired results. This belief arises for from being 
secure in the efficacy of one's mind and emotions. Lillemyr (1982) found that a "positive classroom climate stimulates students' emotional responses to the group, their selfconcepts and motivation toward legitimate educational goals." (p. 1)

Bruckner (1977) explains that a definite relationship exists between self concept and reading achievement. Lynch also found that children's self-perception as readers was significantly related to their reading achievement (2002). Sweet and Burbach determined that increases in self-esteem were followed by increases in reading comprehension achievement; while decreases in self-esteem were followed by decreases in achievement (1977). These researchers posit, "An atmosphere which is conducive to the enhancement of self-esteem should be incorporated into the environment where learning is to occur" (p. 26). The implications of this research for the current study are concurrent with the research on looping as a model to improve reading achievement. The more familiar, nurturing and comforting the learning environment, the more conducive it will be towards developing healthy self-concepts within students; thus positively affecting reading achievement.

In sum, self-concept encompasses the global view or perception a student holds of himself; self-esteem, an outgrowth of self-concept, reflects a student's feelings about himself; and self-efficacy is a student's belief in his ability to be successful in a given situation. These affective constructs are critical to student achievement. As educators, it is incumbent upon us to provide the best instructional education for our students, and also to meet their needs socially and emotionally. Parents and educators are encouraged to establish learning environments and conditions that foster the development of healthy self-concepts in students. The practice of looping offers one such learning environment 
by providing students with continuity, an increased time-span for expected learning and flexibility in meeting academic and behavioral goals. This practice strives to ensure that every child has time to connect with the classroom and feel successful therein. It is expected that the increased self-concept experienced by students as an outgrowth of looping will result in gains in their academic achievement, specifically in the area of reading.

In contrast to other looping studies, for the current study, self-concept was measured quantitatively. In order to measure this construct, The Self-Perception Profile for Children was used. The reasons for selecting this scale are as follow. First, the scale was developed for a target population of third through sixth graders. Because the students in the current study were in fourth grade at the time of the scale's completion, the age range for which the scale was intended provided a logical fit. Also, the scale enables a researcher to render information about the students' global self worth. Harter states, "While the domain-specific approach has merit, it is also the case that children (aged eight and older) can make a more global judgment about their self-worth, a more gestalt-like evaluation about the self, in general $(1985$, p. 6). Similar to the STAIC, other studies employing the The Self-Perception Profile for Children report it as having high validity and reliability ratings (Granleese \& Stephen, 1994; Van Den Bergh \& De Rycke, 2003). More specific information related to the instruments selected for this study will be outlined in the instrumentation section in chapter three.

\section{Conceptual Framework}

While it may appear that much has been written about looping, proportionately, much more has been written about looping theoretically or as an instructional 
intervention than that which has been written as empirical research. However, within the last five years two empirical studies have been published that have formed the springboard for the current work.

Alex Schneyderman, of the Miami-Dade County Schools conducted a broad, district-wide study (2000) evaluating looping in classrooms that participated in this practice across the district. Two groups of 612 students each in looping and matching sample groups in grades 2 through 5 were considered. 1999-2000 data and surveys of teachers and principals were utilized. The looping sample demonstrated positive results on the reading comprehension and mathematics applications sections of the Florida Comprehensive Assessment Test (FCAT), as well as student attendance. Retention figures were also lower for the looping group, and qualitative results in the form of surveys were positive. The above study provided a springboard for the current study because it employed some empirical elements and was conducted in the same school district, analyzing the effect of looping on reading achievement utilizing the same curriculum and the same instrument to measure reading achievement as the current study, the FCAT. Because the Miami-Dade County Public School System provided support for this study of looping, it was expected that the school district would also support the current study. While the Schneyderman study analyzed reading achievement using the FCAT, students' reading achievement was measured using the norm-referenced FCAT results. Conversely, the current study seeks to determine whether looping affects students' reading achievement as measured by the criterion-referenced examination of the FCAT. Using the criterion-referenced version of the FCAT allowed the researcher to measure each individual student's reading achievement gain from year to year. The 
FCAT, an objective, criterion-referenced standardized test, was chosen for the current study because it is a competency based test that is closely aligned to the Sunshine State Standards which serve as the foundation for the Competency Based Curriculum that is used to guide instruction within the Miami-Dade County Public School System. In addition to providing an overall criterion-referenced reading achievement raw score that can be compared across school years, the FCAT also provides a raw score for each student in the reading qualities of main idea and comparisons, two critical reading qualities being examined in the current study. The FCAT provides a criterion-referenced mean score that enables a students' progress to be tracked from school year to school year. This tracking of each individual student's scores from year to year would not be possible using the norm-referenced version of the FCAT. The most important reason for selecting the FCAT for this study is that the Florida Department of Education, in its Technical Report for Test Administrations reports high validity and reliability ratings for this test (2003).

The current study differs from the Schneyderman study outlined above in that it applied a variety of empirical methods to evaluate the academic and affective benefits of looping for students at the point of instruction, within a specific school setting. The Schneyderman study took a broad and generalized look at the impact of looping on academic achievement and attendance throughout the entire school district. In addition to evaluating the effects of looping on reading achievement and reading qualities (main idea and comparisons), the current study examined the effects of looping on anxiety, as related to reading achievement and on overall self-concept. The idea for looking at these affective constructs stems from the writings of Grant, Johnson, and Richardson, who cite 
testimonials from teachers of looping classrooms anecdotally reporting reduced anxiety and improved self-concept in students as outgrowths of the looping model, based upon teacher observations of students over a two to three year cycle (1996). However, none of the empirical studies previously discussed measured anxiety or self-concept quantitatively.

Another study that parallels the current study was conducted by Hill, Lofton and Purvis (1999). These researchers studied four classrooms in a rural elementary school in the Livingston Parish System in Louisiana in which three classes were involved in a looping cycle over a two-year span from third to fourth grade. Both qualitative and quantitative results showed overwhelmingly positive outcomes for parents, students, and teachers. As in other studies, this study revealed that students knew where to go for help, were familiar and comfortable with their teachers' instructional styles, and gave and were given help from peers due to the family-oriented support system that had developed. Similar to the current study, this study quantitatively analyzed reading achievement of students participating in the looping cycle from third through fourth grade using the California Achievement Test, a standardized achievement test. A major difference between this study and the current study is that it took place in a rural setting in a small school comprised of 400 students. Like the Schneyderman study, this case study reported student gains in reading achievement using norm-referenced standardized test data. The current study builds upon the findings of the Hill, Lofton and Purvis study by examining the effects of looping on reading achievement in a large, urban, multicultural school and quantitatively studying the benefits of looping on reducing anxiety and improving selfconcept. 
Major differences between the Miami-Dade County Public School System and the Livingston Parish School System studies from the current study are that the above studies used norm-referenced test results instead of criterion-referenced scores, did not report matching experimental and control group data, failed to discuss the matching of the teachers and curriculum in the study, neglected to report student aptitude scores prior to the beginning of the study, and did not quantitatively examine the affective constructs of anxiety and self-concept. The current study attempts to address each of these deficiencies in its scope and design.

\section{Summary of Literature Review}

The purpose of this chapter was to review related research on theories that support looping, predominantly as related to reading achievement; present a brief history of looping and outline research on looping, including benefits for teachers, parents and students. Additionally this chapter provided a review of research in the areas of reading processes and on the affective constructs of anxiety and self-concept. Of major focus in this chapter was the discussion on empirical studies which served as a springboard for the current study. The theories, research reports and empirical studies discussed in this chapter provided a framework upon which the current study extended to quantitatively evaluate the effects of looping on reading achievement, reading qualities, anxiety and self concept within the context of a large, urban, multicultural school. 


\section{METHODOLOGY}

This study focuses on the impact of looping on reading achievement, reading qualities, anxiety and self-concept within the context of a large, urban, multicultural school. In order to provide an overview of the study, the research design will be presented followed by details related to the design. The purpose of this chapter is to

present: (a) the research design, (b) participants, (c) curriculum, (d) instrumentation, (e) data collection and analysis and (f) summary.

\section{Research Design}

As applied classroom research, this study had a causal-comparative, nonequivalent control group design, using a pretest - posttest model for evaluation. Four intact classrooms were used for this study. It should be noted that in all of these classrooms the same reading series, Harcourt, Brace \& Jovanovich was used. The curriculum followed by the teachers in the study was the Competency Based Curriculum, CBC. Within the entire school district, grade levels are expected to adhere to the $\mathrm{CBC}$, developed by the Miami-Dade County Public School System and aligned with the Sunshine State Standards, developed by the Florida Department of Education. All four teachers in the study also followed the Comprehensive Reading Plan, a reading and language arts plan developed by the district with specific guidelines for teaching reading and writing.

The independent variable in this study pertained to participating in the looping model, being in a classroom with the same teacher and students from third grade during the fourth grade school year (experimental), versus having different teachers and 
classmates in the third and fourth grade years (comparison). Four different teachers in four different fourth grade classrooms participated in this study. Pairs of teachers were matched for experience. (Appendix G) One from each pair was randomly assigned to the experimental (looped) and comparison (non-looped) group so that each group had a teacher with less than five years of experience and each had a teacher with over ten years of experience. Because of the non-equivalent control group design (intact classrooms were assigned treatments) the term comparison group is used throughout the study, in place of the term control group.

For this study, the effects of looping (independent variable) on four dependent variables were measured and analyzed quantitatively. Four dependent variables were studied: reading achievement; reading qualities; anxiety and self-concept. The four hypotheses involving the independent variable and dependent variables were tested via Analyses of Variance (ANOVAs), to determine whether looping was significantly related to reading achievement, reading qualities, anxiety and self-concept.

\section{Participants}

The following section will discuss the sample population and the instrumentation used to measure the effects of the independent variable on the dependent variables.

\section{Sample}

In September 2001, the experimental groups and comparison groups were identified and selected. Four heterogeneously- grouped fourth grade classes at Palm Springs North Elementary (PSNE) were used for this study. The formation of these classes actually began during the summer of 2001. (See Appendix G) At the time of the study, there were eleven third grade classes that over the 2001 summer became the eleven 
fourth grade classes. The two third grade classes which remained intact and moved to the fourth grade with their third grade teacher during the 2001-2002 school year created the looping condition (experimental groups). Students from the remaining third grade classes were dispersed across the remaining nine fourth grade teachers, forming classes in which the teachers and students were new to one another. Two of these fourth grade teachers, and their respective students, were selected for the study and formed the comparison classes.

The sample population of four classes, two looped classes and two comparison classes began with approximately one hundred twenty students. Due to student mobility, the number of students who remained at the school from the 2000-2001 school year to the 2001-2002 school year lowered the sample size to eighty-one. Each of the four classes, therefore, experienced the loss and gain of students throughout the two identified years. The average number of students who remained throughout the two years was approximately twenty in classes whose sizes maintained at an average of approximately thirty-two students. Of the eighty-one students who participated in the study, thirty-eight were male and forty-three were female. Each student who participated in this study completed and signed an assent form. (Appendix B)

\section{Teachers}

The teachers in the study were matched based upon their years of experience and responses to a face-to-face interview by school administrators. Four teachers participated in this study, two in the experimental groups and two in the comparison groups. All of the teachers in the study were experienced language arts teachers. Two of them taught reading and language arts for over 10 years; the other two taught reading and 
language arts for less than five years. The four teachers selected for the study had similar teaching styles and incorporated several similar teaching methods. All four teachers geared their teaching to individuals, favored group work, encouraged parental involvement, maintained order in their classrooms and were open to new ideas and teaching strategies. Through the researcher's role as an administrator at the school for over seven years, she had observed each of these teachers through formal observations for several years prior to the current study, as part of her administrative responsibilities as per Miami-Dade County Public School policy. Therefore, she was able to gain valuable information and insights about the teachers and their teaching styles that enhanced the process of matching the teachers for this study and the monitoring of the implementation of curriculum, lesson plans, grading procedures and delivery of lessons by each teacher. All four teachers were highly respected by their peers, based upon leadership roles to which they had been elected, and parents, based upon the quantity of parents who made formal requests to have their children placed in their classrooms. It is to be emphasized that rather than randomly selecting teachers, teacher selection was made from a pool of strong volunteer teachers who showed excitement and motivation to participate in this intervention through responses to a face-to-face interview by school administrators. Throughout the study the researcher ascertained that the motivation of the teachers for participation in the study remained constant through formal and informal discussions.

\section{Curriculum}

All teachers used the same curriculum, in terms of scope and sequence, the same instructional guidelines for teaching reading and writing and the same instructional materials. The curriculum followed by the teachers in the study was the Competency 
Based Curriculum (CBC).Within the entire school district, grade levels are expected to adhere to the CBC, developed by the Miami-Dade County Public School System and aligned with the Sunshine State Standards, developed by the Florida Department of Education. All four teachers in the study also followed the Comprehensive Reading Plan, a reading and language arts plan developed by the district with specific guidelines for teaching reading and writing. The four classes in the study also used the same reading series, Harcourt, Brace \& Jovanovich. Throughout the study, these teacher and curriculum controls were verified through classroom observations, conducted periodically. Specifically, the researcher observed each teacher three times throughout the duration of the study. During each one hour observation, the researcher took notes on each teacher's instructional strategies and student's learning activities and documented information related to lesson plans, student work samples, tests and grade books to verify that the curriculum and instructional strategies and materials remained constant across all four classes.

While the students who participated in the looping cycle did so for two school years (2000-2002), data were gathered and analyzed during the second year of the looping cycle (2001-2002). Throughout the 2000-2001 school year, the first year of the cycle, the third grade curriculum was implemented from August 2000 to June 2001. Throughout this school year, the school district provided curriculum support materials to assist the third grade teachers in preparing their students for the reading and math portions of the FCAT which would be administered in March 2001. The teachers in this study implemented the objectives of the third grade $\mathrm{CBC}$, along with these curriculum support materials. 
From August 2001 to June 2002, the second year of the looping cycle, the teachers in this study implemented the objectives of the fourth grade $\mathrm{CBC}$. Once again, the school district provided curriculum support materials to prepare students for the fourth grade FCAT that would be administered in March 2002. In addition, district and school-wide curriculum materials were provided to fourth grade teachers to prepare the fourth grade students for the FCAT Writes examination that would be administered in January, 2002. All teachers in this study implemented the review materials provided to support instruction in reading and writing for the fourth grade students.

\section{Instrumentation}

The instruments used to measure the dependent variables in the study will be discussed individually for each variable: reading achievement and reading qualities, anxiety and self-concept. An additional instrument, the Metropolitan Achievement TestSeventh Edition, MAT-7 (See APPENDIX F), was used as a base for calculating changes in reading achievement in this study, for the purpose of matching the experimental and comparison groups. APPENDIX G contains a discussion of this aptitude measure. Reading

Reading achicvement. Reading achievement was measured based upon the comparison of students' raw scores on the 2000-2001 reading subtest of the Florida Comprehensive Achievement Test (FCAT), pre-test and the 2001-2002 administration of the same test, post-test. This test was used because it is the predominant standardized examination used in the state of Florida to determine reading achievement of students in grades three through ten. All students in these grade levels are required to complete this examination. The FCAT provides a criterion-referenced mean score that enables a 
students' progress to be tracked from school year to school year. Because the FCAT is objective, criterion-referenced and standardized, other researchers can transfer the results to other contexts. The reading subtest of the third grade FCAT, administered during the 2000-2001 school year, consisted of 40 items. The fourth grade FCAT, administered during the 2001-2002 school year, consisted of 45 items. For each student participating in this study, the percentage of correct responses in the reading subtest was calculated and analyzed by obtaining the mean difference in percentage of correct responses between the 2000-2001 and 2001-2002 administrations. Throughout both administration years, students were given the reading subtests in two sessions, approximating fifty minutes each.

Reading qualities. The reading qualities variable was also measured by analyzing the raw scores on the reading subtest of the FCAT and comparing the scores on the 20002001 and 2001-2002 administrations. The main idea quality was comprised of fifteen items on the 2000-2001 FCAT and twenty-two items on the 2001-2002 FCAT. The comparisons quality was comprised of sixteen items on the 2000-2001 FCAT and fifteen items on the 2001-2002 FCAT. Because of the difference in number of test items measuring these qualities from year to year, the percentage correct was calculated and compared between the 2000-2001 and 2001-2002 administrations. Anxiety

Anxiety was measured by administering the State-Trait Anxiety Inventory for Children (STAIC), developed by C.D. Spielberger. (Appendix D) The STAIC was developed to provide reliable, brief self-report scales for assessing state and trait anxiety in research and clinical practice. State anxiety refers to the emotional subjective feelings 
of tension, apprehension, nervousness and worry produced at a particular time, under a specific circumstance. The level of intensity of state anxiety can be measured at a given moment in time and fluctuates over time as a function of the extent to which a person perceives his or her environment as dangerous or threatening. "Whether children experience state anxiety depends upon the extent to which a specific situation is perceived as dangerous or threatening by a particular child, and this is greatly influenced by the child's past experience (Spielberger, 1985, p.3).

Trait anxiety is defined as the relatively stable individual differences in anxietyproneness. Trait anxiety is not situational, but exists inherently within the individual; it is their tendency to experience anxiety states. The stronger the trait anxiety an individual possesses, the more likely he will be to experience state anxiety in varied situations.

For the purpose of this study, the STAIC-Form C-1 was used, which measures state anxiety, that which is present within given contexts or situations. This scale was chosen because it provides a simple assessment of a child's anxiety level in the school setting. The scale was developed for use with nine to twelve year old children.

For the purpose of this study, the instructions in the State-Trait Anxiety Inventory for Children (STAIC) were modified to include the words, "while reading," to assess each student's state anxiety during the task of reading. Spielberger states, "For the A-State scale, the instructions may be modified to permit the evaluation of level of A-State intensity for any situation or time interval that is of special interest to the clinician or experimenter (1985, p. 4). The STAIC- Form C-1, entitled, How I Feel Questionnaire, asks subjects to report on the intensity of their feelings of anxiety at a particular time by rating themselves on the following three point scale, which utilizes adjectives to describe 
feelings demonstrative of the presence and absence of anxiety. Students respond to items such as the following, "I feel... (1) Very calm, pleasant, rested...etc.; (2) Somewhat jittery, nervous, frightened...etc.; (3) Not upset, troubled, bothered...etc. For each of the twenty different key adjective terms, the child responds by circling one of the three alternatives that describes him best. The key terms in half the items are demonstrative of the presence of anxiety, while the key terms in the other half of the items reflect its absence. Anxiety present and absent items are scored in the opposite direction. Low scores on this twenty-item scale indicate feeling calm and serene, intermediate scores show moderate levels of tension and worry, and high scores are associated with intense fear, approaching terror and panic (Spielberger, 1985). The lowest score a student could obtain on the STAIC was twenty, indicative of the least amount of anxiety during reading. The highest score a student could obtain was sixty, indicative of extreme anxiety during reading. The scale was administered to all students during a thirty- minute class session, which is longer than the eight to twelve minutes typically required for administration, as per Spielberger. The teachers in this study read the directions to students aloud and students completed the scale independently. Teachers read and clarified items for students who had difficulty reading.

Self-concept

Self-concept was measured using the Self-Perception Profile for Children, developed by Susan Harter.(Appendix E) This scale is composed of six subscales that include: Scholastic competence, social acceptance, athletic competence, physical appearance, behavioral conduct and global self-worth. Harter states, "While the domainspecific approach has merit, it is also the case that children (aged eight and older) can 
make a more global judgment about their self-worth, a more gestalt-like evaluation about the self, in general $(1985$, p. 6). Only one third of the six subscales directly involve competence, the rest of the subscales refer to various forms of self adequacy, however, they do not necessarily involve competence in the form of actual skills. The SelfPerception Profile for Children was developed for a target population of third through sixth graders.

The scale, entitled "What I Am Like," consists of thirty-six items, which ask the child to decide which "kind of kid" is most like him or her, and then asks whether this is only sort of true or really true for him or her (Harter, 1985, p. 7). Each item is then given a score from one to four, where a score of one indicates low perceived competence and a score of four reflects high perceived-competence. The maximum score a child can obtain, reflective of the highest perceived self-concept equals one hundred forty four. The minimum score, reflective of the lowest perceived self-concept equals thirty-six.

The Self-Perception Profile for Children was administered to all students during a forty-five minute class session. The teachers in this study read the directions to students aloud and students completed the scale independently. Teachers read and clarified items for students who had difficulty reading.

\section{Data Collection and Analysis}

The procedures employed in this study for collecting and analyzing data are outlined below.

\section{Data Collection}

The students and teachers in the looping condition were together for two entire school years, from August 2000 to June 2002. With the exception of the use of the third 
grade FCAT scores, all data were collected during the 2001-2002 school year, the second year of the looping cycle. The 2000-2001 and 2001-2002 FCAT criterion-referenced reading subtests were used as pre and post measures to assess gains in reading achievement and reading qualities (main idea and comparisons). The FCAT tests were administered in March of each school year. The STAIC and the Self-Perception Profile for Children were each administered once in order to measure differences between looped and comparison groups. The MAT-7 was given only once, during the fall of 2001. The function of this test within the study was to match the groups on aptitude at the beginning of the study. The classroom teachers administered all measures to their students. Prior to the administration of each instrument, the researcher provided each teacher with the written administration guidelines and met with the teachers to review the instruments and guidelines for administration. The instruments and the dates on which they were administered are shown in Table 1.

Table 1

Administration of Instruments

Instrument Date Administered

Florida Comprehensive Assessment Test (FCAT) (Pretest) March 2001 ${ }^{\mathrm{a}}$

Metropolitan Achievement Tests Seventh Edition (MAT-7) September 2001

State-Trait Anxiety Inventory for Children (STAIC) September 2001

Self-Perception Profile for Children $\quad$ November 2001

Florida Comprehensive Assessment Test (FCAT) (Posttest) March 2002

a. The pretest was administered prior to the study as part of school district's planned testing schedule. 
The FCAT pretest and posttest, were scored by the Florida Department of Education, who furnished score reports by student. Each student received a raw score for both the pretest and posttest, reflective of the total number of correct responses. This report also provided each student's raw score in the reading qualities of main idea and comparisons.

The STAIC, Self-Perception Profile for Children and MAT-7 were hand-scored by this researcher, according to the test manuals. Analysis

Quantitative measures were used to assess gains in reading achievement, determine levels of anxiety and self-concept, and determine the effects of looping on reading achievement, reading qualities, anxiety and self-concept. As a first step, an Analysis of variance, (ANOVA) was used on the independent variables of vocabulary test score (used to determine reading aptitude) and baseline reading comprehension score on the Florida Comprehensive Assessment Test (FCAT) in order to ensure that the looped and comparison groups were equal in reading achievement and aptitude at the beginning of the study. (See APPENDIX G) Next, to test the research hypotheses, four group simple ANOVAs were used to determine significance among looped and comparison groups on the following dependent variables: reading achievement, as measured by the difference in FCAT raw scores between the 2001 administration and the 2002 administration; reading qualities (main idea and comparisons) as measured by the FCAT, 2001 and 2002 administrations; anxiety, as measured by the STAIC; and selfconcept, as measured by the Self-Perception Profile for Children. These simple 
ANOVAs allowed the researcher to make comparisons among all groups in the design. Follow-up, multiple pairwise comparisons were conducted on each of the dependent variables for which a statistical significance was found, in order to make comparisons among each of the four groups, two experimental groups, and two comparison groups in the study.

\section{Summary}

This research study was conducted to determine the effects of looping on reading achievement, reading qualities (main idea and comparisons), anxiety and self-concept. This chapter presented: the research design, procedures and methods including the population, instruments and classroom treatments and data collection and analysis, related to examining the problem. Quantitative research methods were applied. The quantitative measures were used to assess gains in reading achievement, determine levels of anxiety and self-concept, and explore the effects of looping on reading achievement, reading qualities, anxiety and self-concept.

In order to test for statistical significance using data gathered from the experimental groups (looping model) and the comparison groups (traditional model), simple, four group analyses of variance were used on the following dependent variables: reading achievement, reading qualities, (main idea and comparisons) anxiety and selfconcept. Changes (gains or losses) in reading achievement were measured by comparing the difference in population mean FCAT raw scores between the 2001 administration and the 2002 administration. Changes in reading qualities scores (main idea and comparisons) were measured by comparing population mean raw scores on the FCAT, 2001 and 2002 administrations. Anxiety levels were measured by comparing population 
mean anxiety scores on the State-Trait Anxiety Inventory for Children (STAIC). Selfconcept was measured by comparing population mean self-concept scores on the SelfPerception Profile for Children. 


\section{CHAPTER IV \\ RESULTS AND DISCUSSION}

This study sought to explore the looping model and its effects on reading achievement, reading qualities (main idea and comparisons), anxiety and self-concept within the context of a large, urban, multicultural school setting. The purpose of this chapter is to present the results of the study. The findings and discussions are presented under the following headings: (a) improvement of reading, (b) effects related to anxiety, (c) effects related to self concept, and (d) summary of the findings.

\section{Improvement of Reading}

In the first hypothesis, the goal was to determine whether students' reading achievement improved after participating in a looped classroom, two years with the same teacher, as compared to the reading achievement of students who had a different teacher during their third and fourth grade years. Because the population-mean posttest reading achievement scores were significantly higher for the experimental groups than those for the comparison groups, the null hypothesis was rejected and the alternate hypothesis was accepted. This indicated that, indeed, students' reading achievement significantly improved after participating in a looped classroom.

\section{Reading Achievement}

Reading achievement results were interpreted based upon the difference in FCAT scores among the 2000-2001 and the 2001-2002 administrations. Achievement gains for the experimental and comparison groups from pretest to posttest were determined through the use of ANOVA. Posttest means, standard deviations, F statistics and pvalues for the four groups on the FCAT 2002, are shown in Table 2. 
Table 2

Posttest Reading Achievement ANOVA: Reading FCAT 2002

\begin{tabular}{llll} 
Groups & $n$ & $M$ & $S D$ \\
\hline
\end{tabular}

Looped

Experimental

Loop 1

19

71.81

19.82

Loop 2

22

73.64

14.36

Comparison

Comparison 1

Comparison

Comparison 2

21

67.83

15.02

Note: FCAT = Florida Comprehensive Assessment Test

While there were no statistically significant differences between the groups on the mean percentage correct score on the FCAT, 2002 administration, $F(3,77)=.56, p=.64$, these statistics did not consider the pretest scores. Therefore, the effects of looping on the difference in mean percentage correct between the FCAT 2001 and 2002 administrations analyzed; i.e. to determine whether differences in reading achievement of the looped and comparison groups were significant.

Differences in pretest to posttest means, standard deviations, and post-hoc statistics for the four groups in reading achievement are shown in Table 3. The mean reading achievement differences for the experimental and comparison groups are shown graphically in Figure 1.

The statistical analysis, ANOVA, for the four groups on the dependent variable, difference in percentage correct between the FCAT 2001 and 2002 administrations, revealed a significant difference in gains in FCAT scores between the four groups $F$ (3, 
$77)=6.01, p=.001$. Follow-up tests were conducted to evaluate pair-wise differences among the means. The results of these tests, reported in Table 3, revealed a significant difference between the means of each of the looped and each of the comparison groups, but no differences within the looped and comparison groups. On average, the reading achievement scores of the students in the looped classes increased by seven percent, while the scores of the students in the comparison classes decreased by five percent.

Table 3

Difference in Reading Achievement Pretest to Posttest ANOVA: Difference FCAT 2001 to 2002

$\begin{array}{llllll}\text { Groups } & N & M & S D & \text { Post Hoc Comparisons } & p \text { Scheffe }\end{array}$

Looped

Experimental

\begin{tabular}{|c|c|c|c|c|c|}
\hline \multirow[t]{3}{*}{ Loop 1} & \multirow[t]{3}{*}{19} & \multirow[t]{3}{*}{7.34} & \multirow[t]{3}{*}{15.05} & Loop 1 - Loop 2 & 0.99 \\
\hline & & & & Loop 1 - Comparison 1 & 0.03 \\
\hline & & & & Loop 1 - Comparison 2 & 0.03 \\
\hline \multirow[t]{3}{*}{ Loop 2} & \multirow[t]{3}{*}{22} & \multirow[t]{3}{*}{6.82} & \multirow[t]{3}{*}{16.4} & Loop 2 - Loop 1 & 0.99 \\
\hline & & & & Loop 2 - Comparison 1 & 0.03 \\
\hline & & & & Loop 2 - Comparison 2 & 0.04 \\
\hline
\end{tabular}

Comparison

Comparison

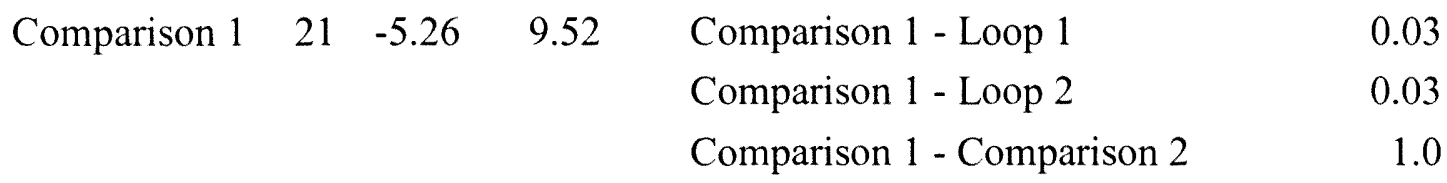

$\begin{array}{llllll}\text { Comparison } 2 & 19 & -5.48 & 9.68 & \text { Comparison 2 - Loop 1 } & 0.03\end{array}$

Comparison 2 - Loop $2 \quad 0.04$

Comparison 2 - Comparison $1 \quad 1.0$

Note: FCAT= Florida Comprehensive Assessment Test 


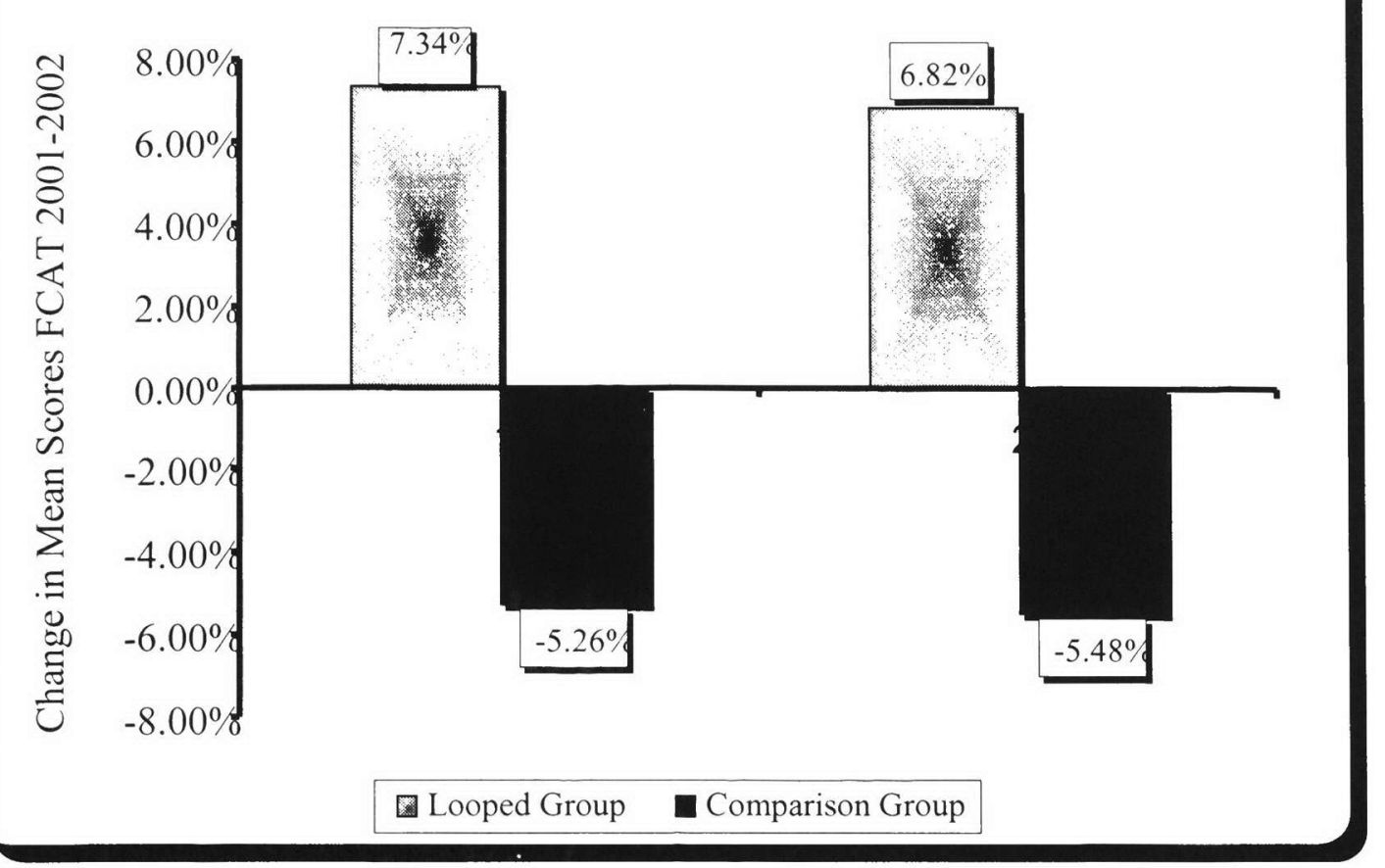

Figure 1. Differences in FCAT overall reading achievement scores

\section{Reading Qualities}

The second hypothesis sought to establish whether students' achievement in reading qualities (main idea and comparisons), improved after participating in a looped classroom, two years with the same teacher, as compared to the reading qualities of students who had a different teacher during their third and fourth grade years. The dependent variables with regard to reading qualities were the difference in the sub-scores of main idea and comparisons on the FCAT, 2001 and 2002 administrations. Since the population-mean posttest sub-scores on the reading qualities, main idea and comparisons were significantly higher for the experimental groups than those for the comparison groups, null hypothesis two was rejected and the alternate hypothesis was accepted. This 
showed that students' achievement in the reading qualities, main idea and comparisons, improved after participating in a looped classroom.

Means, standard deviations, and post-hoc statistics for the four groups for the difference in sub-scores of main idea and comparisons are shown in Table 4 and Table 5. Because there were different numbers of test items in each of these subtests, between the 2001 and 2002 administrations, means and standard deviations reflect the difference in percentage correct on these subtests.

The differences between groups on main idea or comparisons were not statistically significant. The groups were essentially at the same level on reading qualities at the pretest, FCAT 2001. An ANOVA was conducted to determine if the independent variable, participation in a looped classroom, had any effect on student achievement in the reading qualities, that is main idea and comparisons. The difference between pretest and posttest scores showed a significant difference between the experimental and comparison groups related to the first reading quality, main idea, $F(3$, $77)=3.12, p=.03$, as well as to the second reading quality, comparisons, $F(3,77)=$ $4.01, p=.01$. Follow-up tests were conducted to evaluate pairwise differences among the means and revealed that there were no significant differences in the means between the four groups in main idea. The follow-up tests revealed a significant difference between the means of Loop 1 and Comparison 2 on the reading quality, comparisons. The population mean posttest sub-scores on the reading qualities were significantly higher for the experimental groups than those for the comparison groups. These means for the groups are shown graphically in Figure 2 and Figure 3. The experimental groups demonstrated an average $4.2 \%$ increase in main idea sub-scores while the comparison 
groups averaged an $8.1 \%$ decrease. In the reading quality comparisons, the experimental groups showed an average $4.2 \%$ increase and the comparison groups decreased $8.8 \%$.

These results indicate that students who participated in the looping model outperformed students in the comparison groups in both of the reading qualities measured.

Table 4

Difference in Reading Quality (Main Idea) Pretest to Posttest ANOVA: Difference FCAT 2001-2002

\begin{tabular}{llllll} 
Groups & $n$ & $M$ & $S D$ & Post Hoc Comparisons & $p$ Scheffe \\
\hline
\end{tabular}

Experimental

Looped

\begin{tabular}{|c|c|c|c|c|c|}
\hline \multirow[t]{3}{*}{ Loop 1} & \multirow[t]{3}{*}{19} & \multirow[t]{3}{*}{3.6} & \multirow[t]{3}{*}{18.3} & Loop 1 - Loop 2 & 0.99 \\
\hline & & & & Loop 1 - Comparison 1 & 0.16 \\
\hline & & & & Loop 1 - Comparison 2 & 0.47 \\
\hline \multirow[t]{3}{*}{ Loop 2} & \multirow[t]{3}{*}{22} & \multirow[t]{3}{*}{4.8} & \multirow[t]{3}{*}{24.6} & Loop 2 - Loop 1 & 0.99 \\
\hline & & & & Loop 2 - Comparison 1 & 0.09 \\
\hline & & & & Loop 2 - Comparison 2 & 0.34 \\
\hline
\end{tabular}

Comparison

Comparison

$\begin{array}{llllll}\text { Comparison 1 } & 21 & -9.1 & 16.2 & \text { Comparison 1 - Loop 1 } & 0.16 \\ & & & & \text { Comparison 1 - Loop 2 } & 0.09 \\ & & & & \text { Comparison 1 - Comparison 2 } & 0.93\end{array}$

Comparison $2 \quad 19 \quad-6 \quad 12.3 \quad$ Comparison 2 - Loop 1

Comparison 2 - Loop 2

Comparison 2 - Comparison 1

0.93

Note: FCAT = Florida Comprehensive Assessment Test 
Table 5

Difference in Reading Quality (Comparisons) Pretest to Posttest ANOVA: Difference FCAT 2001-2002

\begin{tabular}{llllll} 
Groups & $n$ & $M$ & $S D$ & Post Hoc Comparisons & $p$. Scheffe \\
\hline
\end{tabular}

Experimental

Looped

$\begin{array}{llllll}\text { Loop 1 } 19 & 7.1 & 15.9 & \text { Loop 1 - Loop 2 } & 0.81 \\ & & & \text { Loop 1 - Comparison 1 } & 0.07 \\ & & & \text { Loop 1 - Comparison 2 } & 0.04\end{array}$

Loop 2

$22 \quad 1.7 \quad 22.4 \quad$ Loop 2 - Loop 1

0.81

Loop 2 - Comparison 1

0.36

Loop 2 - Comparison 2

0.25

Comparison

Comparison

$\begin{array}{llllll}\text { Comparison } 1 & 21 & -8 & 16.2 & \text { Comparison 1 - Loop 1 } & 0.07\end{array}$

Comparison 1 - Loop $2 \quad 0.36$

Comparison 1 - Comparison $2 \quad 0.99$

$\begin{array}{llllll}\text { Comparison } 2 & 19 & -9.7 & 14.5 & \text { Comparison 2 - Loop 1 } & 0.04\end{array}$

Comparison 2 - Loop $2 \quad 0.25$

Comparison 2 - Comparison $1 \quad 0.99$

Note: FCAT $=$ Florida Comprehensive Assessment Test 


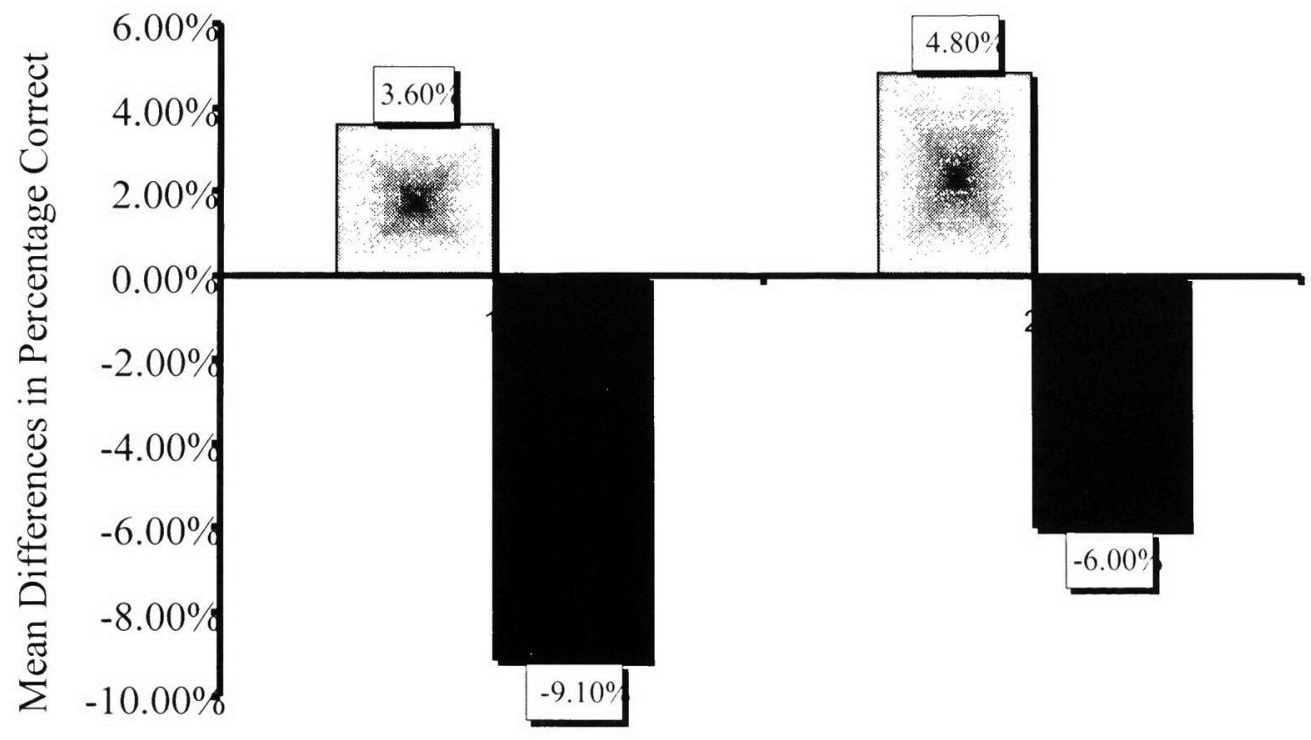

Looped Group Comparison Group

Figure 2. Impact on FCAT Main Idea Scores

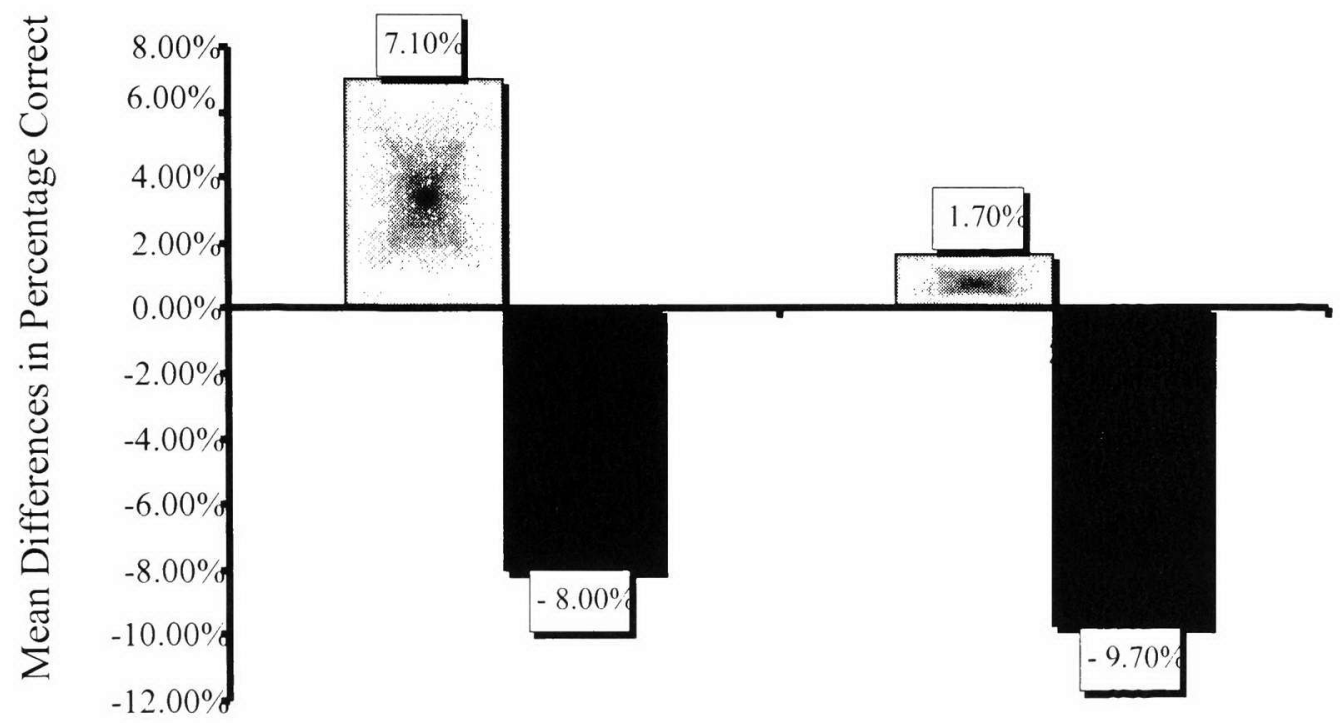

( Looped Group Comparison Group

Figure 3. Impact on FCAT Comparison Scores 


\section{Effects Related to Anxiety}

The third hypothesis was that students' population-mean anxiety measure scores would be lower for the experimental groups (looping model) than for the comparison groups (traditional model). An ANOVA was conducted to determine the relation of looping to student anxiety levels, as measured on the State Trait Anxiety Inventory for Children, C-1 (STAIC). Differences in mean scores, standard deviations, and post-hoc statistics for the four groups on the STAIC are shown in Table 6.

Table 6

Anxiety Measure By Treatment Group: STAIC

\begin{tabular}{|c|c|c|c|c|c|}
\hline Groups & $n$ & $M$ & $S D$ & Post Hoc Comparisons & $p$ Scheffe \\
\hline \multicolumn{6}{|c|}{ Experimental } \\
\hline \multicolumn{6}{|l|}{ Looped } \\
\hline \multirow[t]{3}{*}{ Loop 1} & 19 & 26.42 & 3.75 & Loop 1 - Loop 2 & 0.99 \\
\hline & & & & Loop 1 - Comparison 1 & 0.14 \\
\hline & & & & Loop 1 - Comparison 2 & 0.69 \\
\hline \multirow[t]{3}{*}{ Loop 2} & 22 & 25.77 & 4.57 & Loop 2 - Loop 1 & 0.99 \\
\hline & & & & Loop 2 - Comparison 1 & 0.05 \\
\hline & & & & Loop 2 - Comparison 2 & 0.47 \\
\hline \multicolumn{6}{|c|}{ Comparison } \\
\hline \multirow{4}{*}{$\begin{array}{l}\text { Comparison } \\
\text { Comparison } 1\end{array}$} & & & & & \\
\hline & 21 & 30.86 & 7.63 & Comparison 1 - Loop 1 & 0.14 \\
\hline & & & & Comparison 1 - Loop 2 & 0.05 \\
\hline & & & & Comparison 1 - Comparison 2 & 0.73 \\
\hline \multirow[t]{3}{*}{ Comparison 2} & 19 & 28.74 & 6.74 & Comparison 2 - Loop 1 & 0.69 \\
\hline & & & & Comparison 2 - Loop 2 & 0.47 \\
\hline & & & & Comparison 2 - Comparison 1 & 0.73 \\
\hline
\end{tabular}

The analysis yielded a significant difference in levels of anxiety among the four groups $F$ $(3,77)=3.25, p=.03) . \quad$ Therefore, null hypothesis three was rejected and the alternate 
hypothesis was accepted. The population-mean STAIC scores, measuring anxiety, was lower for the experimental groups than those for the comparison groups. Post-hoc tests revealed a significant difference between the means of Loop 2 and Comparison 1. The mean differences for the experimental and comparison groups in anxiety levels are shown graphically in Figure 4.

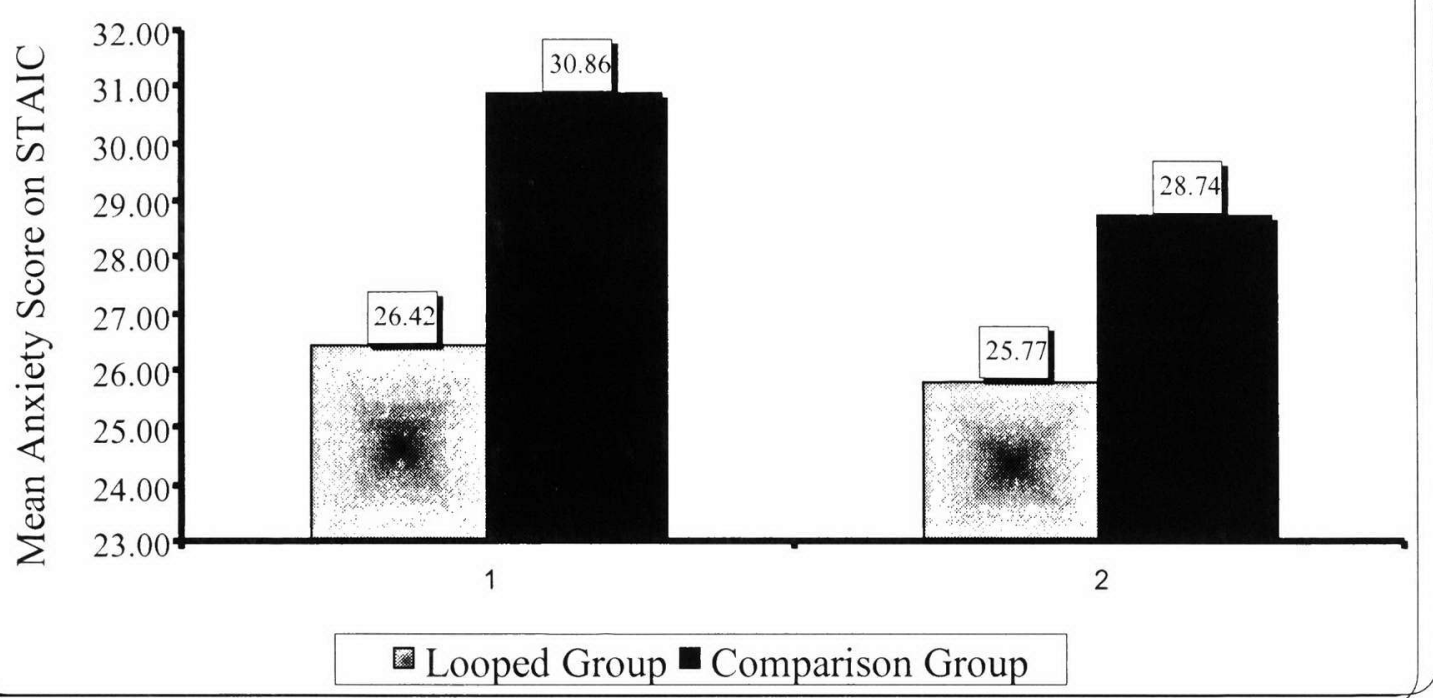

Figure 4: Anxiety Measures

The experimental groups demonstrated an average STAIC score of 27, while the comparison groups averaged an anxiety score of 30 . This showed that students who participated in the looped classes were less prone to experience feelings of anxiety toward reading than students who participated in non-looped classes.

\section{Effects Related to Self-Concept}

The fourth hypothesis sought to determine whether the population-mean selfconcept scores would be higher for the experimental groups (looping model) than those for the comparison groups (traditional model). An Analysis of Variance was conducted 
to determine the effect of looping on the students' self-concept, as measured by the SelfPerception Profile for Children. Differences in mean scores and standard deviations for the four groups on the STAIC are shown in Table 7.

Table 7

Self Concept Measure By Treatment Group: Self-Perception Profile For Children

\begin{tabular}{llll} 
Groups & $n$ & $M$ & $S D$ \\
\hline
\end{tabular}

Looped

Experimental

Loop 1

19

105.9

Loop 2

22

106.9

18.3

Comparison

Comparison 1

Comparison

21

108.9

21.7

Comparison 2

19

110.2

21

The analysis, ANOVA, revealed no statistically significant difference in selfperception scores among the four groups $F(3,77)=.16, p=.92$. The population-mean self-perception score was three points lower for the experimental groups than those for the comparison groups. Although the experimental groups' self-perception score was lower $(M=106.4)$ than the comparison groups' $(M=109.5)$ the differences among all groups were not significant among the groups. Although responses of all four groups were above average ( $M=106.4$ and $M=109.5$ out of a possible 144 points), they were not statistically significant. The lack of statistical significance does not allow for the assertion that looping was related to changes in self-concept in students. 


\section{Summary of the Findings}

Results of the study of the effect of looping on reading achievement showed significant improvement in reading achievement for fourth grade students in a large, urban, multicultural school. The statistical analysis, ANOVA, for the four groups on the dependent variable, difference in percentage correct between the FCAT 2001 and 2002 administrations, revealed a significant difference in gains in FCAT scores between the four groups. On average, the reading achievement scores of the students in the looped classes increased while those of the students in the comparison classes decreased. The difference between pretest and posttest scores showed a significant difference between the experimental and comparison groups in reading qualities: main idea and comparisons. The population mean posttest subs-cores on the reading qualities, main idea and comparisons was higher for the experimental groups than those for the comparison groups. The experimental groups demonstrated increases in main idea, while the comparison groups' scores decreased. In the reading quality, comparisons, the experimental groups also showed an increase, while the comparison groups' scores decreased.

Analyses of Variance were also used to determine whether significant differences existed between the anxiety levels and self-concept of students in looped and non-looped classes. These statistical analyses revealed a significant difference between the looped and non-looped groups in anxiety levels but no significant difference was demonstrated between the groups in self-concept. Therefore, these results revealed that students who participated in looped classes demonstrated less anxiety than those who had different 
teachers in their third and fourth grade school years. However, gains in self-concept did not accrue from participation in a looped class.

Based upon the findings of this study, within the context of a large, urban, multicultural school setting, looping does not seem to have an effect on increasing students' self-concept. However, within this context, looping does seem to positively affect the reading achievement and reading qualities of fourth grade students who participate in looping classes. Further, findings indicate that looping serves to decrease students' anxiety as related to reading during the beginning of the second year of the looping model. 


\section{CHAPTER V}

\section{DISCUSSION AND CONCLUSIONS}

This research studied the effects of looping on reading achievement, reading qualities (main idea and comparisons), anxiety and self-concept of fourth grade students who had the same teacher and classmates during their third and fourth grade school years. This study took place within the context of a large, urban, multicultural school. The purpose of this chapter is to present (a) a restatement of the problem, (b) related research, (c) an overview of design and procedures, (d) the findings of the study, (e) conclusions, (f) implications, (g) a discussion, and (h) recommendations for further research.

\section{Restatement of the Problem}

Palm Springs North Elementary School (PSNE) is a large, urban multicultural school with an array of problems typical of schools with large, diverse, transient student populations. Of particular concern at PSNE is bolstering students' reading achievement, which is at the forefront of school accountability by district and state mandates, while providing students with the psychological and emotional stability that is often lacking in the home and community. PSNE continuously seeks workable, cost-effective interventions to meet the academic, social and emotional needs of students and to find an alternative for students who do not meet grade level standards to receive additional time for learning, rather than the current options of retention, social promotion or referral to special education courses.

Across the United States, several schools have implemented looping as an alternative instructional model. Proponents advocate that the looping model provides more efficient use of instructional time and continuity for teachers to deliver instruction 
to students at their individual levels, regardless of students' current grade level expectations, however, little empirical research exists related to looping in general, and virtually no research exists related to looping in large, urban, multicultural schools. Therefore, this empirical study was implemented at PSNE and designed to quantitatively evaluate the effects of looping on the reading achievement, reading qualities (main idea and comparisons), anxiety as related to reading and self-concept of students within a large, urban, multicultural school.

\section{Related Research}

The theories that support looping, and provide a theoretical framework for this study, emphasize that motivation highly influences learning, that it is critical to literacy learning and that by reducing anxiety and by providing a stable and secure environment for students, looping provides a context that is conducive to literacy learning (Little \& Little, 2001; O’Flahavan, Gambrell, Guthrie, Stahl, \& Alvermann, 1992; Gambrell, 1996). Additional theories that support looping for literacy learning suggest that selfconcept is associated with literacy learning and that increased time on task increases opportunities for reading achievement (Ford, 1992; Henk \& Melnick, 1995; Wigfield, 1994). Further, because reading is comprised of physical, social, emotional and psychological and linguistic processes (Weaver, 1988), there seems to be a logical fit between the study of looping and reading achievement.

Prior to the current study, research studies on looping have been more general in focus or have been conducted in smaller, urban school districts or in rural schools. A broad study of looping within the Miami-Dade County Public School System, conducted by Schneyderman (2000), provided a springboard for the current study by demonstrating 
that leaders within this school district felt that the practice of looping may provide benefits worthy of study. The information presented by the above research gave support for the implementation of looping at PSNE, a large, urban, multicultural school, representative of schools throughout the Miami Dade County Public School System, as an instructional intervention that could be of benefit to the particular population of students at the school. Schneyderman analyzed reading and math test scores from statemandated norm-referenced standardized tests, as well as attendance and retention figures. From a district-wide sample of students, at varying grade levels from a variety of schools he found that students who participated in looping classes demonstrated positive results based on the data he gathered. The current study sought to more closely examine the benefits of looping at the point of instruction, employing well-developed empirical methods, to quantitatively examine the effects of looping within the context of a large, urban, multicultural school.

Based on teachers' testimonials, looping seems to reduce anxiety and foster a positive self-concept in students (Grant, Johnson \& Richardson, 1996). These two affective factors can potentially impact learning (Forsten, Grant \& Richardson, 1999; Payne, 1998, Grant, Johnson \& Richardson, 1996). While a case study examining the positive effects of looping on affective factors was conducted by Hill, Lofton, and Purvis (1999), prior to the current study, these affective factors have not been researched empirically. The current study expanded on the work of the above researchers by quantitatively examining the effect of looping on reading achievement and reading qualities (main idea and comparisons) and on the affective constructs of reduced anxiety 
as related to reading and increased self-concept of students within the context of a large, urban, multicultural school.

\section{Design and Procedures}

As applied classroom research, this study had a causal-comparative, nonequivalent control group design, using a pretest - posttest model for evaluation. Four previously established classrooms consisting of a total of eighty-one students were used in this study. The teachers of these classes were matched for years of experience, prior years' observations, formal and informal discussions and responses to a face-to-face interview conducted by school administrators, which revealed that these four teachers had similar teaching styles and incorporated several similar teaching methods. These four teachers geared their teaching to individuals, favored group work, encouraged parental involvement, maintained order in their classrooms and were open to new ideas and teaching strategies. The teachers of the experimental groups (looping model) had volunteered to remain with their students as the class moved intact from the third to fourth grade. The two fourth grade teachers of the comparison groups had classes consisting of students who came from across the remaining third grade classes.

Because of the quasi-experimental design of the study, it was necessary to match the experimental and comparison groups in order to accurately evaluate changes in the dependent variables. The experimental groups were matched to the comparison groups based upon the mean raw scores on the reading subtest of the 2000-2001 CriterionReferenced Florida Comprehensive Achievement Test (FCAT). Both experimental groups were also matched to the comparison groups in aptitude, as assessed by scores on a vocabulary measure (MAT-7). Student's ability levels were identified according to 
their performance on the vocabulary subtest of the Metropolitan Achievement Tests Seventh Edition (MAT-7), Elementary 1 Basic Battery Test Booklet to ensure that students from all levels of performance were included in the analysis.

This study was conducted over a period of one school year, using a variety of instruments. Quantitative measures were used to assess gains in reading achievement, determine levels of anxiety and self-concept, and determine the effects of looping on reading achievement, reading qualities, anxiety and self-concept. Analysis of variance, (ANOVA) was used on the independent variables of vocabulary test score (used to determine reading aptitude) and baseline reading comprehension score on the Florida Comprehensive Assessment Test (FCAT) in order to ensure that the looped and comparison groups were equal in reading achievement and aptitude at the beginning of the study. To test the research hypotheses, four group simple ANOVAs were used to determine significance within and between each of the looped and comparison groups on the following dependent variables: reading achievement, as measured by the difference in FCAT raw scores between the 2001 administration and the 2002 administration; reading qualities (main idea and comparisons) as measured by the FCAT, 2001 and 2002 administrations; anxiety, as measured by the STAIC; and self-concept, as measured by the Self-Perception Profile for Children.

Reading achievement was measured based upon the comparison of students' raw scores on the 2000-2001 reading subtest of the Florida Comprehensive Achievement Test (FCAT), pre-test and the 2001-2002 administration of the same test, post-test. The reading qualities variable was also measured by analyzing the raw scores on the reading subtest of the FCAT and comparing the scores on the 2000-2001 and 2001-2002 
administrations. Anxiety was measured by administering the State-Trait Anxiety Inventory for Children (STAIC), developed by C.D. Spielberger. Self-concept was measured using the Self-Perception Profile for Children, developed by Susan Harter.

Findings of the Study

The results of the data analysis indicated a significant difference in the overall reading achievement and reading qualities subtests of students who participated in the experimental groups (looping model) as compared with students in the comparison groups (traditional model). Additionally, when reading gain scores were examined, the experimental groups had made significant gains on all reading measures from pretest to posttest, whereas the comparison group's scores decreased on overall reading achievement and on reading qualities.

Regarding the affective constructs, anxiety and self-concept, the results of the data analysis indicated a significant difference in the anxiety level related to reading of students who participated in the looping model as compared with students in the comparison groups. Students in the experimental groups demonstrated significantly less anxiety related to reading than those in the comparison groups. Data analysis related to self-concept did not reveal any statistically significant differences between the students in the experimental groups as compared to the students in the comparison groups. The mean self-concept score for the four groups in the study was approximately the same.

Based upon the findings of this study, within the context of a large, urban, multicultural school setting, looping does not seem to have an effect on increasing students' self-concept. However, looping does seem to positively affect reading achievement and reading qualities. Further, there was a difference in students' anxiety as 
related to reading between the experimental and comparison groups, of fourth grade students who participate in looping classes within this educational context.

Conclusions

The findings, within the limitations of the study, serve to present several conclusions, within the context of a large, urban, multicultural school setting.

1. Looping did contribute to improving students' reading achievement.

2. Reading qualities (main idea and comparisons) were improved as a result of looping.

3. Students who participated in the looping model possessed lower anxiety levels related to reading than students in the comparison groups.

4. There was no difference in self-concept between students who participated in the looping classes and students who participated in the comparison classes.

\section{Implications}

The following implications are an outgrowth of the current study on looping within the context of a large, urban, multicultural school setting.

1. Looping provides a viable alternative towards improving students' overall reading achievement.

2. The looping model seems to enhance the development of the reading qualities, main idea and comparisons.

3. A relationship may exist between looping and the anxiety students experience related to reading. 


\section{Discussion}

This study concurs with and adds to the research literature that looping positively impacts reading achievement (Hampton, Mumford, \& Bond, 1997; Krogman \& Van Sant, 2000; Yang, 1997; Schneyderman, 2000). The current study examined the affective constructs of anxiety as related to reading and self-concept, adding to the empirical knowledge base in these areas. Because of the causal-comparative design of the study, several areas merit discussion. These include teacher effect, student mobility, affective constructs and decline in reading achievement scores of the comparison groups.

\section{Teacher Effect}

From the onset of this study, it was recognized that teachers greatly impact students' success within the classroom setting. (Rowan, Correnti \& Miller, 2002; Rowan, Chiang \& Miller, 1997). The teacher effect may have impacted the study in the area of self-concept. The four teachers who participated in the study were comparable with respect to professional preparation and content knowledge, use of teaching routines, and patterns of content coverage as evidenced by classroom observations conducted prior to and during the current study. Additionally, these teachers provided nurturing classroom environments for their students. For example, during classroom observations, it was noted that these four teachers provided positive feedback and a comfortable and secure learning environment. Teachers encouraged students to participate in class without the risk of being ridiculed, as "Respect one another," was a common written rule in the four classes. Through their teaching strategies, and by providing a comfortable and nurturing learning environment, perhaps the teachers in the comparison groups were able to foster positive self-concepts in their students in a relatively short period of time, perhaps 
accounting for the lack of difference in self-concept scores between the looped and comparison groups. Further research in the area of looping and teacher effect is warranted, especially as related to this affective domain. In future studies, perhaps the effect of moving a class as a whole to a new teacher in the subsequent grade could be compared to the effect of moving another intact class along with the same teacher to the subsequent grade. By controlling for teacher effect it may be determined that the group dynamics among the classmates accounts for differences in academic achievement and on affective variables.

Another example of the potential impact of teacher effect could be seen in the improvement of reading achievement in the looped classes. Because of the context of the study, within a school setting, the teachers in the experimental and comparison groups knew each other, taught the same grade level, and had developed a positive relationship with this researcher, in her role as an administrator at the school. Also, at PSNE, block scheduling is implemented throughout the school so that teachers at each grade level can meet and plan together regularly, allowing for ample opportunities for the experimental and comparison group teachers to discuss their involvement in the current study among themselves. Since the experimental teachers knew they were being looped, as part of the study and that looping is an instructional intervention expected to positively impact student achievement, they may have felt special and the Hawthorne Effect may have been manifested in the looped classes, accounting for some of improvement in reading achievement, reading qualities and decrease in anxiety as related to reading (Brannigan \& Zwerman, 2001). 


\section{Student Mobility}

Another key issue that may have impacted self-concept results, that remains a major concern to the current study is that of student mobility. Being a large, urban, multicultural school, PSNE is constantly faced with transient students. Due to student mobility, the number of students who remained at the school from the 2000-2001 school year to the 2001-2002 school year lowered the sample size from one hundred twenty to eighty-one. Each of the four classes, therefore, experienced the loss and gain of students throughout the two identified years. The average number of students who remained throughout the two years was approximately twenty in classes whose sizes maintained at an average of approximately thirty-two students. Because teachers and students in the looped classes were forced to accommodate and adapt to new students, the group dynamics were forced into a state of flux due to the new personalities, attitudes and learning styles of the new students. This factor may have affected the "sense of family" characteristic of looped classrooms. The issue of student mobility may have been a key factor in explaining the lack of variance in self-concept scores between the experimental and comparison groups. Additional study on the impact of student mobility consistent with large, urban, multicultural schools is needed to provide information on how mobility impacts the success of the looping model.

\section{Affective Constructs}

The professional literature reviewed for this study suggested that looping impacted self-concept (Grant, Forsten \& Richardson, 1996). One of the aims of this study was to empirically measure this construct. In seeking an instrument for empirically looking at self-concept, the Self Perception Profile for Children was selected because it 
provides a global measure of self-concept, appropriate for use with children within the age group of the students in the current study. Of concern is the sensitivity of the instrument to pick up the differences in self-concept that may have resulted from the looping condition. The instrument may have been too global for this type of sensitivity. This may have contributed to the lack of statistical significance between the experimental and comparison groups on self-concept.

This study set out to look at the impact of looping on two affective constructs. Findings from this study indicated that there may be a relationship between looping and anxiety as related to reading and that looping does not seem to have a relationship to selfconcept. The fact that one affective variable was impacted and the other was not merits discussion. Of issue in examining these results was the instrument used to measure selfconcept or of the construct itself. Perhaps a shift from self-concept to the construct of self-efficacy would be more closely aligned to reading. Since self-concept is broader than self-efficacy, perhaps the examination of self-concept was less sensitive to the impact of looping. Further refining of the Self-Perception Profile for Children or the development of an instrument to measure self-efficacy directly related to reading may have revealed a positive relationship between looping and self-efficacy as related to reading. Therefore, more research in the area of looping and self-efficacy is recommended.

Another issue related to the study of looping and self-concept was the timing and administration of the instruments. The instruments measuring anxiety and self-concept were only administered once because this study was concerned with looking at the differences in these variables across the groups. With anxiety there was a difference but 
with self-concept there was no difference. It would be important to determine changes in these constructs over time. It is advised that more quantitative research be conducted on the effects of looping on anxiety and self-concept, administering measures for both of these variables at the beginning and end of the first year of the two-year cycle, as well as at the beginning and end of the second year and at varying intervals. With this information, a researcher would be able to measure the changes in each of these affective constructs throughout the entirety of the looping condition. Therefore, findings related to looping and affective constructs could be reported as increases or decreases resulting from the looping condition, rather than as differences between the experimental and comparison groups, as in this study.

\section{Comparison Groups' Reading Achievement}

Of interest in this study was the finding that the comparison groups' reading achievement scores declined from the third to the fourth grade while the experimental groups' scores increased. Several factors may have accounted for this decline. One important consideration is that during the fourth grade school year, all students in the Miami-Dade County Public School System are required to take the FCAT Writes, a statewide, mandated, standardized writing test in January, in addition to the criterionreferenced FCAT, which measures reading and math and is given in March. The FCAT Writes examination is not given in the third grade but is of major emphasis during the language arts instructional block during the fourth grade. Therefore, fourth grade teachers devote a great deal of instructional time towards teaching the writing process and preparing their students for the FCAT Writes. The instructional focus on the teaching of writing was noted during classroom observations and evidenced by teachers' lesson 
plans, student work samples and grades. The added time spent focusing on the teaching of the writing process could have taken away from the reading instruction in the fourth grade.

Because the teachers of the looped groups knew their students better, and had already established classroom routines from the previous year, they could maintain the flow of the reading instruction from the previous year while adding the extra layer of writing instruction. Therefore, the reading instruction remained seamless from the third to the fourth grade. These teachers had diagnosed their students' reading strengths and weaknesses throughout the third grade school year and could delve into the instruction of reading and writing from the first day of school of the fourth grade year.

On the other hand, the teachers of the comparison groups, who were unfamiliar with their students, had to allot instructional time for getting to know their students, diagnosing students' reading levels, determining their areas of strengths and weaknesses in reading and establishing classroom routines. Additionally, these teachers had to implement both, the fourth grade reading curriculum and writing curriculum to a group of students about whom they had little or no knowledge. Perhaps the state and district-wide emphasis on completing preparation for the FCAT Writes and the increased focus by teachers on writing instruction in the preparation for this writing examination, with less emphasis on reading instruction, could account for some of the decrease in the reading achievement scores of the students in the comparison groups.

Further investigation in this area is needed to determine the degree to which the attention to writing instruction affects students' reading achievement scores in the fourth grade. One way to study this would be to compare the reading achievement scores of 
students in the looped classes, who had remained with the same teachers from the third to the fourth grade, with the reading achievement scores of students who were new to the looped classes. Because the looped teachers had to take instructional time to get to know these new students, diagnose their strengths and weaknesses in reading, and acclimate them to the classroom routines prior to providing reading and writing instruction, the reading achievement of these students may not have been as high as the achievement of students who had participated in the looped classroom with the same teacher during the third and fourth grade. While this was not a focus for the current study, further research in this area is warranted.

\section{Cautions for the Implementation of Looping}

Findings from this study support the use of looping with children in large, urban, multicultural school settings. In structuring the looping condition in the development of this study, close attention was paid to certain cautions made by proponents of looping. Grant et al. (1996) warn that all classes should be similar in the number and composition of students therein. For example, looped classes should be heterogeneously grouped and not heavily weighted with gifted of exceptional education students. While special needs students stand to benefit most from looping classes, care must be given not to overburden these classes with these students. These classes should also contain the same number of students as the other classes on the grade level and students who leave looped classes should be replaced with new students. For this study, care was given to ensure that the looping and comparison classes were heterogeneous in composition with regard to student academic ability levels, gender and socio-economic and ethnic backgrounds. Also, all classes had approximately the same number of students as the other classes on 
the grade level, since students who left the looped and comparison classes were replaced by new students.

Grant also warns against placing students with a marginal teacher for more than one year, explaining that they will never recover from the setback they will endure. A review of the literature on looping strongly warns that the looping of a class with a teacher who is not highly motivated will be a detriment to student progress (Gaustad, 1998; Grant, Richardson, \& Forsten, 2000; Vann, 1997). It is to be noted, therefore, that rather than randomly selecting teachers, teacher assignment was made from a pool of strong volunteer teachers who showed excitement and motivation to participate in this intervention. At PSNE, the teachers who volunteered to participate in the current study were extremely qualified, as evidenced by past performance observations.

One major stipulation in the practice of looping is that flexibility be given to the regrouping of students, especially if a personality conflict exists between the students and/or parent and the teacher (Grant et al., 1996). Vann (1997) also cautions against the negative consequences for children who are ostracized by their peers; a new class should be considered to give these children a fresh start. Fortunately, in this study, these issues did not arise.

A study by Dacus, (1999) discussed the hard realities of looping. They included issues as follows: Physically moving teachers every year can cause problems, especially for teachers who have difficulty changing grade levels; the sharing of materials and space can become a problem; new curriculum must be learned and implemented by the teachers; mismatches in teacher/student placements need to be addressed; extension of negative social issues for children, such as those students who may be the brunt of 
ridicule may have to continue with the same students; and mandating cannot work, teachers need to buy into the initiative.

At PSNE, close attention was paid to the configuration of the looping classes, the quality and willingness to participate of the teachers involved the match of the teachers and students and the training and support materials suggested by the proponents of looping. It is recommended that any school planning to implement looping be mindful of the aforementioned cautions of looping proposed by Grant et al. (1996), Vann (1997), and Dacus, (1999).

\section{Recommendations for Future Research}

The conclusions drawn from this study serve as the basis for several suggestions for future research. These recommendations are presented in light of the actual results of this study and from the available research on looping. Recommendations Based Upon Results of the Study

1. Replicate this study administering an instrument to measure self-efficacy as related to reading, rather than self-concept, to analyze the effect of looping on students' self-efficacy as related to reading.

2. Replicate this study administering the self-concept scale at the end of the second year of looping, as opposed to earlier in the looping cycle, to determine if gains in the self-concepts of students who participate in looped classes are evident after two entire years with the same teacher.

3. Build upon this study to evaluate the degree to which the attention to writing instruction affects students' reading achievement scores in the fourth grade, comparing the reading achievement scores of students in the looped classes, who had remained with 
the same teachers from the third to the fourth grade, with the reading achievement scores of students who were new to the looped classes.

4. Conduct further research in the area of looping to determine the degree to which teacher effect versus group dynamics among classmates and extended time accounts for differences in academic achievement and on affective variables, anxiety and self-concept.

5. Analyze the impact of student mobility consistent with large, urban, multicultural schools to provide information on how mobility impacts the success of the looping model in these educational contexts.

6. Build upon this study to quantitatively research the effects of looping on anxiety and self-concept, administering measures for both of these variables at varying intervals during the two-year cycle to measure the changes in each of these affective constructs over time.

7. Conduct a longitudinal study of the students who participated in this study to analyze whether participation in the looping model had any long-term effects on their reading achievement, anxiety levels and self-concepts.

Recommendations Based Upon the Available Research on Looping

1. Build upon the study to determine if the effects of looping on academic achievement differ among students of different ability levels. For example, "Are high achievers more positively impacted by the looping model than low achievers?"

2. Build upon the study to determine whether students at different ability levels benefit more from looping on the affective constructs of anxiety and self-concept. 
3. Examine whether the looping model may be more effective in the primary grades, for example kindergarten to first grade, where greater academic and social development occurs.

4. Investigate the effectiveness of looping over a three-year period, as compared to the two-year model in this study.

5. Conduct research to quantitatively measure the actual amount of instructional time that is gained throughout the two-year looping cycle.

\section{Summary}

This study quantitatively evaluated the effect of looping on reading achievement, reading qualities (main idea and comparisons), anxiety and self-concept within the context of a large, urban, multicultural school setting. While further research is warranted on this topic, especially in large, urban, multicultural schools, this study adds to the limited empirical research base on looping. The results of this study show that a relationship exists between looping and anxiety as related to reading. Further, looping appears to be a promising instructional intervention for the improvement of reading achievement and reading qualities for children who live and attend schools in these urban settings. 


\section{LIST OF REFERENCES}

American Educational Research Association (2001). AERA position statement concerning high-stakes testing in PreK- 12 education. AERA.net

Anderson, R.C., Hiebert, E.H., Scott, A., \& Wilkinson, I.A.G. (1985). Becoming a nation of readers: The report of the Commission on Reading. Washington, D.C.: National Institute of Education.

Anderson, R. C. \& Pearson, P.D. (1984). A schematheoretic view of reading. In P.D. Pearson, M. Kamil, P. Mosenthal, \& R. Barr (Eds.), Handbook of reading research (vol. 1, pp. 225-291). New York: Longman.

Anderson, R.C., Wilson, P.T., \& Fielding, L. G. (1988). Growth in reading and how children spend their time outside of school. Reading Research Quarterly, 23, 85303.

Balow, I., Farr, R., \& Hogan, T. (1993). Elementary 1 basic battery test booklet. In Metropolitan achievement tests $\left(7^{\text {th }}\right.$ ed.). (pp. 4-5). New York: Harcourt Brace Educational Measurement.

Bandura, A. (1997). Self-efficacy: the exercise of control. New York: Longman.

Blanton-Smith, N. (2000). American reading instruction. Delaware: International Reading Association.

Bellis, M. (1999). Look before you loop. Young Children, 70-71.

Borkowski, J.G., Carr, M., Rellinger, E., \& Pressley, M. (1990). Self-regulated strategy use: Interdependence of metacognition, attributions, and self-esteem. In B.F. Jones \& L. Idol (Eds.), Dimensions of thinking: Review of research 2-60. Hillsdale, NJ: Erlbaum.

Bracey, G. (1999). Going loopy for looping. Phi Delta Kappan, 81(2), 169.

Brandt, D. (1990). Literacy as involvement: The acts of writers, readers, and texts. Carbondale, IL: Southern Illinois University Press.

Brannigan, A., Zwerman. W. (2001, January/February). The real Hawthorne Effect. Society, 38(2), 55-60.

Brown, M. \& Vaughan, J. (2002, July 26). Governor Bush's F-school statistics overstated. Tampa Tribune, Tampa, Florida. 
Bruckner, J. E. (1977) A study of the relationship between self concept and reading. U.S. Department of Education: Office of Educational Research and Improvement. (ERIC Document Reproduction Service No. ED157005).

Burke, D.L. (1996). Multi-year teacher/student relationships are a long-overdue arrangement. Phi Delta Kappan, 77, 360-361.

Csikszentmihaly, M. (1991). Literacy and intrinsic motivation. In S.R. Graubard (Ed.), Literacy: An overview by fourteen experts (pp. 115-140). New York: Farrar, Staus, Giroux.

Crosby, P. (1998). Looping in middle school: Why do it? Teaching Pre-K - 8, 29(3), 4647.

Dacus, N. (1999, September). Moving up with the class. Educational Leadership, 57(1), $42-45$.

Danis, R. (2001, July). Using assessment to improve performance. Concurrent Session conducted at the 2001 Summer Institute for Nova Southeastern University's National Ed. D. Program for Education Leaders participants, Scottsdale, Arizona.

Darling-Hammond, L. (1998, August). Alternatives to grade retention. School Administrator, 55(7), 18-24.

Darling-Hammond, L. (1998, November). Avoiding both grade retention and social promotion. The Education Digest, 64(3), 48-53. Teaching K-8.

Dechant, E. (1970). Improving the teaching of reading. 2nd ed. Englewood Cliffs, N.J.: Prentice Hall.

Deci, E., \& Ryan, R. (1985). Intrinsic motivation and self-determination in human behavior. New York: Plenum.

Denault, L. (1999). Restructuring? Keep it simple ... consider looping! The Delta Kappa Gamma Bulletin, 65(4).

Evans, R. (1995, April 12). Getting real about leadership. Education Week.

Ferandino, V. \& Tirozzi, G. (2001, May 23). Test driven or data driven? Education Week.

Finn, C., Petrilli, M., \& Vanourek, G. (1998, November 11). The state of state standards: Four reasons why most "Don't cut the mustard." Education Week. 
Florida Department of Education. (2001). Florida comprehensive assessment test. Tallahassee, Florida: State of Florida Department of State.

Ford, M.E. (1992). Motivating humans. Newberry Park, California: Sage.

Forsten, C., Grant, J., \& Richardson, I. (1999). Multiage and looping: Borrowing from the past. Principal, 78(4), 15-16.

Fuhr, D. (1998, May). Where's the accountability in education reform? The School Administrator.

Gambrell, L., Palmer, B.M., Codling, R.M., \& Mazzoni, S.A.. (1996, April). Assessing Motivation to Read. The Reading Teacher, 49(7), 518-533.

Gambrell, L. (1996, September). Creating classroom cultures that foster reading motivation. The Reading Teacher, 50(1),14-25.

Garner, R. (1987). Metacognition and reading comprehension. Norwood, NJ: Ablex.

Gaustad, J. (1998). Implementing looping. U.S. Department of Education: Office of Educational Research and Improvement. (ERIC Document Reproduction Service No. EDO- EA-98-7).

Gordon, B. (2000, Fall). On high stakes testing. AERA.net, Division G Newsletter.

Goodman, K. S. (1967). Reading: a psycholinguistic guessing game. Journal of the Reading Specialist, (6) 126-135.

Granleese, J., Stephen, J. (1994, December). Reliability of the Harter Self-Perception for Children and predictors of global self-worth. The Journal of Genetic Psychology, 155 (4), 487-489.

Grant, J., Johnson, B., (1995). Looping, the two grade cycle: A good starting place. In A common sense guide to multiage practices, primary level (pp. 33-36).

Columbus, $\mathrm{OH}$ : Teacher's Publishing Group.

Grant, J., Johnson, B., \& Richardson, L. (1996). The Looping Handbook. New Hampshire: Crystal Springs Books.

Guthrie, J. Schafer, W., VonSecker, C., \& Alban, T. (2000). Contributions of instructional practices to reading achievement in a statewide improvement. The Journal of Educational Research, 93(4), 211-225. 
Hampton, F., Mumford, D., \& Bond, L. (1997, March). Enhancing urban student achievement through family oriented school practices. Paper presented at the Annual Meeting of the American Educational Research Association, Chicago, IL.

Hanford, G. (1994, July 13). Principals and pendulums. Education Week.

Hanson, B. (1995, November). Getting to know you multiyear teaching. Educational Leadership.

Harcourt Educational Measurement. (2003). Florida comprehensive assessment test for reading and mathematics: Technical Report for Test Administrations of FCAT 2003. San Antonio, Texas: Harcourt Educational Measurement.

Harter, S. (1985). Manual: Self-perception profile for children. Denver, Colorado: University of Denver.

Henk, W., \& Melnick, S.A. (1995). The reader self-perception scale (RSPS): a new tool for measuring how children feel about themselves as readers. The Reading Teacher, 48(1), 470-482.

Hill, F., Lofton, G., \& Purvis, A. (1999). Looping for the 21st century: Research findings on multi-year teaching and learning strategies. Paper presented at the annual meeting of the American Educational Research Association, Montreal, Canada.

Hodges, C, . (1997). How valid and useful are alternative assessments for decisionmaking in primary grade classrooms? Reading Research and Instruction, 36, 157173.

House, G. (2000, April 5). Re-creating a school system. Education Week.

Hung, D.W. (2002). Metaphorical ideas as mediating artifacts for the social construction of knowledge: Implications from the writings of Dewey and Vygotsky. International Journal of Instructional Media, 29 (2), 197-214.

Hurley, J.C. (2001, May 23). The principalship: Less may be more. Education Week.

Hurst, B. \& Wilson, C. (1997). Making the connection .for reading teachers between authentic assessment practices and qualitative research techniques. Reading Horizons, 38, 67-77.

Jordan, D. (2000). Looping: Discovering the difference. Teaching Pre-K - 8, 30(6), 5859. 
Jorgensen, M., Newman, D., \& Terry, R. (2001, July). Testing, testing ... tool or toll? General Session conducted at the 2001 Summer Institute for Nova Southeastern University's National Ed.D. Program for Educational Leaders participants, Scottsdale, Arizona.

Jubert, J. (1996). What is looping?. In J. Grant, B. Johnson, \& I. Richardson (Eds.), The looping handbook (pp.37-38.) New Hampshire: Crystal Springs Books.

Kelly, P., Brown, S., Butler, A. Gittens, P., Taylor, C. Zeller, P. (1998). A place to hang our hats. Educational Leadership, 56(1), 62-64.

Kieff, J. (2001). Small schools: great strides: a study of new small schools in chicago. Childhood Education, 77(4), 253-254.

Kuhl, J. (1986) Motivation, thought and action. New York: Praeger.

Kohn, A. (2001, July). The deadly effects of "tougher standards.," General Session conducted at the 2001 Summer Institute for Nova Southeastern University's National Ed.D. Program for Educational Leaders participants, Scottsdale, Arizona.

Krogmann, J., \& Van Sant, R. (2000). Enhancing relationships and improving academics in the elementary school setting by implementing looping. Unpublished Master's Action Research Project, Saint Xavier University \& Field-Based Masters Program, Chicago, Illinois.

Kuball, Y. (1999). A case for developmental continuity in a bilingual $k$-2 setting. Young Children, 54(3), 74-79.

Lashway, L. (1996). The strategies of a leader. ERIC Digest, Number 105. (ERIC Document Reproduction Service No. ED 406718).

Lashway, L. (2002). The state of standards. Research Roundup. National Association of Elementary School Principals, 17(4).

Lepper, M.R. (1988). Motivational considerations in the study of instruction. Cognition and Instruction, 5, 289-309.

Lillemyr, O. F. (1982). The relationship of self-perceptions and achievement motives in Norwegian children. Paper presented at eh Annual Meeting of he American Educational Research Association. New York, New York.

Little, T., Little, L.P. (2001). Looping: creating elementary school communities. Phi Delta Kappan Fastbacks, 478, 7-39. 
Liu, J. (1997). The emotional bond between teachers and students: multi-year relationships. Phi Delta Kappan, 79(2), 156-157.

Lynch, J. (2002). Parents' self-efficacy beliefs, parents' gender, children's reader selfperceptions, reading achievement and gender. Journal of Research in reading, 25(1), 54-67.

Mann, D. (1985, December 18). Principals, leadership, and reform. Education Week.

Maehr, M. L. (1976). Continuing motivation: an analysis of a seldom considered educational outcome. Review of Educational Research, 46, 443-462.

McCabe, P. (2003). Enhancing self-efficacy for high-stakes reading tests. The Reading Teacher, (57)1, 12-20.

McCombs, B. L. (1989). Self-regulated learning and academic achievement: A phenomenological view. In B.J. Zimmerman \& D.H. Schunk (Eds.), Selfregulated learning and achievement: Theory, research, and practice (pp. 51-82). New York: Springer Verlag.

McCombs, B.L. (1991). Unraveling motivation: new perspectives from research and practice. Journal of Experimental Education, 60, 3-88.

McMackin, M. \& Blackwell, A. (1997). Exploring the multiage classroom. The New England Reading Association Journal, 33(2), 22-23.

Miami-Dade County Public Schools. (2001, June). District and school profiles, 20002001. Office of Educational Planning and Quality Enhancement.

Morrow, L.M. (1992). The impact of a literature-based program on literacy achievement, use of literature, and attitudes of children from minority backgrounds. Reading Research Quarterly, 27, 250-275.

National Education Commission on Time and Learning, (1994). Prisoners of time. Washington, D. C: U.S. Government Printing Office.

Nichols, J. D., and Nichols, G. W. (2002, Fall). The impact of looping classroom environments on parental attitudes. Preventing School Failure, 47(1), 18-25.

Nye, B. (1993). Some questions and answers about multiage grouping. ERS Spectrum $11,38-45$.

Obiakor, F.E., Obi, S., Algozzine, B. (2001). Shifting assessment and intervention paradigms for urban learners. Western Journal of Black Studies, 25(1), 61-71. 
O'Flahavan, J., Gambrell, L.B., Guthrie, J., Stahl, S., \& Alvermann, D. (1992, August). Poll results guide activities of research center. The Reading Teacher, 46, 672681.

Olson, L. (2000, Jan. 12). Policy focus converges on leadership. Education Week.

Olson, L. (2000, January 19). New thinking on what makes a leader. Education Week.

Olson, L. (2000, November 1). Principals try new styles as instructional leaders. Education Week.

O’Neil, H. F. \& Spielberger, C. D.. (1979) Cognitive and affective learning strategies. New York: Academic Press.

Paris, S.G., \& Oka, E.R. (1986). Self-regulated learning among exceptional children. Exceptional Children, 53, 103-108.

Payne, R.K. (1998). A framework for understanding poverty. Baytown TX: RFT Publishing Co.

Pressley, M., Borowski, J.G., \& Schneider, W. (1987). Cognitive strategies: Good strategy users coordinate metacognition and knowledge. In R. Vasta \& $\mathrm{G}$. Whitehurst (Eds.), Annals of child development, 4 (pp. 89-120). Greenwich, CT: JAI Press.

Purkey, W. W. (1988). An overview of self-concept theory for counselors. Ann Arbor, Michigan: ERIC Counseling and Personnel Services Clearinghouse, The University of Michigan.

Quandt, I. (1973). Self concept and reading. ERIC Digest, (ERIC Document Reproduction Service No. ED071064).

Rappa, J.B. (1993). Presentation to the National Education Commission on time and learning. (Available from the Attleboro School District, 100 Rathburn Willard Drive, Attleboro, MA 02703).

Rasmussen, K. (1998). Looping-Discovering the benefits of multi year teaching. Educational Leadership, 40 (2).

Reeves, D. (2001, June 6). If you hate standards, learn to love the bell curve. Education Week.

Renchler, R. (1992). School leadership and student motivation. ER.IC Digest, number 71. (ERIC Document Reproductions Service No. ED346558). 
Reynolds, J.C., Barnhart, B., \& Martin, B. (1999, Spring). Looping: A solution to the retention is. social promotion dilemma? ERS Spectrum, 16-20.

Richard, A. (2000, Nov. 1). Panel calls for fresh look at duties facing principals. Education Week.

Rosenblatt, L. M. (1978). The reader, the text, the poem: the transactional theory of the literary work. Carbondale, Ill.: Southern Illinois University Press.

Rowan, B., Chiang, F., Miller, R. (1997, October).Using research on employees' performance to study the effects of teachers on students' achievement. Sociology of Education, 70, (4), p. 256-285.

Rowan, B., Correnti, R. Miller, J. (2002). What large-scale, survey research tells us about teacher effects on student achievement: Insight from the prospects study of elementary schools. Teachers College Record, 104(8), 1525-1567.

Sadowski, M. (2001). Closing the gap one school at a time. Harvard Education Letter.

Samway, K.D., Whang, G., \& Pippit, M. (1995). Cross-age tutoring in a multicultural school. Portsmouth, New Hampshire: Heinemann.

Sartorius, N. (1991). Anxiety: psychobiological and clinical perspectives. Washington: Hemisphere/Taylor \& Francis.

Schachter, S. (1964). The interaction of cognitive and physiological determinants of emotional state. In. L. Berkowitz (Ed.), Advances in experimental social psychology (Vol. 1, 49-80). New York: Academic Press.

Schneyderman, A. (2000). Evaluation of Looping. Miami-Dade County Public Schools Office of Evaluation and Research.

Serafini, F. (2000/2001). Three paradigms of assessment: measurement, procedure, and inquiry. The Reading Teacher, 54(4), 384-393.

Smith, E., Goodman, K., \& Meredith, R. (1970, 1972). Language and thinking in the elementary school. New York: Holt, Rinehart and Winston.

Spielberger, C.D. (1985). Assessment of state and trait anxiety: conceptual and methodological issues. The Southern Psychologist, 2, 6-16.

Spielberger, C.D. (1997). State-trait anxiety inventory for children. Palo, Alto, Ca: Consulting Psychologists Press Inc.

Steiny, J. (1999, May 9). "Looping" catches on in Barrington. The Providence Journal. 
Sternberg, R. J. (1986). Intelligence applied: understanding and increasing your intellectual skills. San Diego, California: Harcourt, Brace Jovanovich, Publishers.

Stolp, S. (1994). Leadership for school culture. ERIC Digest, number 91 (ERIC Document Reproduction Service No. ED370198).

Sweet, A. E. and Burbach, H. J. (1977). Self-esteem and reading achievement. Paper presented at the Annual Meeting of the American Educational Research Association. New York, New York.

Taylor, B.M., Frye, B.J., \& Maruyama, G.M. (1990). Time spent reading and reading growth. American Education Research Journal, 27, 351-362.

Thomson, S. (1991, October 16). Leadership revisited. Education Week.

Thomson, S. (2001). The authentic standards movement and its evil twin. Phi Delta Kappan, 82(5), 358-362.

Turner, J.C., \& Paris, S.G. (1995). How literacy tasks influence children's motivation for literacy. The Reading Teacher, 48, 662-675.

Valencia, S. (1997). Authentic classroom assessment of early reading: alternatives to standardized tests. Preventing School Failure, 41, 63-70.

Van Den Bergh, B., De Rycke, L. (2003, June). Measuring the multidimensional selfconcept and global self-worth of 6 to 8-year-olds. The Journal of Genetic Psychology, 164(2), 201-214.

Vann, A. (1997, May). Looping: Looking beyond the hype. Principal, 59(7), 1-2.

Vasconcellos, J., Reasoner, R., Borba, M., Duhl,. L \& Canfield, J. (2000). In defense of self-esteem. Normal, Illinois: National Association for Self-Esteem, p. 1-6.

Vellutino, F. \& Scanlon, D. (1999). Early intervention can reduce the number of children diagnosed as reading disabled. The New England Reading Association Journal, $35(3), 3-13$.

Walz, G. R. \& Bleuer, J. (1991). The esteem-achievement connection. Ann Arbor, Michigan: Counseling and Personnel Services Clearinghouse.

Warford, J. (2003). Report on K-12 Activities. State Board of Education Meeting. Florida Department of Education.

Weaver, C. (1988). Reading process and practice: from socio-psycholinguistics to whole language. Portsmouth, New Hampshire: Heinemann Educational Books. 
Wigfield, A. (1994). Expectancy-value theory of achievement and motivation: A developmental perspective. Educational Psychology Review, 6(1), 48-78.

Winne, P. (1985). Steps toward promoting cognitive achievements. Elementary School Journal, 85, 673-693.

Winograd, P., \& Greelee, M. (1986). Students need a balanced reading program. Educational Leadership, 43(7), 16-21.

Wood, C. (1998). Yardsticks: Children in the classroom ages 4-14. Northeast Foundation for Children.

Yang, X. (1997). Educational Benefits in Elementary School through Looping and Friday In-Services. Part 2: Benefits of Looping. Paper presented at the Annual Seminar of the National Association for Year-Round Education. San Diego, California. 
APPENDIX A

PARENTAL CONSENT TO PARTICIPATE IN A RESEARCH STUDY 


\section{PARENTAL CONSENT TO PARTICIPATE IN A RESEARCH STUDY}

\section{The Impact of Looping on Reading Achievement}

My name is Mary Jo Almeida-Shore and I am an assistant principal at Palm Springs North Elementary and a Doctoral Student at Florida International University. Your child is being asked to be part of a research study during the 2001-2002 school year. I hope to learn whether the practice of looping, having a teacher proceed to the next grade level with his/her class, has an impact on reading achievement. I will be comparing your child's score on the third grade FCAT with his/her score on the fourth grade FCAT, which will be administered this March. Your child will also be asked to complete three brief paper and pencil tasks that measure vocabulary aptitude, anxiety and self-perception. These instruments are created for children and can be completed in approximately thirty minutes in total.

If you choose to let your child participate, this is all that will be asked of him/her. All of your child's scores will remain locked in my office and the results will be anonymous. No child's name will be reported in the study.

There are no risks to your child as a participant in this study. Neither you nor your child will be charged for participating. The tasks your child is asked to complete are similar to those he/she completes on a daily basis. There are no good or bad scores. Your child can request to stop during a task and that will be allowed. You may discontinue your child's participation at any time without any penalty to him/her. Your child's participation will not hurt or help your child's grades. There are no direct benefits to your child or to you from being a participant in this project. Please understand that this study may help researchers learn about how looping can be used to improve reading achievement.

If any information about looping and reading achievement is learned during your child's participation that may affect you wanting your child to continue participation you will be notified at once. A special code will be used to record your child's scores and your child's name will not be used when this research is presented. The scores will be kept until the end of the study and then destroyed. All files will be kept in a locked cabinet.

You and your child are free to ask questions now or later pertaining to this research. You can contact Mary Jo Almeida-Shore, at (305) 817-8910 for answers to questions. If you have questions about your child as a research subject you can contact the Chairperson of the Institutional Review Board at Florida International University, Dr. Bernard Gerstman at 305-3483115 or 305-348-2494, who has been given a copy of this form. Please complete and return this form as soon as possible, if you give permission for your child to participate. I thank you, in advance, for your support in this research project.

I give permission for my child, research project.

$$
\text { Child's Name }
$$
, to participate in this

Parent's Signature

$$
\text { Printed Name }
$$

Date

Witness

Date 
APPENDIX B

ASSENT TO PARTICIPATE IN A RESEARCH STUDY 


\section{ASSENT TO PARTICIPATE IN A RESEARCH STUDY}

\section{The Impact of Looping on Reading Achievement}

My name is Ms. Almeida-Shore and I am an assistant principal at Palm Springs North Elementary. I am also a Doctoral Student at Florida International University. Please read the information below so that you can decide if you will participate in my study.

- You are being asked to do some paper and pencil tasks so that I can learn more about reading.

- The tasks you will be similar to those you complete in your classroom.

- Your names will not be used in the study, so your answers will be kept private.

- Your answers on the tasks will not hurt or help your grades in your classroom.

- There are no good or bad scores on the tasks. The scores will help me learn about reading.

- You can request to stop during a task if you decide to do so.

You may ask any questions about the study now or later. If you have any questions, you can ask me, Ms. Almeida-Shore, or you can call me at (305) 817-8910 for answers to questions.

If you have questions about being part of research you can contact the Chairperson of the Institutional Review Board at Florida International University, Dr. Bernard Gerstman at 305-3483115 or $305-348-2494$, who has been given a copy of this form.

When you sign below it means that you agree to take part in this study and that you understand the things you will be asked to do.

I thank you, in advance, for your support in this research project.

Student's Signature

Student's Printed Name

Date

Witness

Date 


\section{APPENDIX C \\ CONSENT TO PARTICIPATE IN A RESEARCH STUDY}




\section{CONSENT TO PARTICIPATE IN A RESEARCH STUDY}

\section{The Impact of Looping on Reading Achievement}

My name is Ms. Almeida-Shore and I am an assistant principal at Palm Springs North Elementary and a Doctoral Student at Florida International University. You are being asked to be part of a research study during the 2001-2002 school year. I hope to learn whether the practice of looping, having a teacher proceed to the next grade level with his/her class, has an impact on reading achievement. I will be comparing your students' scores on the third grade FCAT with their scores on the fourth grade FCAT, which will be administered this March. Your students will also be asked to complete three brief paper and pencil tasks that measure vocabulary aptitude, anxiety and self-perception. These instruments are created for children and can be completed in approximately thirty minutes in total. You will also be asked to participate two face-to-face interviews with me. I may also be observing your class.

If you choose to participate, this is all that will be asked of you. All of your responses will remain locked in my office and the results of all instruments will be anonymous. No teacher's name will be reported in the study.

There are no risks to you as a participant in this study. You will not be charged for participating. The tasks you will be asked to complete are similar to those you complete on a daily basis. There are no good or bad responses. You can request to stop during a task and that will be allowed. You may discontinue participating at any time without any penalty. Your participation will not hurt or help you. There are no direct benefits to you from being a participant in this project. Please understand that this study may help researchers learn about how looping can be used to improve reading achievement.

If any information about looping and reading achievement is learned during your participation that may affect your wanting to continue participation, you will be notified at once. A special code will be used to record your responses and your name will not be used when this research is presented. The responses will be kept until the end of the study and then destroyed. All files will be kept in a locked cabinet.

You are free to ask questions now or later pertaining to this research. You can contact Ms. Almeida-Shore, at (305) 817-8910 for answers to questions. If you have questions about being part of research you can contact the Chairperson of the Institutional Review Board at Florida International University, Dr. Bernard Gerstman at 305-348-3115 or 305-348-2494, who has been given a copy of this form.

Please complete and return this form as soon as possible, if you sign below it means that you want to take part in this study and that you understand the things you will be asked to do. I thank you, in advance, for your support in this research project.

Participant's Signature

Printed Name

Date

Witness

Date 


\section{APPENDIX D}

STATE-TRAIT ANXIETY INVENTORY FOR CHILDREN 
DIRECTIONS: Think about how you feel when you are reading. Read each statement below and decide if it describes how you feel when you are reading or when you think about reading. There are no right or wrong answers. Do not spend too much time on any one statement. Remember, choose the word or phrase which seems to describe how you feel about reading.

1. I feel . . . . . . very calm

calm

2. I feel . . . . . . very upset

3. I feel

4. I feel

5. I fee

6. I feel

7. I feel

8. I feel

9. I feel

10. I feel

11. I fee

12. I feel

13

14. I feel

15. I feel

16. I feel

17

18. I feel

19. I feel

20. I feel very pleasant

very nervous

very jittery

very rested

very scared

very relaxed

very satisfied

very frightened

very happy

very sure

very good

* very troubled

very bothered

very nice

$\checkmark$ very terrified

very mixed-up

very cheerful relaxed

worried

satisfied

happy

upset

pleasant

nervous

jittery

rested

2 scared

(a)

frightened

sure

good

troubled

bothered

nice

terrified

. mixed-up

cheerful not calm

not upset

not pleasant

not nervous

not jittery

not rested

not scared

not relaxed

2 not worried

not satisfied

not frightened

not happy

not sure

not good

not troubled

not bothered

$\checkmark$ not nice

not terrified

$\therefore$ not mixed-up

$\checkmark$ not cheerful 
APPENDIX E

SELF-PERCEPTION PROFILE FOR CHILDREN 
Boy or Girl (Circle which)

Month Day

\section{SAMPLE SENTENCE}

Really Sort of

True True

(a) for me for me

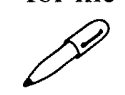

Some kids would rather play outdoors in their spare time
Other kids would rather BUT watch T.V.
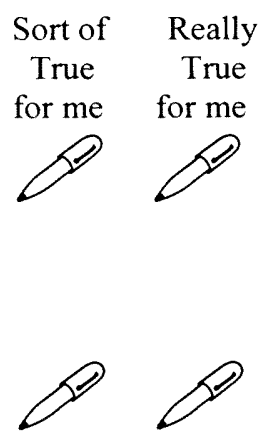

are very good at their school work

BUT

Other kids worry about whether they can do the school work assigned to them

Some kids find it hard to make friends

Other kids find it's pretty BUT easy to make friends
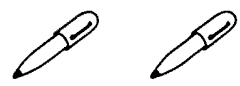

Other kids don't feel that

Some kids do very well at all kinds of sports

they are very good when it comes sports
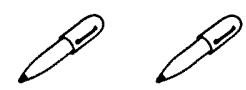

Some kids are happy with the way they look

Other kids are not happy BUT with the way they look

Other kids usually like

Some kids often do not like the way they behave

BUT the way they behave
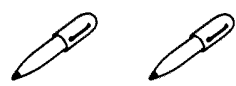

Other kids are pretty

Some kids are often unhappy with themselves

BUT pleased with themselves
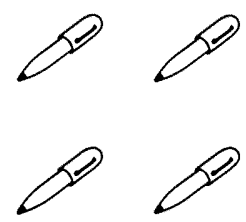

Some kids feel like they are just as smart as other BUT kids their age

Other kids aren't so sure and wonder if they are as smart

Some kids have a lot of friends
Other kids don't have BUT very many friends
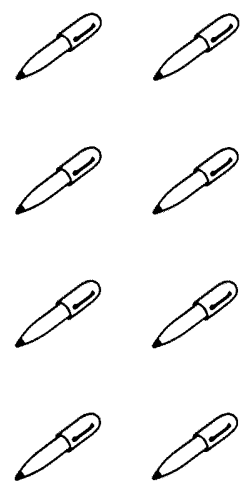

8.<smiles>C1=CC=C1</smiles>

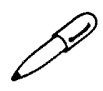




\begin{tabular}{|c|c|c|c|}
\hline 9. & $\begin{array}{l}\text { Really } \\
\text { True } \\
\text { for me }\end{array}$ & $\begin{array}{l}\text { Sort of } \\
\text { True } \\
\text { for me }\end{array}$ & $\begin{array}{l}\text { Some kids wish they } \\
\text { could be a lot better at } \\
\text { sports }\end{array}$ \\
\hline 10. & & & $\begin{array}{l}\text { Some kids are happly } \\
\text { with their height and } \\
\text { weight }\end{array}$ \\
\hline 11. & & & $\begin{array}{l}\text { Some kids usually do the } \\
\text { right thing }\end{array}$ \\
\hline 12. & & & $\begin{array}{l}\text { Some kids don't like the } \\
\text { way they are leading } \\
\text { their life }\end{array}$ \\
\hline 13. & & & $\begin{array}{l}\text { Some kids are pretty } \\
\text { slow in finishing their } \\
\text { school work }\end{array}$ \\
\hline 14. & & & $\begin{array}{l}\text { Some kids would like to } \\
\text { have a lot more friends }\end{array}$ \\
\hline 15. & & & $\begin{array}{l}\text { Some kids think they } \\
\text { could do well at just } \\
\text { about any new sports } \\
\text { activity they haven't } \\
\text { tried before }\end{array}$ \\
\hline 16. & & & $\begin{array}{l}\text { Some kids wish their } \\
\text { body was different }\end{array}$ \\
\hline 17. & & & $\begin{array}{l}\text { Some kids usually act the } \\
\text { way they know they are } \\
\text { supposed to }\end{array}$ \\
\hline 18. & & & $\begin{array}{l}\text { Some kids are happy } \\
\text { with themselves as a } \\
\text { person }\end{array}$ \\
\hline 19. & & & $\begin{array}{l}\text { Some kids often forget } \\
\text { what they learn }\end{array}$ \\
\hline 20. & & & $\begin{array}{l}\text { Some kids are always } \\
\text { doing things with a lot } \\
\text { of kids }\end{array}$ \\
\hline
\end{tabular}

Some kids are happy with their height and

Some kids usually do the Some kids don't like the way they are leading their life

\section{BUT}

Other kids do like the way they are leading their life

\section{BUT school work quickly \\ Other kids can do their}

Other kids have as BUT many friends as they want

Other kids are afraid BUT they might not do well at sports they haven't ever tried

Other kids like their BUT body the way it is

Other kids often don ' $t$

BUT act the way they are supposed to

Other kids are often not BUT happy with themselves

BUT remember things easily,

Other kids can Other kids usually do BUT things by themselves
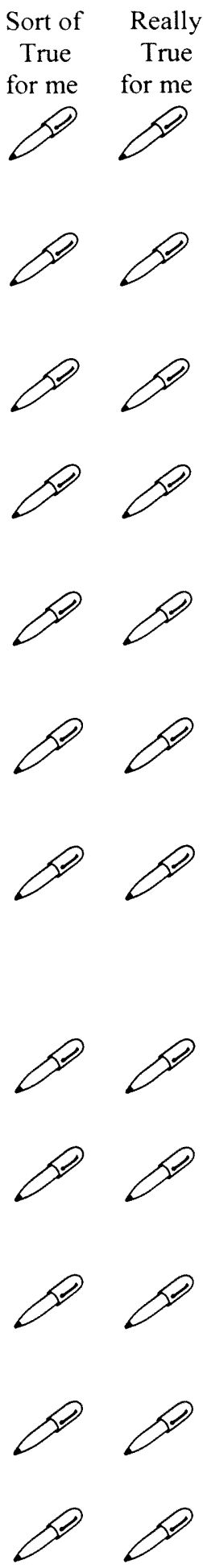

Really Sort of
True True
21.
for me for me
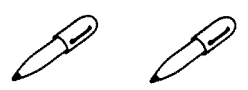
Some kids feel that they are better than others their age at sports
Some kids wish their physical appearance (how they look) was different

23.
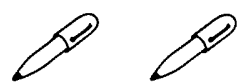

24.
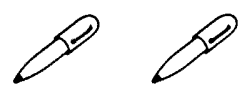

25.
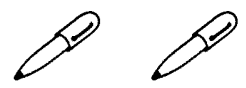

26.

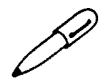

$B$

27.
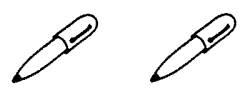

28.
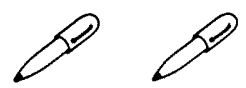

29
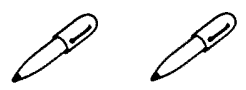

30.
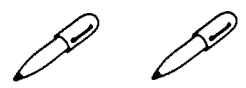

31.
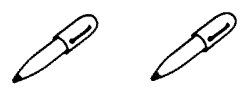

32.

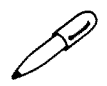

Some kids usually get in trouble because of things they do

Some kids like the kind of person they are

Some kids do very well at their classwork

Some kids wish that more people their age liked them

In games and sports some kids usually watch instead of play

Some kids wish something about their face or hair looked difference

Some kids do things they know they shouldn't do

Some kids are very happy being the way they are

Some kids have trouble figuring out the answers in school

Some kids are popular with others their age
Sort of

Really

True

True

for me

Other kids don't feel

BUT they can play as well

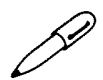

for me

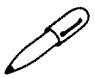

BUT

Other kids like their physical appearance the
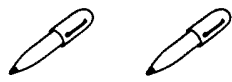
way it is

Other kids usually don't

BUT do things that get them
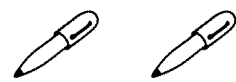

in trouble

Other kids often wish

BUT they were someone else
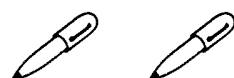

Other kids don ' $t$ do

BUT very well at their
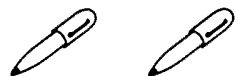

classwork

BUT

Other kids feel that most people their age
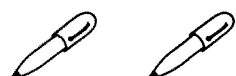
do like them

Other kids usually play BUT rather than just watch
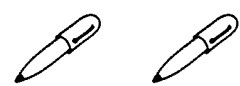

Other kids like their face and hair the way they are
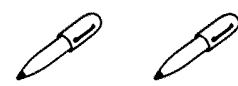

Other kids hardly ever BUT do things they know they shouldn't do
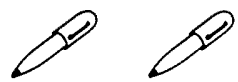

Other kids wish they

BUT were different
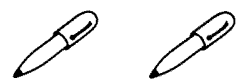

Other kids almost

BUT always can figure out the answers

Other kids are not very BUT popular
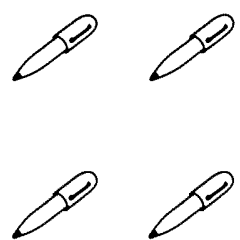

Sort of Really 
Really Sort of

True True

for me for me

33.

s

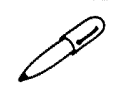

34.<smiles>C1=CC=C1</smiles><smiles>C1=CC=C1</smiles>

35.<smiles>C1=CC=C1</smiles><smiles>C1=CC=C1</smiles>

36.<smiles>C1=CC=C1</smiles><smiles>C1=CC=C1</smiles>

Some kids don't do well at new outdoor games

Some kids think that they are good looking

Some kids behave themselves very well

Some kids are not very happy with the way they do a lot of things
True

for me

True

for me

BUT

Other kids are good at new games right away
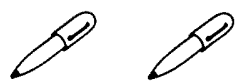

Other kids think that

BUT they are not very good
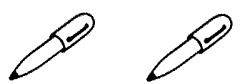
looking

BUT

Other kids often find it hard to behave themselves
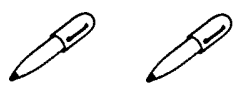

Other kids think the BUT way they do things is fine

Susan Harter, Ph.D., University of Denver, 1985 


\section{APPENDIX F}

Vocabulary Subtest: Metropolitan Achievement Test (Mat-7) 
Teacher

Student's name
Grade

Date

\section{What to Do}

Choose the word or group of words that means the same, or about the same, as the underlined word. Then mark the space for the answer you have chosen.

\section{SAMPLE A}

Help me repair the fence.
$\circ$ fix
o wash
○ paint
o cover

1. The delicious salad didn't last long.

o healthy

o tasty

○ picnic

○ colorful

2. She could see the whole room from that position.
o corner
o seat
- place
$\circ$ hall

3. The spider was under a twig.
o bug
- leaf
o stone
o stick

4. That is a common sight.

o sad

○ ugly

o welcome

o ordinary 
5. The ground was firm.
o muddy
○ solid
o thick
o rocky

6. We went to the school banquet.
o show
o dinner
O concert
o class

7. The apartment looked empty.
o clean
o bare
o cozy
$\circ$ huge

8. The ocean was peaceful.
o calm
- enormous
○ cold
o beautiful

9. He wanted immediate help.
o extra
○ steady
o more
$\circ$ instant

10. She carried the bundle.
○ laundry
o ticket
○ package
o firewood

11. The animal was tame.
o warm
- clever
- gentle
o safe 
12. Carrie was uncertain about her answer.
○ careful
$\circ$ right
o too slow
$\circ$ not sure

\section{What to Do}

Choose the word or group of words that has the opposite, or most nearly the opposite, meaning of the underlined word.

\section{SAMPLE B}

The can was heavy.
o new
○ shiny
$\circ$ light
$\circ$ frozen

13. The house looks wonderful.
o silly
o terrible
o hidden
o complete

14. The conductor said to pause.
o sing
o improve
- continue
o listen

15. The story was mysterious.
- clear
o forgotten
o written
$\circ$ repeated 
APPENDIX G

Formation and Equivalence of Experimental and Comparison Groups 


\section{Formation of the Experimental and Comparison Groups}

Four heterogeneously- grouped fourth grade classes were used for this study. The formation of these classes actually began during the summer of 2001 . The two experimental classes were looped, meaning that the students remained with their third grade teacher for their fourth grade, 2001-2002, school year. The fourth grade comparison classes were comprised of students from across the third grade and had a different teacher for the 2001-2002 school year. In order to understand how the classes used in this study were formed, it is important to consider the procedures that occurred prior to the beginning of the current study. During the 2000-2001 school year, the students' third grade year, all students had been randomly assigned to their third grade classes. At the end of that school year, all third grade teachers were given the opportunity to volunteer for the looping classes. Of those who volunteered, two were chosen to participate in the looping model for the current study based upon their years of experience and the respect they had earned over the years from administrators, colleagues, parents and students. While teachers were given the opportunity to request that a student be removed from the class for the second year, no students were removed.

Additionally, in June 2001, a parent meeting was held for parents of students who would potentially participate in the looping model, to give parents the prerogative of having their child continue with the same teacher or to request a different teacher for the subsequent school year. At this meeting, parents were notified of the school's intent to loop the teachers in the two chosen classes and were given the opportunity to request a different teacher. None of the parents requested a different teacher for the fourth grade school year. 
Because of the quasi-experimental design of the study, it was necessary to match the experimental and comparison groups in order to accurately evaluate changes in the dependent variables. Students across the classes were matched on both, reading achievement and aptitude. The experimental groups (looping model) were matched to the comparison groups (traditional model) based upon the mean raw scores on the reading subtest of the 2000-2001 Criterion-Referenced Florida Comprehensive Achievement Test (FCAT). This third-grade reading pretest that was used to obtain baseline scores was administered during the first week of March 2001.

Both experimental groups were also matched to the comparison groups in aptitude, as assessed by scores on a vocabulary measure. Student's ability levels were identified according to their performance on the vocabulary subtest of the Metropolitan Achievement Tests Seventh Edition (MAT-7), Elementary 1 Basic Battery Test Booklet to ensure that students from all levels of performance were included in the analysis. (Appendix F) While it would have been preferable to administer an individualized intelligence test to each student in the study, it was legally and logistically impossible. Therefore, a vocabulary measure was used instead. The reason for selecting a vocabulary measure to determine aptitude can best be explained through the research of Sternberg, who posits, "It is well known that vocabulary is one of the best predictors, if not the single best predictor of overall IQ score. Yet vocabulary tests are clearly achievement tests. Can the underlying ability tapped by vocabulary tests be measured without presenting people with what is essentially an achievement test?" $(1986$, p. 29) One major reason for the predictability of vocabulary over intelligence is that it indirectly measures a person's ability to obtain information in context (Sternberg, 1986). 
In order to establish equivalence among the groups, an Independent Samples t-test was used. This t-test enabled the researcher to determine the equivalence of the pooled experimental and comparison groups on the variables, FCAT 2001 raw score (percentage correct) and on the MAT-7, aptitude measure. Because the t-test statistics revealed that pretest means, FCAT 2001, were slightly higher in the comparison groups (traditional model) than those of the experimental groups (looping model), follow-up analyses were conducted among the four groups in the study and two Analyses of Variance, ANOVAs, were conducted to ensure that the four groups were equal on the pretest, FCAT 2001 (percentage correct) and on the vocabulary measure, MAT-7. The ANOVA was used because this analysis allows the researcher to evaluate whether the group means on the above variables differ significantly from each other, when there are more than two groups in a study. This procedure was conducted once with the variable of FCAT 2001 and again with that of the MAT-7. No significant difference was reported for the experimental and comparison groups on either of these factors. Therefore, it could be assumed that the looped and comparison groups were equivalent on reading achievement as well as on aptitude at the beginning of the study and that any gains in reading achievement or reading qualities could be attributed to participating in a looped classroom.

School administrators met with teachers who would potentially be looped during the 2001-2002 school year and provided them with literature on looping in May 2001. Teachers who volunteered to loop were interviewed and selected in June 2001. Teacher consent forms were attained from the four teachers who participated in the study. (Appendix C) Consent forms were obtained from all parents of students who would 
participate in the study (Appendix A) and from the students themselves (Appendix B).

Teachers of classes involved in the study also signed consent forms (Appendix C).

\section{The Equivalence of the Experimental and Comparison Groups}

Because of the quasi-experimental design of the study, it was necessary to match the experimental and comparison groups in order to accurately evaluate changes in the dependent variables. Students across the classes were matched on both, reading achievement and aptitude. The experimental groups (looping model) were matched to the comparison groups (traditional model) based upon the mean raw scores on the reading subtest of the 2000-2001 Criterion-Referenced Florida Comprehensive Achievement Test (FCAT). This third-grade reading pretest that was used to obtain baseline scores was administered during the first week of March 2001.

Both experimental groups were also matched to the comparison groups in aptitude, as assessed by scores on a vocabulary measure (MAT-7). Student's ability levels were identified according to their performance on the vocabulary subtest of the Metropolitan Achievement Tests Seventh Edition (MAT-7), Elementary 1 Basic Battery Test Booklet to ensure that students from all levels of performance were included in the analysis. Each student in each of the four groups was administered this fifteen item test to complete independently in a twenty-minute class session. Mean raw scores were derived from each group to ascertain that all groups were equivalent on this aptitude measure. This researcher hand-scored the vocabulary subtest of this instrument.

In order to establish equivalence among the groups, an Independent Samples t-test was used. This t-test enabled the researcher to determine the equivalence of the pooled experimental and comparison groups on the variables, FCAT 2001 raw score (percentage 
correct) and on the MAT-7, aptitude measure. Because the t-test statistics revealed that pretest means, FCAT 2001, were slightly higher in the comparison groups (traditional model) than those of the experimental groups (looping model), follow-up analyses were conducted among the four groups in the study and two Analyses of Variance, ANOVAs, were conducted to ensure that the four groups were equal on the pretest, FCAT 2001(percentage correct) and on the vocabulary measure, MAT-7. The ANOVA was used because this analysis allows the researcher to evaluate whether the group means on the above variables differ significantly from each other, when there are more than two groups in a study. This procedure was conducted once with the variable of FCAT 2001 and again with that of the MAT-7. No significant difference was reported for the experimental and comparison groups on either of these factors. Therefore, it could be assumed that the looped and comparison groups were equivalent on reading achievement as well as on aptitude at the beginning of the study and that any gains in reading achievement or reading qualities could be attributed to participating in a looped classroom.

Pretest means, standard deviations, t-test statistics and p-values of the pooled looped and comparison groups for the baseline reading measure, FCAT 2001, and the aptitude/vocabulary measure are shown in Table 8 . Pretest means and standard deviations of the four groups for the baseline reading measure, FCAT 2001, measure are shown in Table 9. Means, standard deviations, F statistics and p-values for the four groups for the vocabulary measure, MAT-7 are shown in Table 10. Because there were different numbers of test items on the pretest, FCAT 2001, and on the posttest, FCAT 
2002 , the percentage of correct responses rather than the raw scores were reported for the variables, FCAT 2001 and difference in FCAT score.

The t-test for the pooled looped and comparison groups and the ANOVAs revealed that there were no significant differences between the groups on the pretest or on the vocabulary/aptitude measure. The independent variable, grouping, included four levels, two looped groups and two comparison groups. The dependent variable to determine equivalence between groups at the beginning of the study was percentage correct on the FCAT 2001 (pretest). The ANOVA was not significant, $F(3,77), p=.352$. Therefore, it can be assumed that any changes that accrued on the dependent variables, reading achievement, reading qualities, anxiety and self-perception were a result of the treatment, participating in a looped class.

Table 8

Pretest Means Pooled Experimental Groups and Comparison Groups: Reading FCAT 2001 (percentage correct) and Vocabulary MAT-7

\begin{tabular}{lcccccc}
\hline Groups & $n$ & $M$ & $S D$ & $T$ & $p$-value \\
\hline & & \multicolumn{5}{c}{ Reading } \\
Experimental & 41 & 65.73 & 23.08 & -1.790 & $.077^{\mathrm{a}}$ \\
& & & & & \\
Comparison & 40 & 73.81 & 17.01 & \\
\hline
\end{tabular}

Vocabulary $.660^{\mathrm{b}}$

$\begin{array}{llll}\text { Experimental } \quad 41 & 11.34 & 2.82\end{array}$

$\begin{array}{llll}\text { Comparison } & 40 & 11.60 & 2.44\end{array}$

Note: FCAT $=$ Florida Comprehensive Assessment Test

aNot statistically significant at $\mathrm{p}<.05$.

bNot statistically significant at $\mathrm{p}<.05$. 
Table 9

Pretest Reading Achievement ANOVA: Reading FCAT 2001

\begin{tabular}{|c|c|c|c|}
\hline Groups & $n$ & $M$ & $S D$ \\
\hline \multicolumn{4}{|c|}{ Experimental } \\
\hline Looped & & & \\
\hline Loop 1 & 19 & 64.47 & 26.16 \\
\hline Loop 2 & 22 & 66.82 & 20.63 \\
\hline \multicolumn{4}{|c|}{ Comparison } \\
\hline Comparison & & & \\
\hline Comparison 1 & 21 & 73.10 & 16.12 \\
\hline Comparison 2 & 19 & 74.61 & 18.36 \\
\hline
\end{tabular}

Note: FCAT $=$ Florida Comprehensive Assessment Test

Table 10

Vocabulary/Aptitude Measure ANOVA: MAT-7

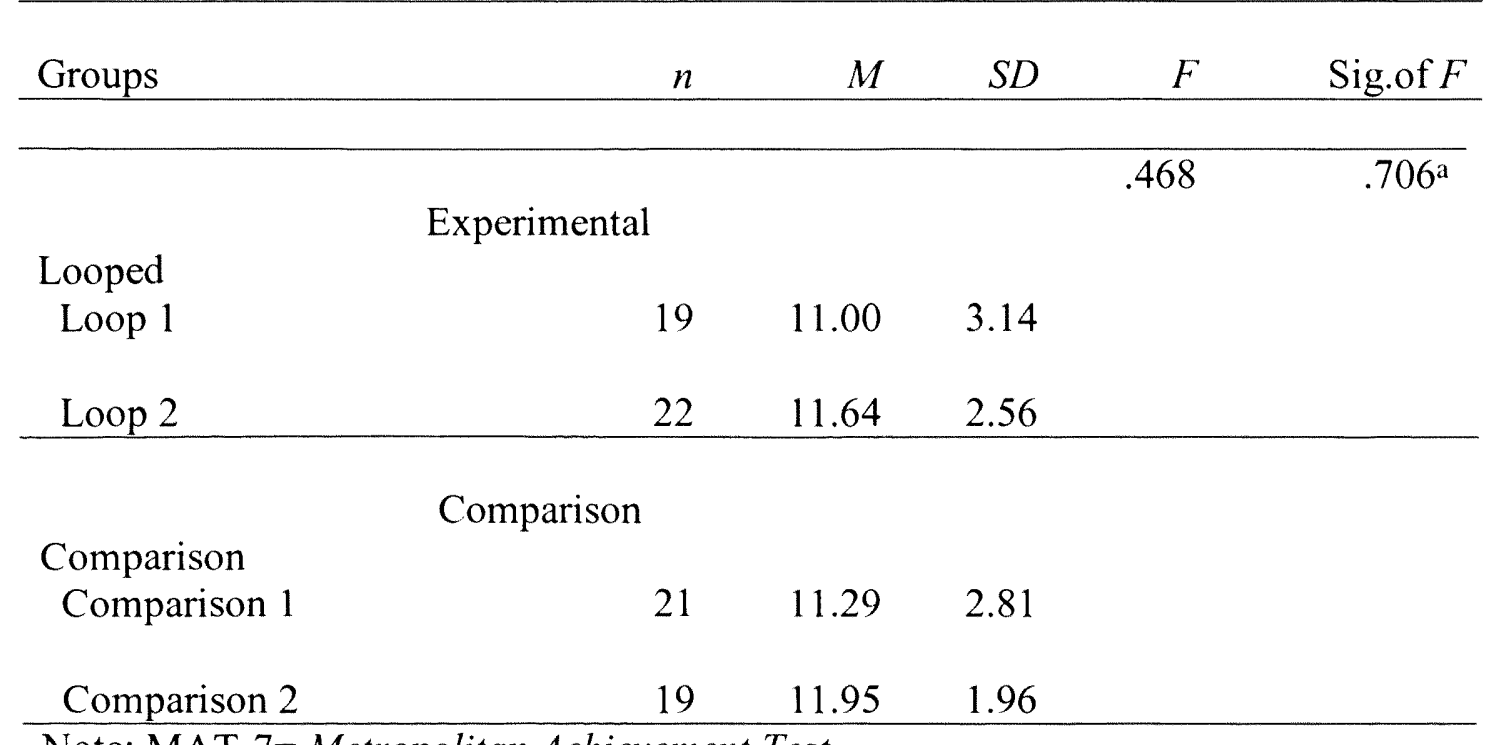

Note: MAT-7 = Metropolitan Achievement Test

aNot statistically significant at $\mathrm{p}<.05$. 
VITA

\section{MARY JO ALMEIDA}

1986

Graduate,

Our Lady of Lourdes Academy

Miami, Florida

1989

Bachelor of Science in Education

Florida International University

Miami, Florida

Graduated Summa Cum Laude

1989-1992

E.S.O.L. Teacher

M. A. Milam Elementary

Hialeah, Florida

1989-1992

Lab Instructor, Florida International University

Miami, Florida

1991

Master of Science in Education, Florida International University

Miami, Florida

Graduated with Honors

1992-1994

Classroom Teacher

M. A. Milam Elementary

Hialeah, Florida

1994-present

Assistant Principal, Palm Springs North Elementary Hialeah, Florida 